\title{
Patterns of Glutamate Immunoreactivity in the Goldfish Retina
}

\author{
Robert E. Marc, ${ }^{1}$ Wei-Ley S. Liu, ${ }^{1}$ Michael Kalloniatis, ${ }^{1}$ Steven F. Raiguel,, ${ }^{2}$ and Eduarda Van Haesendonck ${ }^{3}$ \\ University of Texas Graduate School of Biomedical Sciences, Sensory Sciences Center, Houston, Texas 77030 and \\ ${ }^{2}$ Neuro- and Psychophysiology Laboratory and ${ }^{3}$ Eye Research Laboratory, Katholieke Universiteit te Leuven, Belgium
}

\begin{abstract}
Postembedding silver-intensified immunogold procedures reveal high levels of glutamate immunoreactivity in "vertical" elements of the goldfish retina: (1) Red-sensitive and green-sensitive cones display strong glutamate immunoreactivity, especially in their synaptic terminals, but bluesensitive cones are poorly immunoreactive. (2) All type Mb (on-center) and $\mathrm{Ma}$ (off-center) mixed rod-cone bipolar cells and all identifiable cone bipolar cells are highly glutamate immunoreactive. We find no evidence for bipolar cells that lack glutamate immunoreactivity. (3) The majority of the somas in the ganglion cell layer and certain large cells of the amacrine cell layer resembling displaced ganglion cells are strongly glutamate immunoreactive. (4) Despite their high affinity symport of acidic amino acids, the endogenous levels of glutamate in Müller's cells are among the lowest in the retina. (5) GABAergic neurons possess intermediate levels of glutamate immunoreactivity. Quantitative immunocytochemistry coupled with digital image analysis allows estimates of intracellular glutamate levels. Photoreceptors and bipolar and ganglion cells contain from 1 to $10 \mathrm{~mm}$ glutamate. The bipolar and ganglion cell populations maintain high intracellular glutamate concentrations, averaging about $5 \mathrm{~mm}$, whereas red-sensitive and green-sensitive cones apparently maintain lower levels. Importantly, photoreceptor glutamate levels are extremely volatile, and in vitro maintenance is required to preserve cone glutamate immunoreactivity in the goldfish. GABAergic horizontal and amacrine cells contain about $0.3-0.7 \mathrm{~mm}$ glutamate, which matches the values predicted from the $K_{m}$ of glutamic acid decarboxylase. Müller's cells and non-GABAergic amacrine cells contain less than $0.1 \mathrm{~mm}$ glutamate. Though Müller's cells are known to possess potent glutamate symport, they clearly possess equally potent mechanisms for maintaining low intracellular glutamate concentrations.
\end{abstract}

The vertebrate retina can be parceled into 2 kinds of signal processing channels: (1) vertical channels, composed of photoreceptor $\rightarrow$ bipolar cell $\rightarrow$ ganglion cell chains; and (2) lateral channels, composed of a variety of horizontal cell or amacrine cell networks. Considerable evidence has accumulated to support the view that the outputs of vertical-channel elements are transmitted by acidic amino acids. In 1975, Murakami and his

Received Mar. 19, 1990; revised June 8, 1990; accepted Aug. 20, 1990.

This research was supported by NIH Grants EY02576 (R.E.M.) and EY06077 (M.K.) and Texas Higher Education Coordinating Board Grant 1953 (R.E.M.).

Correspondence should be addressed to Robert E. Marc, University of Texas, Sensory Sciences Center, 6420 Lamar Fleming, Houston, TX 77030.

Copyright (C) 1990 Society for Neuroscience $0270-6474 / 90 / 124006-29 \$ 03.00 / 0$ colleagues demonstrated that the application of exogenous glutamate to the isolated carp retina evoked hyperpolarization in on-center bipolar cells and depolarization in off-center bipolar cells, as expected of the native photoreceptor neurotransmitter. The ensuing years of pharmacological analysis of retinal synaptic transmission further emphasized that photoreceptors, at least, used some neurotransmitter similar in action to acidic amino acids. The sign-conscrving naturc of photorcceptor transmission to horizontal cells and off-center bipolar cells, and the signinverting nature of photoreceptor to on-center bipolar cell transmission, has become a working tenet of retinal circuitry analysis (Werblin and Dowling, 1969; Trifonov et al., 1974; Miller and Dacheux, 1976a-c; Naka, 1977; Toyoda et al., 1978; Slaughter and Miller, 1981). Furthermore, Slaughter and Miller (1981, 1983a) have demonstrated that the light-evoked responses of bipolar cells may be blocked with various glutamate analogs. On balance, only 1 natural compound has consistently mimicked these effectors: glutamate. It remains the most promising candidate for the photoreceptor neurotransmitter.

Because the synapses of bipolar cells onto third-order retinal neurons possess ribbonlike presynaptic specializations reminiscent of photoreceptors (Dowling, 1968; Dowling and Werblin, 1969), it is a reasonable speculation that synaptic transmission from bipolar cells to other neurons functions similarly. Direct current injection into catfish bipolar cells during monitoring of ganglion cell single-unit potentials provided compelling evidence that direct bipolar cell to ganglion cell transmission was sign conserving (Naka, 1977). Again, glutamate antagonists block light-evoked responses of ganglion cells (Slaughter and Miller, 1983b; Massey and Miller, 1988), providing further evidence that the bipolar cell neurotransmitter is glutamatelike. The nature of ganglion cell transmission to central neurons is much less clear. Even so, glutamate is the most plausible ganglion cell transmitter candidate in the optic tectum of the goldfish because tectal potentials evoked by optic nerve stimulation can be blocked by certain glutamate antagonists (Langdon and Freeman, 1986, 1987).

Chemical and structural support for this view has been less persuasive. Many experiments have failed to discriminate among glutamate, aspartate, cysteine, or other congeners as retinal neurotransmitter candidates. For example, goldfish rods appear to preferentially accumulate glutamate by high-affinity symport, while cones transport both aspartate and glutamate with comparable facility (Marc and Lam, 1981). These attributes are also true of frog rods and cones (R. E. Marc and S. F. Basinger, unpublished observations), so the phenomenon is not simply a twist of teleostean heritage. While the symport experiments support the hypothesis that glutamate is a photoreceptor transmit- 
ter, they are not decisive: They do not exclude roles for aspartate or other compounds.

The uptake studies are, so far, applicable to photoreceptors alone and not the other neurons of the retina. High-affinity symport of micromolar levels of acidic amino acids by photoreceptors and Müller's cells is so potent that it effectively shields bipolar cells from exogenous ${ }^{3} \mathrm{H}$-glutamate or aspartate (e.g., Marc and Lam, 1981). Thus, evidence that bipolar cells are glutamatergic has, until recently, rested almost exclusively on physiological/pharmacological studies. Similar problems have arisen for ganglion cells. Some experiments have demonstrated variable retrograde transport of apparently selectively accumulated ${ }^{3} \mathrm{H}$-D-aspartate from the optic tectum to ganglion cell somas in the pigeon retina (Beaudet et al., 1981). Only a fraction of the ganglion cells were labeled, however, and no firm conclusions emerged regarding the portion of the ganglion cell population labeled by such techniques.

Immunochemical techniques for detecting small molecules are well established in immunochemistry (Landsteiner, 1936), but only in recent years have those procedures been exploited to map neurotransmitters. In a landmark study, Ehinger et al. (1988) reported that bipolar cells, some ganglion cells, photoreceptors, and some amacrine cells in the turtle retina displayed glutamatelike immunoreactivity and could thus employ glutamate as their neurotransmitter. We have used similar methods to investigate the goldfish retina and strongly support those general observations. We have extended the analysis of retinal glutamate immunoreactivity in several directions. After incubation in physiological media, it can be shown that both red-sensitive and green-sensitive cones are glutamate immunoreactive. Blue-sensitive cones exhibit little glutamatelike immunoreactivity. Rods in the goldfish are particularly volatile, though reasonable ellipsoidal labeling can be obtained. All identifiable bipolar cell types ( $\mathrm{Ma}, \mathrm{Mb}$, and cone bipolar cells) show robust glutamate immunoreactivity, including the characteristic tristratified blue-cone bipolar cell and a possible green-cone bipolar cell. Most somas and all bundles of axons in the ganglion cell layer are glutamate immunoreactive. Müller's cells contain very little intracellular glutamate under normal conditions, despite their uptake capacities for acidic amino acids. Aspartate immunoreactivity patterns are inconsistent with any major role in retinal neurotransmission for aspartate. Finally, quantitative comparisons reveal that each cell type is associated with a unique range of glutamate levels, validating both the methodological and the biological reliability of postembedding methods and demonstrating potent cell-specific control of acidic amino acid metabolism. The specific imaging techniques and interpretations that led to many of our quantitative assessments have been segregated to an appendix, thereby simplifying the descriptions of our biological findings.

Portions of this work were presented in abstract form at the 1989 meeting of the Association for Research in Vision and Ophthalmology (Marc et al., 1989).

\section{Materials and Methods}

Tissue preparation. Common and comet goldfishes of $\approx 10 \mathrm{~cm}$ standard length were killed by cervical transection/pithing, and the eyes were rapidly excised. Some eyecups were immediately fixed in a conventional buffered $2 \%$ glutaraldehyde, $1.5 \%$ paraformaldehyde solution (e.g., Marc et al., 1978, 1988). Isolated retinas were fixed immediately or incubated in an oxygenated teleost saline (Marc and Lam, 1981) for 10 min prior to fixation. Some of the incubation media were modified to load cells with glutamate or aspartate (0.01-1 mM added to the saline). The pres- ervation of glutamatelike immunoreactivity was tested by fixing isolated retinas in varying proportions of paraformaldehyde $(0 \%, 1 \%, 2 \%, 4 \%)$ and glutaraldehyde $(0 \%, 0.5 \%, 1 \%, 2.5 \%, 4 \%)$. Conventional fixation was found to be adequate (see Appendix). Fixed retinas were dehydrated through cold methanols to acetone, infiltrated with Medcast (Pelco, Tustin, CA), and embedded at $65^{\circ} \mathrm{C}$ overnight. No osmication was used. Some specimens from prior research were also analyzed by immunocytochemistry. In these cases, retinas prepared as long as 13 yr ago were sectioned (see below) and processed. All of these "archival" studies involved tissues that had been incubated in teleost saline with radioligands of various types (e.g., Marc, 1982), fixed as described previously, and osmicated.

Sectioning. The immunocytochemistry in this report employed postembedding techniques and silver-intensified immunogold (SIG) detection. A variety of sectioning approaches were used to provide sampling ease, serial section analysis, and uniformity of reaction environment. Samples were sectioned at $500 \mathrm{~nm}$ on a Sorvall MT2-B ultramicrotome. Single sections were placed on droplets of water on 12-spot teflon-coated slides (Cel-Line, Newfield, NJ) and heat dried. Some samples were sectioned as a stack to provide immunochemical uniformity. Stacks were created by first sectioning blocks of retina at $120 \mu \mathrm{m}$ thickness on a sliding microtome (Stell and Lightfoot, 1975) and gathering individual sections from 4-7 different blocks. These were then carefully trimmed with a scalpel, lightly coated in fresh Medcast resin, and simply "stacked" on top of each other in a free-standing pile. Each stack was cured overnight, stripped from its slide, then reembedded in a conventional mold with the sectioning edges of the stacks flush against the face of the block. These stacks of sections were also cut at $500 \mathrm{~nm}$. We have also tested 250- and 100-nm sections with outstanding results. All sections shown in this manuscript are $500 \mathrm{~nm}$ thick.

Immunochemistry. Anti-glutamate, anti-aspartate, anti-taurine, and anti-GABA IgGs were purchased from Chemicon International, Inc. (Temecula, CA). Each antiserum was tested by dot immunoassay against a panel of antigens to establish specificity and potency. Artificial antigens were prepared as described in Matute and Streit (1986) by cross-linking the amino acid of interest to BSA (fraction V; Sigma, St. Louis, MO) with glutaraldehyde. Our specific protocols are described in Marc et al. (1988). Standard reference antigens were constructed for glutamate, glycine, aspartate, GABA, taurine, and $\beta$-alanine, aliquoted, and stored frozen at $-20^{\circ} \mathrm{C}$.

Graded concentrations (a 6-log-unit range in steps of 0.5 ) of each antigen were spotted in $2-\mu 1$ drops onto Immobilon P membrane (Millipore, Bedford, MA) and adsorbed. The undiluted concentration of soluble antigen was $90 \mu \mathrm{M}$ BSA, and isotopic tests showed the carrier to be effectively saturated with hapten (30-35 sites/molecule; Van Regenmortel et al., 1988). Thus, the theoretical maximum hapten concentration was $\approx 3.2 \mathrm{~mm}$ in solution. Because the sample is adsorbed to a solid phase, the effective concentration is unknown, though the mass is known precisely (Tijssen, 1985). Immediately thereafter, the membrane was covered with $3 \%$ goat serum in Tris-phosphate buffer (GSTPBS; Marc et al., 1988) just up to the edges and allowed to fully adsorb until the membrane was shiny. The membrane was rolled and placed in a 3-ml glass vial with the spotted surface facing in. The membrane was incubated $1 \mathrm{hr}$ in 3\% GSTPBS as a blocking step, then overnight in various dilutions (typically 1:100-1:400) of anti-neurotransmitter IgGs in 1\% GSTPBS. The original antisera were obtained as buffered glycerol solutions at an estimated 10 -fold dilution from raw serum levels so that the actual dilutions were in the 1:1000-1:4000 range. After antiserum incubation, the membranes were washed $1 \mathrm{hr}$ in $1 \%$ GSTPBS and incubated $1 \mathrm{hr}$ in a $1: 50$ dilution (in $1 \%$ GSTPBS) of 1- or 5-nm gold granules coated with goat anti-rabbit IgG (Janssen, Warren, PA), followed by another 1-hr wash in Tris-phosphate buffer (TPBS). Bound $\mathrm{IgG}$ was fixed in place with $1 \%$ glutaraldehyde in $0.1 \mathrm{M}$ phosphate buffer $(\mathrm{pH}, 7.4)$ for $10 \mathrm{~min}$. This step is not always needed on blots, but is critical for SIG immunochemistry on slides because the low $\mathrm{pH}$ values encountered during silver intensification can promote dissociation of the antibodies from their antigens. The preparations were washed in 35 -min changes of TPBS, 35 -min changes of deionized water, and a $10-\mathrm{min}$ wash in $0.2 \mathrm{M}$ citrate buffer $(\mathrm{pH}, 3.85)$. The dot assays were silver intensified according to the protocol of Moremans et al. (1984). In brief, the samples were intensified for $7 \mathrm{~min}$ at room temperature in freshly made developer $(0.11 \%$ silver lactate and $0.85 \%$

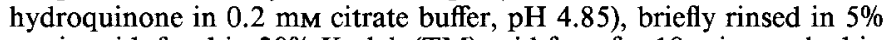
acetic acid, fixed in $20 \%$ Kodak (TM) acid fixer for $10 \mathrm{~min}$, washed in deionized water for $10 \mathrm{~min}$, and air dried. 
Immunocytochemistry. Sections were deplasticized in sodium methoxide and brought to deionized water. Osmicated specimens were pretreated for $7 \mathrm{~min}$ with $1 \%$ sodium metaperiodate, then rinsed in deionized water. Each slide was quickly dried with a stream of clean air and blocked for $1 \mathrm{hr}$ by placing $25 \mu \mathrm{l}$ 3\% GSTPBS on each section spot in a humid chamber. Each droplet was wicked away and replaced by 25 $\mu$ primary antiserum for an overnight incubation. The antisera were thereafter flicked off and the slides briefly rinsed in phosphate buffer prior to a $1-\mathrm{hr}$ wash in $1 \%$ GSTPBS. Each slide was then briefly rinsed in deionized water and dried in an air stream. Each section was covered with $25 \mu \mathrm{l}$ of a 1:50 dilution of 1- or 5-nm gold granules coated with goat anti-rabbit IgG for $1 \mathrm{hr}$. This antiserum was subsequently flicked off, and the slides were rinsed in phosphate buffer and subjected to a final 1-hr rinse in TPBS. The silver-intensification step was identical to the procedure just described, beginning with glutaraldehyde fixation and ending with an air-drying step. Some specimens were stained with toluidine blue (Marc et al., 1978), and all slides were coverslipped with Medcast as a mountant.

Design and analysis. Immunoreacted samples were analyzed by digital imaging. Each dot immunoassay or section was captured as a $510 \times$ 492 pixel image via a CCD camera (Sony SSC-D5) on a Comtal VisionLabII frame grabber/display system (supported on a Compaq 80386-25 computer system). The density of staining was encoded as an 8-bit value, and a look-up table was configured for each assay, which simply assigned a unique intensity to each binary density value from 0 to 255. This is a nonlinear metric because CCD cameras are not flux linear. However, when a preparation was imaged, captured, and displayed with an intensity look-up table defined by the dot immunoassay palette, it was possible to characterize the relative levels of an antigen in different cell types over a 2.5-log-unit range. A second, confirmatory approach was taken by measuring densities of dot immunoassays and immunocytochemical staining by microphotometry (Marc et al., 1988) with a $1.25 \times$ and a $63 \times$ objective, respectively. These measurements demonstrated that digital imaging and conventional photometry yielded equivalent results. Finally, assessments of intracellular glutamate concentrations were made by scaling the intensity histograms of vertical sections to reveal the mass of glutamate associated with each cellular compartment. Routines for digital image capture, thresholding, masking, and intensity histograms were obtained from Media Cybernetics, Inc. (Silver Spring, MD); image registration routines were obtained from PCI, Inc. (Richmond Hill, Canada).

\section{Results}

\section{Immunochemistry}

Our first objective was to characterize the abilities of the antisera to discriminate between different antigens and different levels of a given antigen. While not comprehensive, dot immunoassays demonstrate that good selectivity and low cross-reactivity are possessed by the anti-glutamate IgGs used in this study. Figure 1 is a digital image composite of dot immunoassays for $4 \mathrm{IgGs}$ against antigens containing the haptens GABA, glutamate, aspartate, or taurine tested against a selected 3-log-unit range of 6 haptens linked by glutaraldehyde to BSA: GABA (Fig. 1, row 1 ), glutamate (row 2), aspartate (row 3), glycine (row 4), taurine (row 5), and $\beta$-alanine (row 6). The anti-glutamate antisera are very selective for glutamate compared to all other haptens tested. Digital analyses of dot assays (see Appendix) demonstrate that anti-glutamate IgGs have at least $3.5 \mathrm{log}$ units of selectivity for glutamate over aspartate and minimally $4.0 \mathrm{log}$ units of selectivity over the other 4 haptens tested, and that there is little type 1 cross-reactivity (due to $\operatorname{IgG}$ heterogeneity) and no detectable type 2 cross-reactivity (binding of different antigens by a single IgG). Thus, we expect good histological selectivity of the anti-glutamate IgGs for glutaraldehyde crosslinked glutamate if the ranges of intracellular antigen concentrations are appropriately mimicked by our model antigens.

These results do not, however, guarantee selectivity for "fixed" haptens at tissue concentrations, which are not known and not ascertainable a priori because (1) the efficiency of the fixation process, (2) concentrations of intracellular competitors, and (3) the intracellular densities of free amino sites for cross-linking on macromolecules are all unknown. However, we can powerfully assess antibody selectivity in situ by "force" loading certain cells with substrates of interest and evaluating the performances of antisera in detecting saturating loads of substrate. For biological reasons (which will be elaborated in the section on Mïller's cells), we performed such assays in isolated frog (Rana pipiens) retinas that had been incubated for $10 \mathrm{~min}$ in amphibian saline (Basinger and Hall, 1973) containing $1 \mathrm{~mm}$ of either glutamate or aspartate prior to fixation (Marc and Basinger, unpublished observations; fixation as described in Materials and Methods). The frog retinas were embedded as a stack, sectioned serially at $500 \mathrm{~nm}$, and processed simultaneously for immunocytochemistry with antisera against glutamate, aspartate, and GABA (Fig. 2). Müller's cells loaded with glutamate were highly immunoreactive to anti-glutamate IgGs but completely unreactive to either anti-aspartate or anti-GABA IgGs. Conversely, Müller's cells loaded with aspartate were immunoreactive to anti-aspartate IgGs but unreactive to any other antisera. An important aspect is that the labeling densities evoked by preloading are as high or higher than endogenous glutamate immunoreactivity in other cells and thus indicate that these antisera have adequate selectivity (1) at the serum dilutions we used and (2) at the endogenous levels of antigens encountered in fixed retina. As will be further documented in subsequent samples, some cells that were extremely GABA immunoreactive, such as most frog amacrine cells, were detected exclusively by anti-GABA IgGs. Thus, in actual use on tissue samples, the anti-glutamate IgGs employed here reliably detect exogenously loaded glutamate and are completely blind to GABA, aspartate, and several other antigens (not shown). Similarly, the anti-GABA and anti-aspartate IgGs selectively detect the appropriate antigens and do not cross-react with the heterologous molecules tested here. This is very important, as we will make arguments that depend on our confidence that low levels of glutamate immunoreactivity actually reflect low but measurable concentrations of native glutamate and not high levels of an unknown antigen.

\section{General retinal labeling patterns}

The overall pattern of glutamate immunoreactivity in the goldfish retina is complex, but is dominated by bipolar cells. Under light-adapted conditions, photoreceptors typically lack any appreciable accumulation of glutamate immunoreactivity in their myoids, axons, or ellipsoids, though they are immunoreactive at their synaptic terminals, as noted by Ehinger et al. (1988). However, when retinas from dark-adapted fishes are incubated in physiological saline for 10-30 min, red-sensitive and greensensitive cones demonstrate strong somatic immunoreactivity from their ellipsoid/outer segment junctions to their pedicles. Figure 3 displays the distribution of labeling in a typical 500$\mathrm{nm}$ vertical section after SIG detection of anti-glutamate $\mathrm{IgG}$ binding. We have not been able to evoke strong glutamate immunoreactivity throughout goldfish rods, but dark adaptation and postincubation does enhance ellipsoidal labeling of these small cells.

The inner nuclear layer is richly labeled at several differential levels (Fig. $3 a$ ). Fusiform somas, obviously bipolar cells, are the most immunoreactive, with large- to medium-sized somas showing highest levels of binding. Horizontal cells exhibit intermediate levels of immunoreactivity, with some proximal non- 

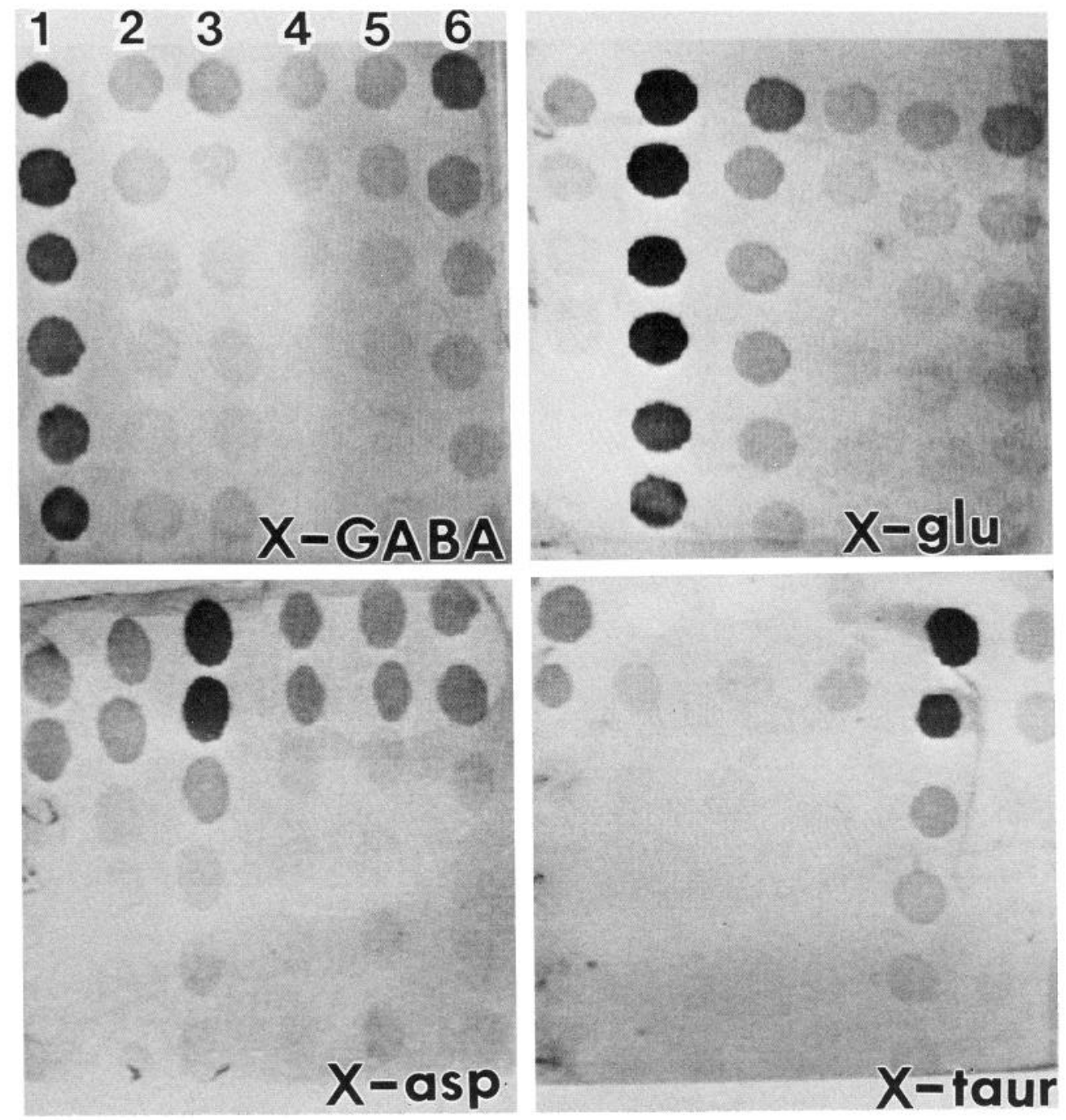

Figure 1. Dot immunoassays of antiserum binding to model antigens. Each panel is labeled in its lower right corner according to the antiserum employed: $X$-GABA, anti-GABA IgG; $X$-glu, antiglutamate IgG; $X$-asp, anti-aspartate IgG; $X$-taur, anti-taurine IgG. The 6 vertical rows of $2-\mu \mathrm{l}$ spots on each panel represent GABA (row I), glutamate (row 2), aspartate (row 3), glycine (row 4), taurine (row 5), and $\beta$-alanine (row 6) spotted in a descending concentration of 0.5 -log-unit steps. Anti-GABA and anti-glutamate IgGs were used at a dilution of 1:200, and anti-aspartate and anti-taurine IgGs at 1:100. The mottled background is due to variations blocking serum adsorption.
GABAergic variety being most immunoreactive. Cell bodies in the amacrine cell layer are a heterogeneous grouping, displaying immunoreactivity ranging from little or no antibody binding to rather strong binding.

The inner plexiform layer is studded with various immunoreactive puncta and globular structures, mostly terminal endings of various bipolar cells, and occasional dendritic processes of ganglion cells. The largest profiles are found in sublayers 4 and 5 and are easily identified as the terminal endings of $\mathrm{Mb}$ bipolar cells (mixed rod-cone bipolar cells; Fig. $3 a$; see Famiglietti et al., 1977). Many smaller puncta are distributed through the inner plexiform layer in a laminar fashion and can be assigned to several other bipolar cell types (see below). The ganglion cell layer of the goldfish is sparsely populated with ganglion cells and one variety of displaced amacrine cell; all cells that appear to be ganglion cells are strongly glutamate immunoreactive. The optic fiber layer is a spray of pepperlike profiles that are immunoreactive axon bundles from ganglion cells.

The vasculature of the goldfish retina is confined to the vitreoretinal border, and the vascular endothelium displays immunoreactivity equivalent to or higher than any retinal neuron. Paradoxically, Müller's cells are invariably the least glutamate immunoreactive of all retinal cells (see also Ehinger et al., 1988), even though they are known for their potent transport of acidic amino acids (Marc and Lam, 1981; Brew and Attwell, 1987).

Aspartate immunoreactivity of the goldfish retina is much weaker and less differentiated than glutamate immunoreactivity. Figure 4 is a $500-\mathrm{nm}$ serial section from the same specimen shown in Figure 3. The anti-aspartate IgGs were used at a 1:50 dilution to compensate for a roughly 4 -fold difference in apparent titer compared to the anti-glutamate IgGs. Even though the aspartate antiserum has lower titer, it has good selectivity in practice (Figs. 1, 2), and this dilution is sufficient to saturate all tissue sites (see Appendix). Four points emerge: (1) All cone types display the same levels of aspartate immunoreactivity (cf. Fig. 3). (2) Müller's cells possess modest endogenous aspartate immunoreactivity, which produces a filigree pattern in the outer nuclear layer. (3) Many cells that exhibit potent glutamate immunoreactivity often show weak aspartate immunoreactivity, but we have not yet established a quantitative linkage between the 2 patterns. (4) The inner plexiform layer label is diffuse and nonpunctate and lacks the differentiation of glutamate immunoreactivity.

While this general pattern of photoreceptor terminal, bipolar cell, and ganglion cell labeling is demonstrable in all retinal specimens, the absolute levels of immunoreactivity among tis- 
X-GABA

$1 \mathrm{mM}$ glu

X-GABA

$1 \mathrm{mM}$ asp

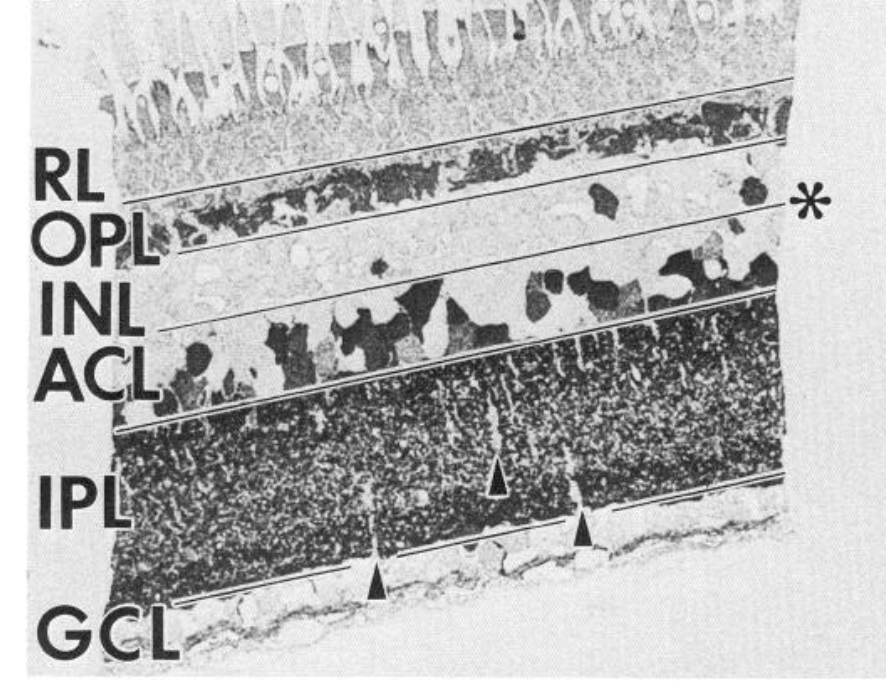

$X$ glu $\quad 1 \mathrm{mMglu}$
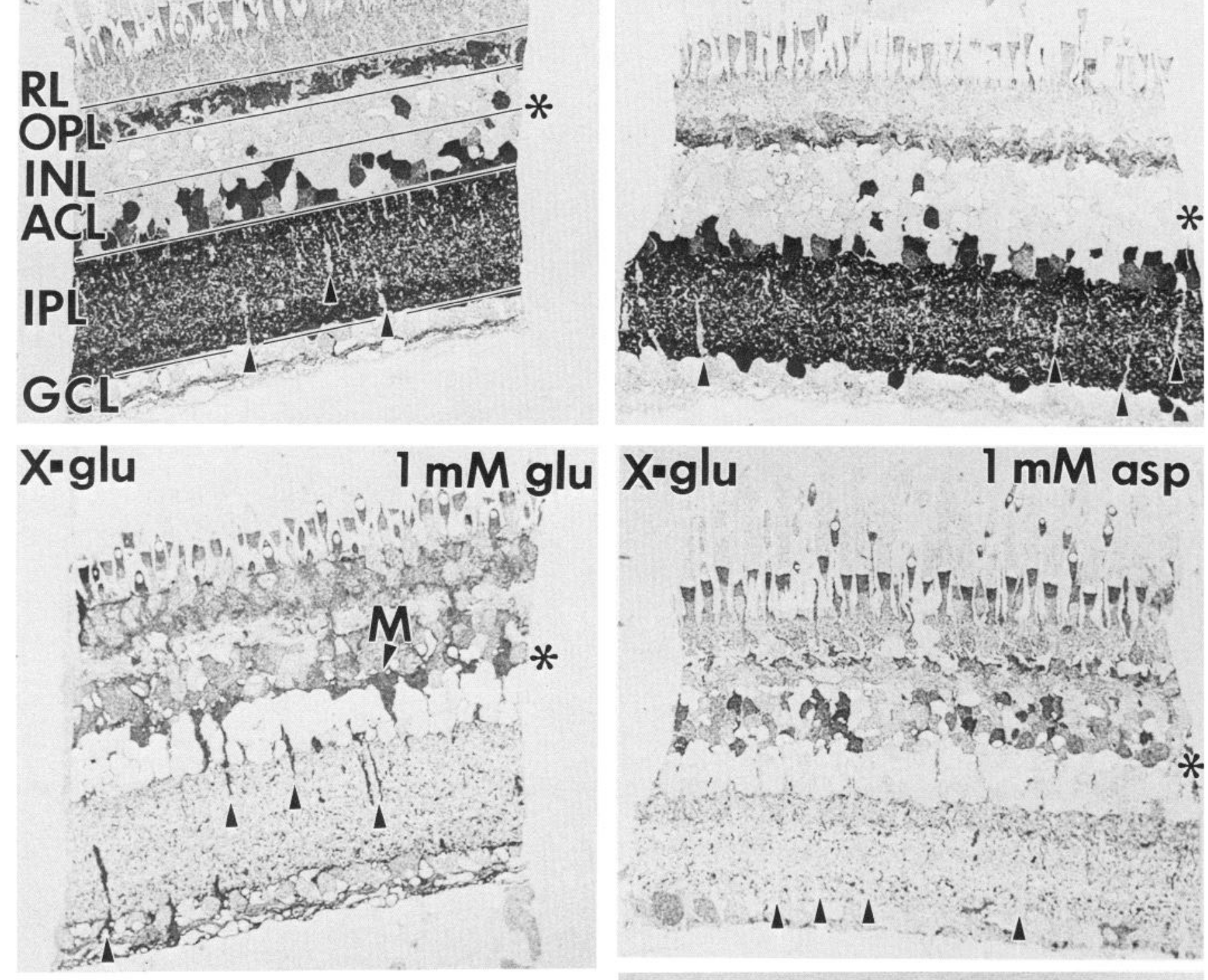

X-asp

$1 \mathrm{mM}$ glu $X$-asp

$1 \mathrm{mM}$ asp

*

$\overline{50 \mu \mathrm{m}}$

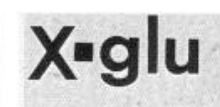

$1 \mathrm{mM}$ asp

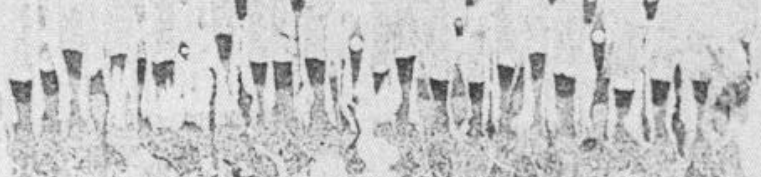

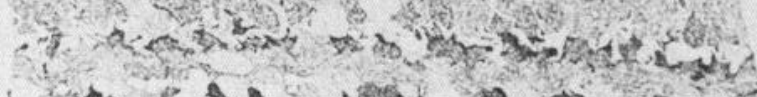

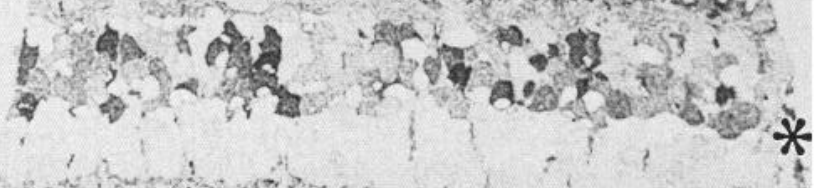

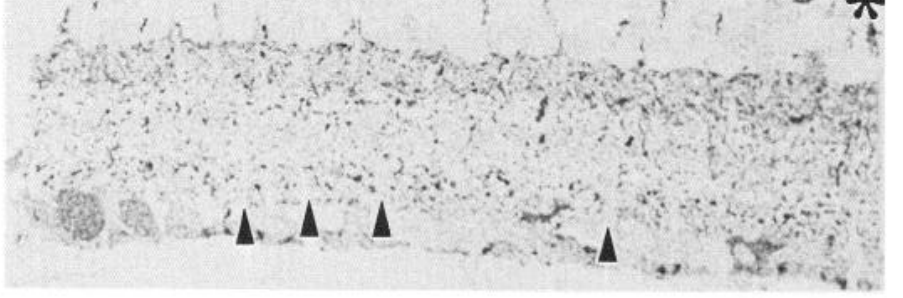



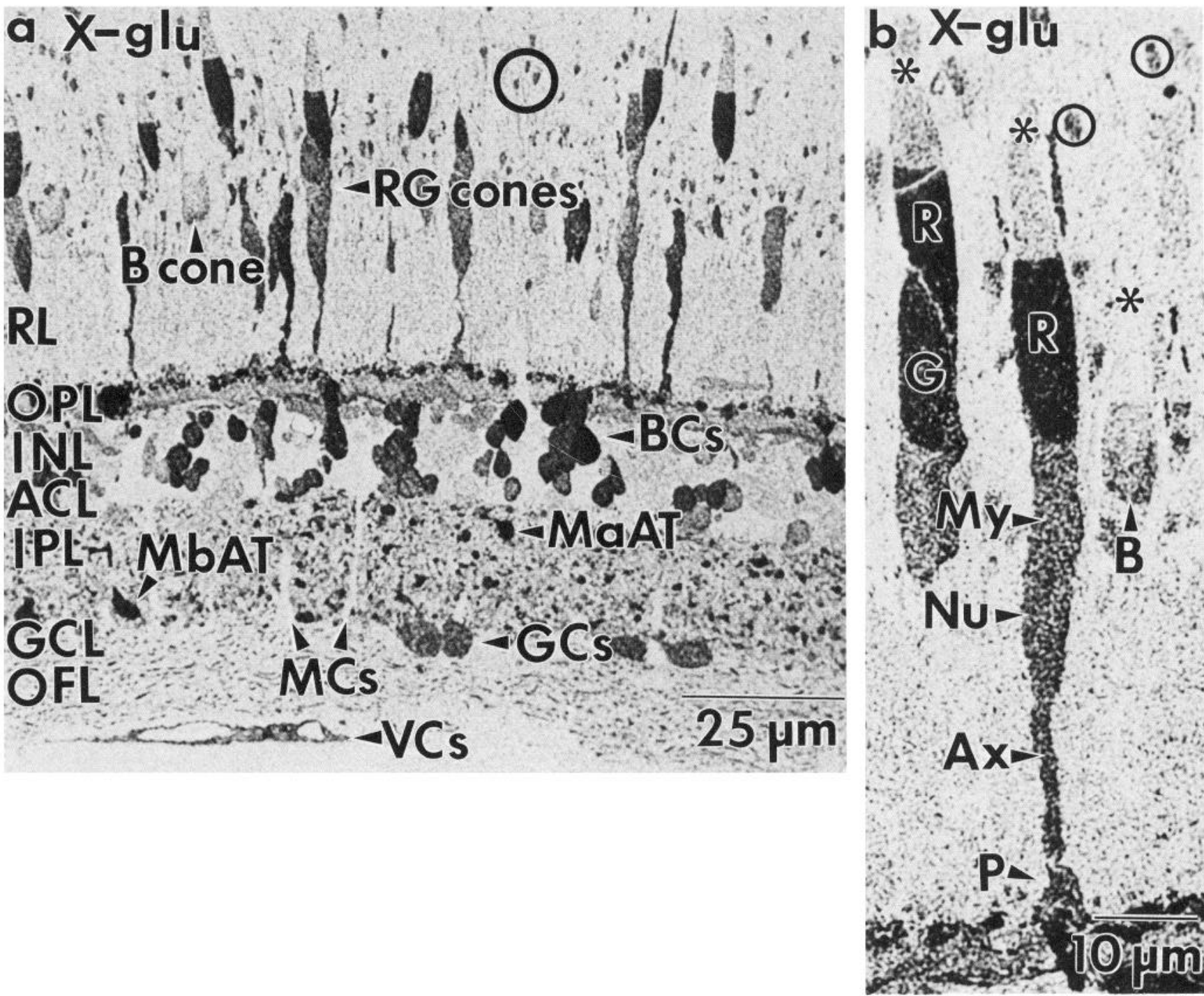

Figure 3. Glutamate immunoreactivity $(X-g l u)$ of isolated goldfish retina (500-nm vertical section, SIG detection). A wide range of label densities can be observed. $a$, Full-thickness view showing cone, bipolar-cell, and ganglion-cell labeling. $b$, Section through the full length of a red-sensitive cone, showing large intracellular gradients of glutamate immunoreactivity. $A x$, axon; $B$, blue; $B C$, bipolar cell; $G$, green; $G C$, ganglion cell; $M a A T$, axon terminal of a type Ma bipolar cell; $M b A T$, axon terminal of a type Mb bipolar cell; $M C$, Müller's cell; $M y$, myoid; $N u$, nucleus; $O F L$, optic fiber layer; $P$, pedicle; $R$, red; $V C$, vascular cell; see Figure 2 caption for other abbreviations. Asterisks denote cone outer segments, and rod ellipsoids are circled.

sue samples and the relative levels among neurons exhibit noticeable variation. Bipolar cells are the most immunoreactive cells, though it is possible for ganglion cells to approach the bipolar cell level of immunoreactivity. Within the bipolar cell population, Ma bipolar cells (off-center bipolar cells) are typically the most immunoreactive, followed by $\mathrm{Mb}$ bipolar cells and, last, by cone bipolar cells. However, some preparations clearly exhibit overall diminution of labeling. In these cases, cells that are normally nonimmunoreactive remain so. While a full parametric analysis of these events is not yet complete, we can make several observations we hope will be of use to others: (1) Retinas that have experienced anoxia (delayed dissection, ungassed incubation media) always display low overall immunoreactivity. (2) Regions of retina obviously damaged during dissection can display near-total loss of immunoreactivity even though many cells in these areas appear intact. (3) Photoreceptor immunoreactivity is extremely labile and is best preserved by postincubating isolated dark-adapted goldfish retinas in oxygenated physiological medium for at least $10 \mathrm{~min}$ prior to rapid but gentle fixation. (4) Rapid fixation of eyecups after dissection

Figure 2. Stack immunoassays of frog retinas preloaded with $1 \mathrm{~mm}$ glutamate (left panels) or aspartate (right panels) and reacted with antisera against GABA $(X-G A B A ; 1: 200)$, glutamate $(X$-glu; $1: 200)$, and aspartate $(X$-asp; $1: 100)$. In all panels, the arrowheads indicate the radial stalks of Müller's cells $(M)$, and the asterisks denote the level of the inner nuclear layer at which Müller's cell somas are placed. $R L$, photoreceptor layer; $O P L$, outer plexiform layer; $I N L$, inner nuclear layer; $A C L$, amacrine cell layer; $I P L$, inner plexiform layer; $G C L$, ganglion cell layer. 


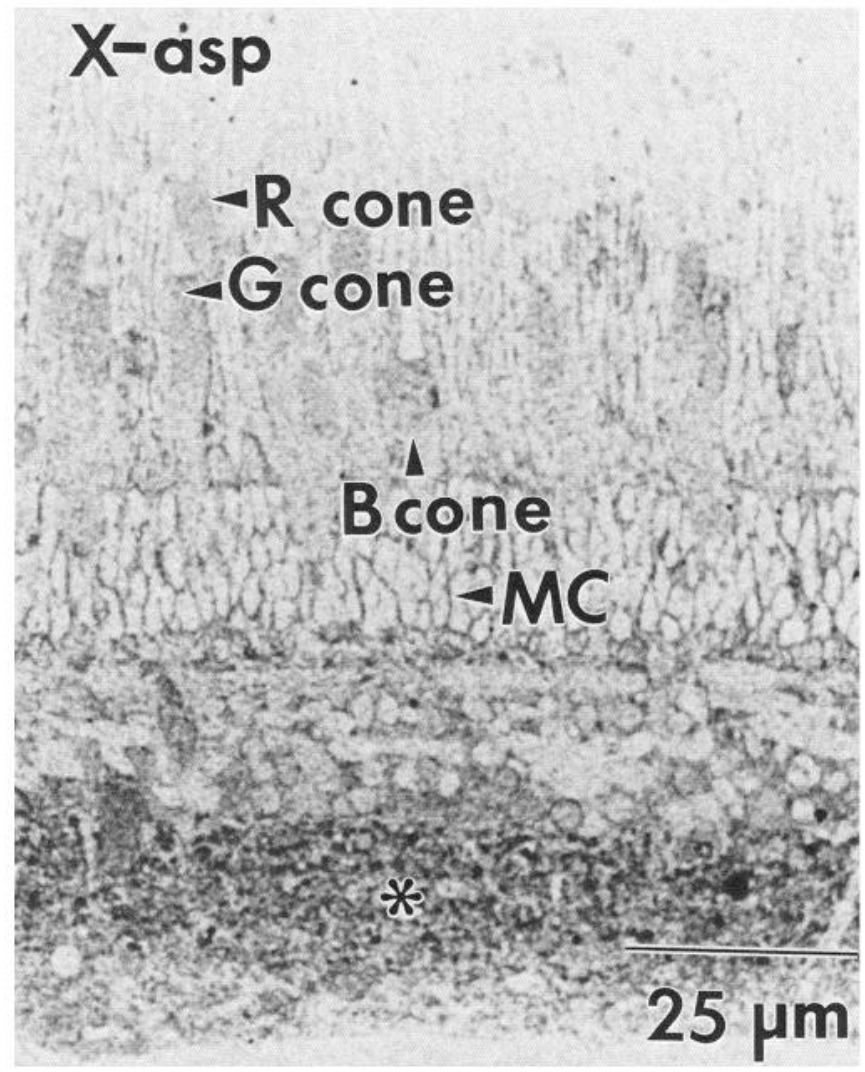

Figure 4. Aspartate immunoreactivity ( $X$-asp) of goldfish retina (500nm vertical section, SIG detection). Note the generally diffuse label, the similarity of immunoreactivity across cone types, and the fine filigree of label in the outer nuclear layer, apparently due to the distal processes of Müller's cells. See Figure 3 caption for abbreviations.

yields poor preservation of glutamate immunoreactivity (see Storm-Mathisen et al., 1986, for a discussion of fixation issues in immunocytochemistry for glutamate).

\section{Photoreceptors: detailed observations}

In the goldfish, we have discovered that postincubation of darkadapted isolated goldfish retinas ( 5 experiments, 10 retinas) under mesopic conditions for $10 \mathrm{~min}$ in teleost saline prior to fixation evoked a significant increase in the glutamate immunoreactivity of certain cone cells. In particular, all double cones and long single cones (Marc and Sperling, 1976a,b; Stell and Hárosi, 1976) displayed glutamate immunoreactivity from their pedicles to the junction between the ellipsoid and the outer segment. This indicates that red- and green-sensitive cones may have particularly dramatic fluxes in intracellular glutamate lev- els. Even miniature long single cones, which are thought to be red sensitive (Marc and Sperling, 1976a,b) show strong glutamate immunoreactivity. Neither class of blue-sensitive cones, short single or miniature short single, exhibited glutamate immunoreactivity. Vertical sections through identified cone types show that there is a strong subcellular partitioning of glutamateimmunoreactive sites. The ellipsoids of red- and green-sensitive cones are extremely immunoreactive, with a large density decrease in the myoid (Fig. $3 b$ ), pervasive nuclear staining, and a gradual increasing gradient down the axon into the pedicle, which matches the ellipsoid in density. This could represent an intracellular glutamate gradient in excess of a log unit. The uniformity of this labeling is revealed by horizontal 500-nm sections through the photoreceptor layer at the level of the double cone ellipsoids and myoids (Fig. 5). All double cones (red-sensitive/green-sensitive pairs), all long single cones (individual red-sensitive or green-sensitive cones), and miniature long single cones (redsensitive) are highly glutamate immunoreactive. Following these horizontal serial sections through the outer nuclear layer, it is possible to encounter the paths of cone axons among rod nuclei and to trace them to an array of highly immunoreactive pedicles in the outer plexiform layer (Fig. 6). Although the goldfish outer plexiform layer lacks the crystalline synaptic arrays of many other kinds of fishes (cf. Callionymus lyra L., Van Haesendonck and Missotten, 1979), local mosaic elements composed of 4 double-cone pedicle pairs can be identified. In contrast, the array of blue-sensitive cones is uniformly poorly immunoreactive for anti-glutamate IgGs (Fig. $5 b$ ). There is some immunoreactivity in blue-sensitive cones, however, though its subcellular distribution seems subtly different in that the distal ellipsoids are poorly immunoreactive and higher binding seems localized to the ellipsoid-myoid transition (Fig. $3 b$ ).

\section{Bipolar cells: detailed observations}

Unlike photoreceptors, which display a remarkable ability to compartmentalize glutamate, bipolar cells are uniformly glutamate immunoreactive from dendrites to axon terminals, and it is possible to distinguish several specific types of bipolar cells as glutamate immunoreactive through alignment of $500-\mathrm{nm} \mathrm{sec}-$ tions. Though thicker sections increase the probability of obtaining most of a well-oriented bipolar cell in a single section, resolution of the thin axon in the inner plexiform layer is irremediably compromised by crossing immunoreactive structures. The thinnest practical sections provide the best view of the bipolar cell types. Bipolar cells with the morphological signatures of Golgi-impregnated $\mathrm{Mb}$ bipolar cells all display strong glutamate immunoreactivity (Fig. 7). Most such cells are similar to $\mathrm{Mb} 1$ or Mb2 bipolar cells (Ishida et al., 1980), with a large soma in the middle to distal part of the inner nuclear layer, a thick and short primary dendrite, a long unbranched axon descending to sublamina $b$ (specifically to sublayers 4 and 5), and

\footnotetext{
Figure 5. Glutamate immunoreactivity $(X-g l u)$ of goldfish photoreceptors viewed in 500-nm horizontal sections (SIG detection). The upper panel (a) is a section at the level of the red-sensitive and green-sensitive cones, showing strong glutamate immunoreactivity in all double cones (arrowheads; $L D R$, red-sensitive member; $S D G$, green-sensitive member), all long single cones ( $L S R$, red-sensitive long single cone; $L S G$, green-sensitive long single cone), and miniature long single cones ( $M L S R$, red-sensitive miniature long single cone). The differential assignment of LSR and LSG cones is made on the assumption that they behave similarly to double cones, which show subtle but reliable differences in glutamate immunoreactivity. Double cones form characteristic rows of alternating ellipsoid axes (Marc and Sperling, 1976b), as indicated by the row of 6 arrowheads. The asterisk indicates the outer segment of a blue-sensitive cone. A cluster of rod outer segments is circled. The lower panel $(b)$ is a section through the ellipsoids of the blue-sensitive cones. A complete array of 59 blue-sensitive cones can be identified by the shape and position of the ellipsoids (circles), their outer segments (asterisks), or the outer/inner segment junction (double arrowheads). The 2 straight lines denote the major axes of the rhomboidal array. $M y$, myoid.
} 
$X$-gla a.0 0 -MLSR 0 . 5 .

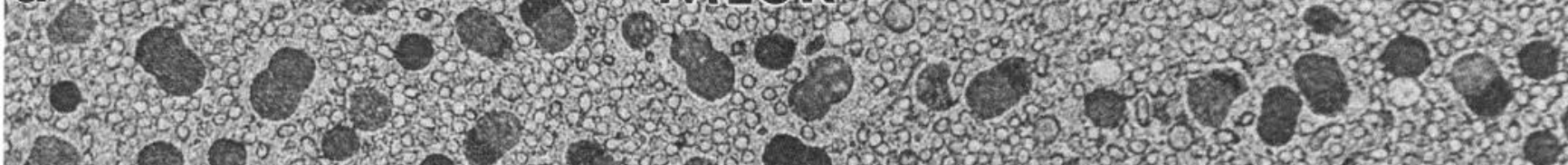

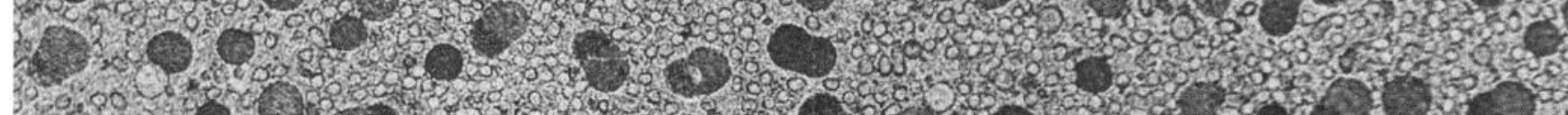

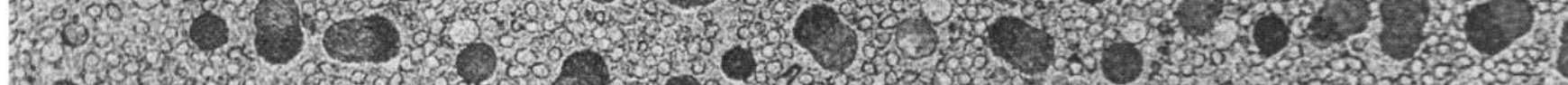

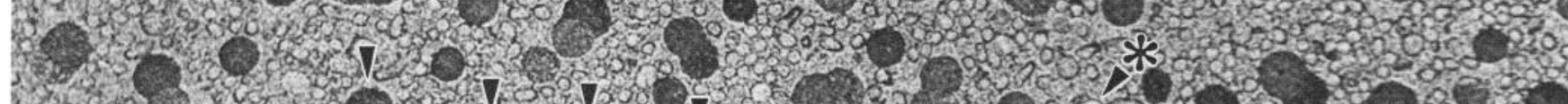

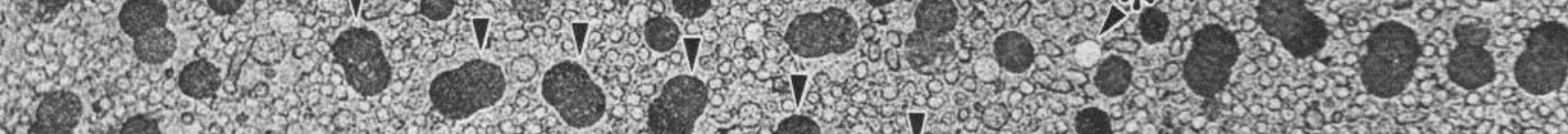

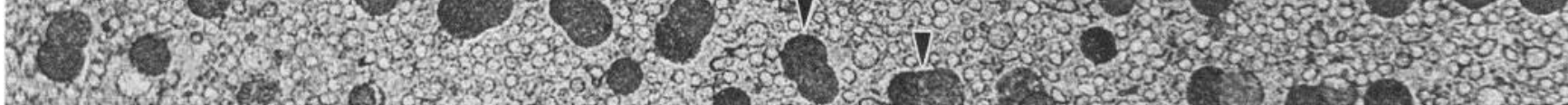

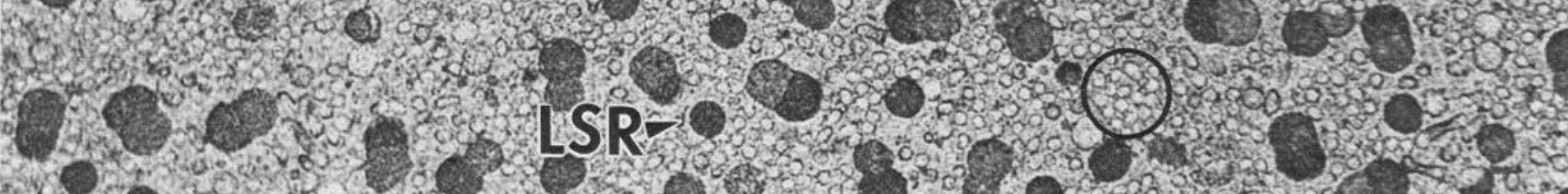

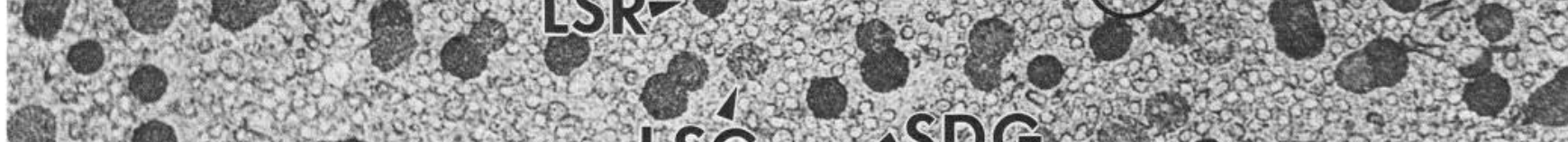

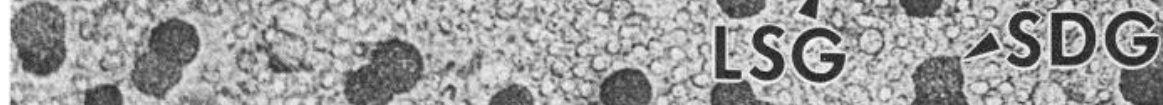

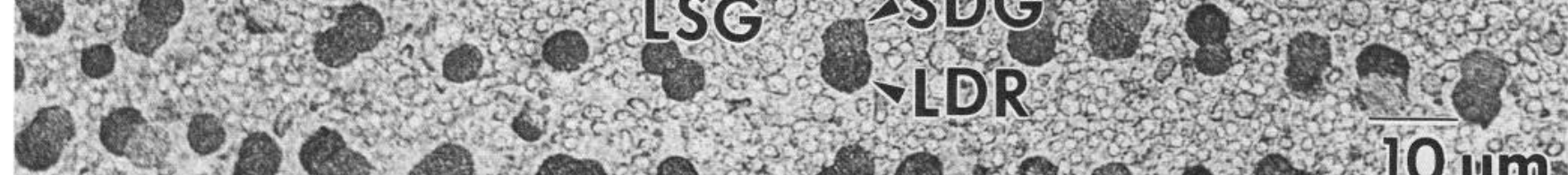
45. 0.0.0.0.0.10.m

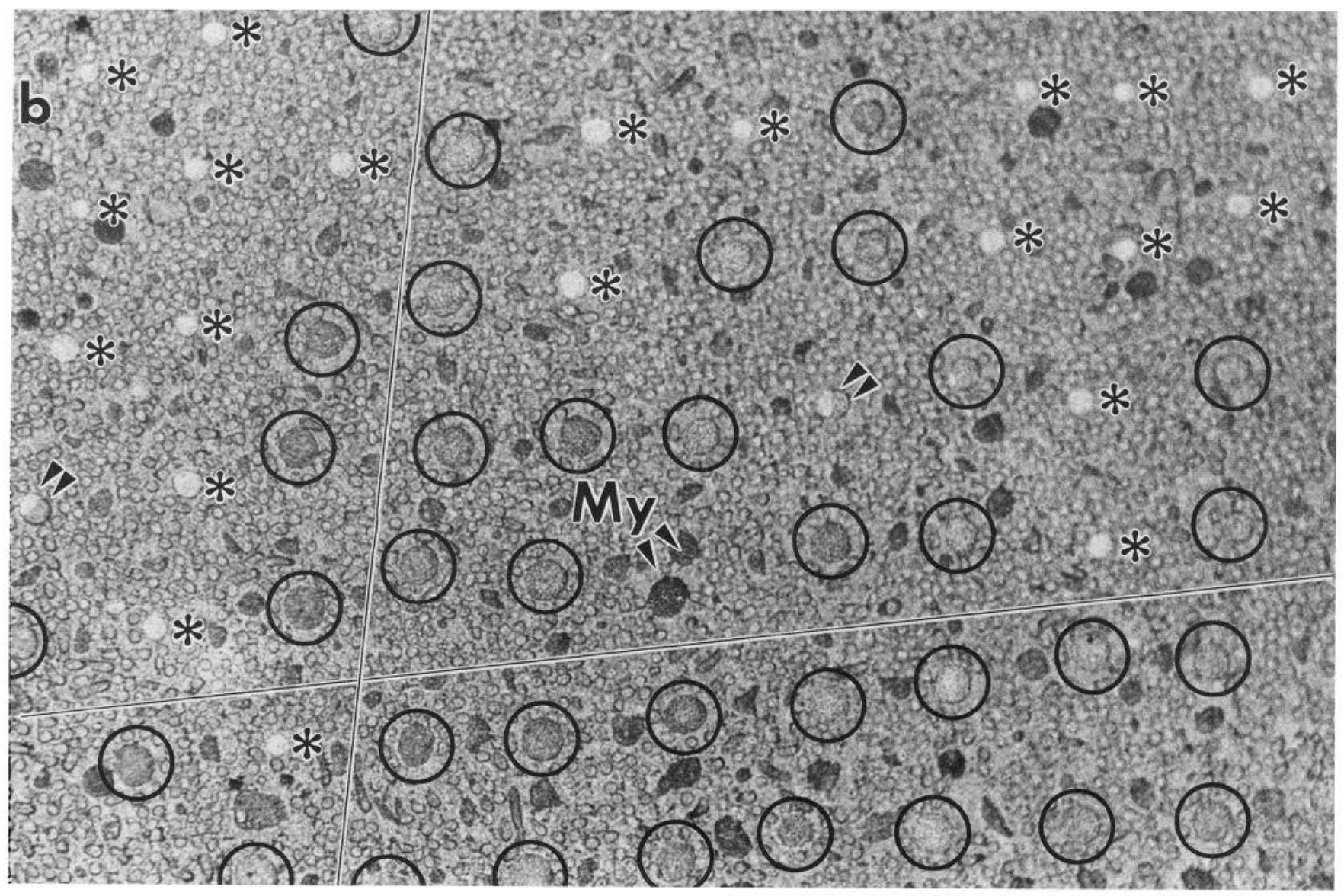




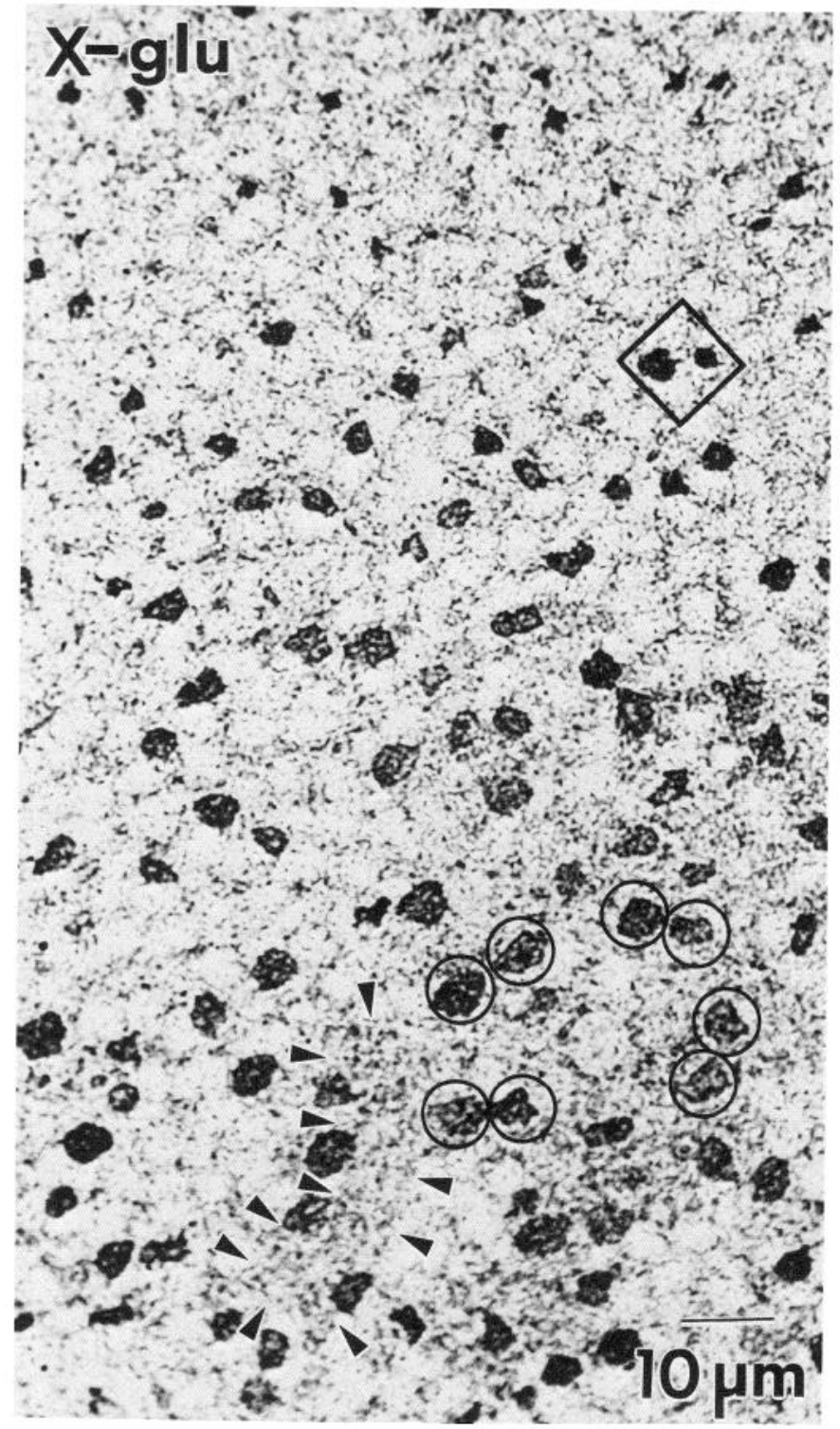

Figure 6. Glutamate immunoreactivity $(X-g l u)$ of cone pedicles (500$\mathrm{nm}$ section, SIG detection). This slightly oblique section shows the axons (diamond) and pedicles (circles) of goldfish cones at the level of the outer plexiform layer. Four pairs of pedicles, representing the red-sensitive/ green-sensitive cone mosaic, are marked with circles. Just proximal to the pedicles, the flat somas of GABAergic horizontal cells form large lakes of weak glutamate immunoreactivity. The borders of one of these horizontal cells is outlined by arrowheads.

a large, rounded axon terminal up to $5 \mu \mathrm{m}$ in diameter with occasional lobular telodendria. That all such cells are glutamate immunoreactive can be documented in horizontal sections of the inner plexiform layer (Fig. 8), where all $\mathrm{Mb}$ terminals are labeled. The terminal $\mathrm{Mb}$ array displays a characteristic pattern of about 1500-2000 terminals $/ \mathrm{mm}^{2}$ with frequent lobular extensions (Marc, 1982).

Ma bipolar cells were distinguishable by their smaller, distinctively flask-shaped somas, shorter axons terminating in sublayers 1 and 2, and irregularly shaped axon terminals displaying a variety of nodules and excrescences (Fig. 9). Ma bipolar cells display the strongest glutamate immunoreactivity of all cells. There are at least 2 varieties of Ma bipolar cells (Ishida et al.,
1980), but we have not been able to unequivocally distinguish them in vertical sections. The cells shown in Figure 9 are probably both Ma1 bipolar cells because they terminate in the proximal half of sublayer 1 . It is certain that $\mathrm{Ma} 2$ bipolar cells are also glutamate immunoreactive because all ${ }^{3} \mathrm{H}$-serotonin-accumulating bipolar cells, which are actually the Ma2 bipolar cells (Marc et al., 1988), are glutamate immunoreactive. This correlation was demonstrated by alternately processing serial 500 -nm sections of goldfish retinas loaded by incubation in 1 $\mu \mathrm{M}{ }^{3} \mathrm{H}$-serotonin for light microscope autoradiography and immunocytochemistry for glutamate immunoreactivity and matching the bipolar cells in adjacent sections (Fig. 10).

Horizontal or oblique sections through the distal inner plexiform layer reveal a rich array of structures that can be differentially labeled by anti-glutamate or anti-GABA IgGs. Figure 11 shows a pair of serial horizontal sections through sublayers 1 and 2 of the inner plexiform layer, and slightly grazing the amacrine cell layer, alternately labeled with anti-glutamate or anti-GABA IgGs. For the moment, we are only concerned with the fact that a high density of glutamate-immunoreactive $\mathrm{Ma}$ bipolar cell terminals can be located in sublayers 1 and 2 (Fig. 11 , structures 10-18), and that there are very few large punctate profiles that are immunonegative for both anti-glutamate and anti-GABA IgGs (Fig. 11, asterisks). Such exceptions turn out to be the radial stalks of Müller's cells, as they extend through the thickness of the inner plexiform layer in serial sections and are also highly taurine immunoreactive (not shown).

The smallest, oval immunoreactive somas in the inner nuclear layer are those of pure cone bipolar cells. They are also the most numerous of bipolar cell somas and indicate that cone bipolar cell systems may be diverse and complex to analyze. Cone bipolar cells have the thinnest of bipolar cell axons and, as they exhibit highly curved trajectories, it is difficult to obtain a complete serial reconstruction of a cone bipolar cell. Even so, very diagnostic features can be documented. Glutamate-immunoreactive somas corresponding to neither $\mathrm{Ma}$ or $\mathrm{Mb}$ bipolar cells extend slender distal processes to the photoreceptor layer and thin axons into the inner plexiform layer (Fig. 12). Cone bipolar cells often have their somas situated directly in the amacrine cell layer (Fig. 12b). Certain cyprinid cone bipolar cells can be classified on the basis of varicose terminal swellings in specific sublayers of the inner plexiform layer. Cone bipolar cells that exclusively contact blue-sensitive cones (Св bipolar cells) have a characteristic axon with varicosities occurring in sublayers 1 , 3, and 5 (Scholes, 1975; Kalloniatis and Marc, 1990). We have found 2 glutamate-immunoreactive bipolar cell axons that correspond nicely to the form of a $\mathrm{C}_{\mathrm{B}}$ bipolar cell (Fig. 12d,e). We have also found some bipolar cells that could be a variety selective for green-sensitive cones (CG bipolar cells; Fig. 12c), with a pair of varicosities in sublayers 3 and 4 or sublayers 4 and 5 (see Scholes, 1975).

Horizontal sections provide strong evidence that all bipolar cells are glutamate immunoreactive. Within the inner nuclear layer proper, serial sections treated alternately with anti-glutamate and anti-GABA IgGs reveal that virtually all structures can be accounted for as horizontal cell axon terminals, Müller's cell profiles, or bipolarlike glutamate-immunoreactive somas (Fig. 13). Upon close examination, it is difficult to find any ovoid somas in the midst of the inner nuclear layer that are not glutamate immunoreactive. So far, every apparently immunonegative region has been documented in serial sections to be (1) a polygonal region of a Müller's cell distal process, (2) a horizon- 

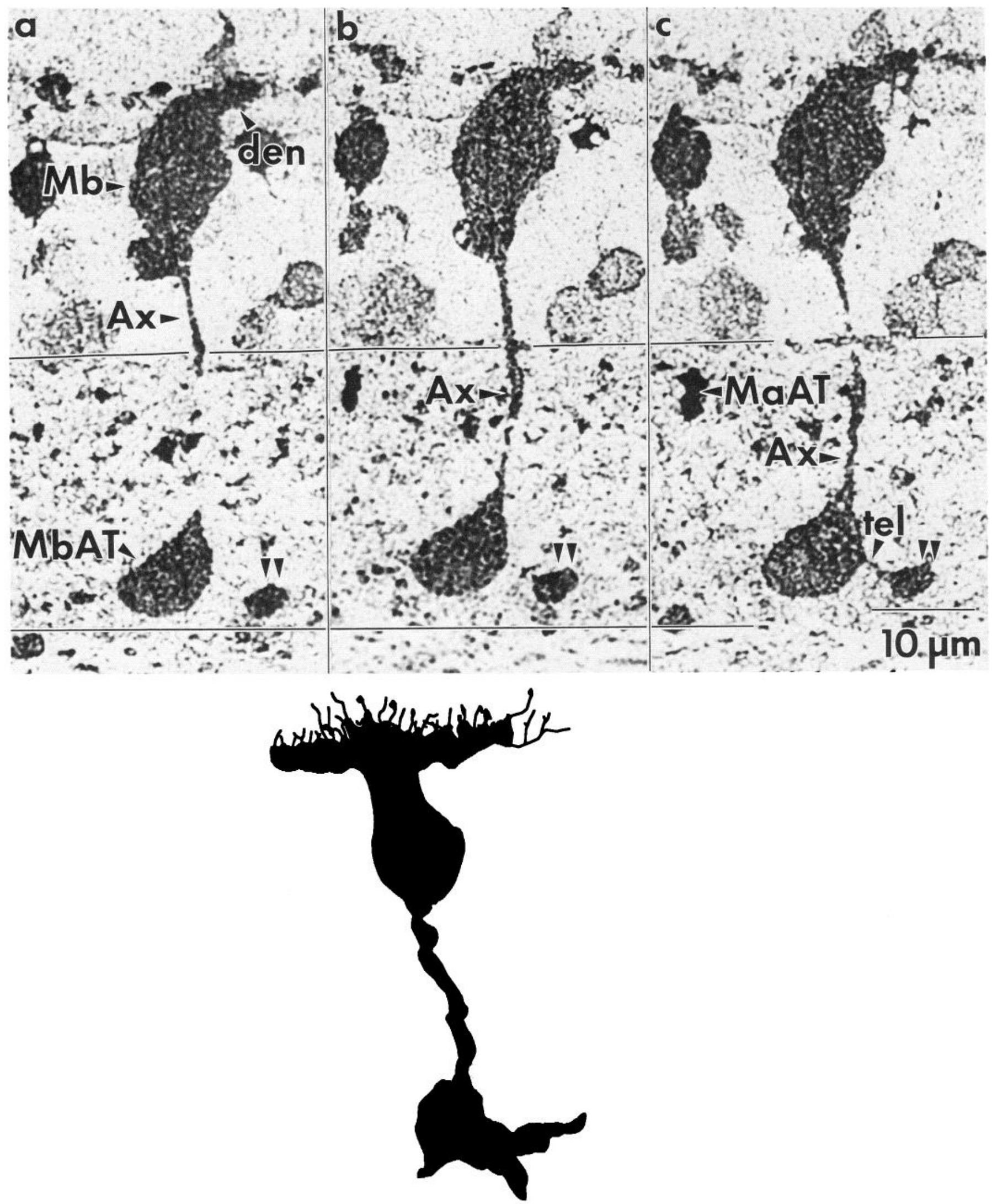

Figure 7. Glutamate immunoreactivity of type $M b$ bipolar cell. The upper panels show 3 serial 500-nm sections $(a-c)$ though a type Mb bipolar cell, displaying its characteristic form and level of termination in the inner plexiform layer. Each section in a series is separated by a solid vertical line. The lower panel is a drawing of a Golgi-impregnated Mb bipolar cell (Kalloniatis and Marc, 1990) at the same scale. den, major dendritic branch; tel, telodendron; see Figure 3 caption for other abbreviations. Double arrowheads indicate the lobular ending of a telodendron. 


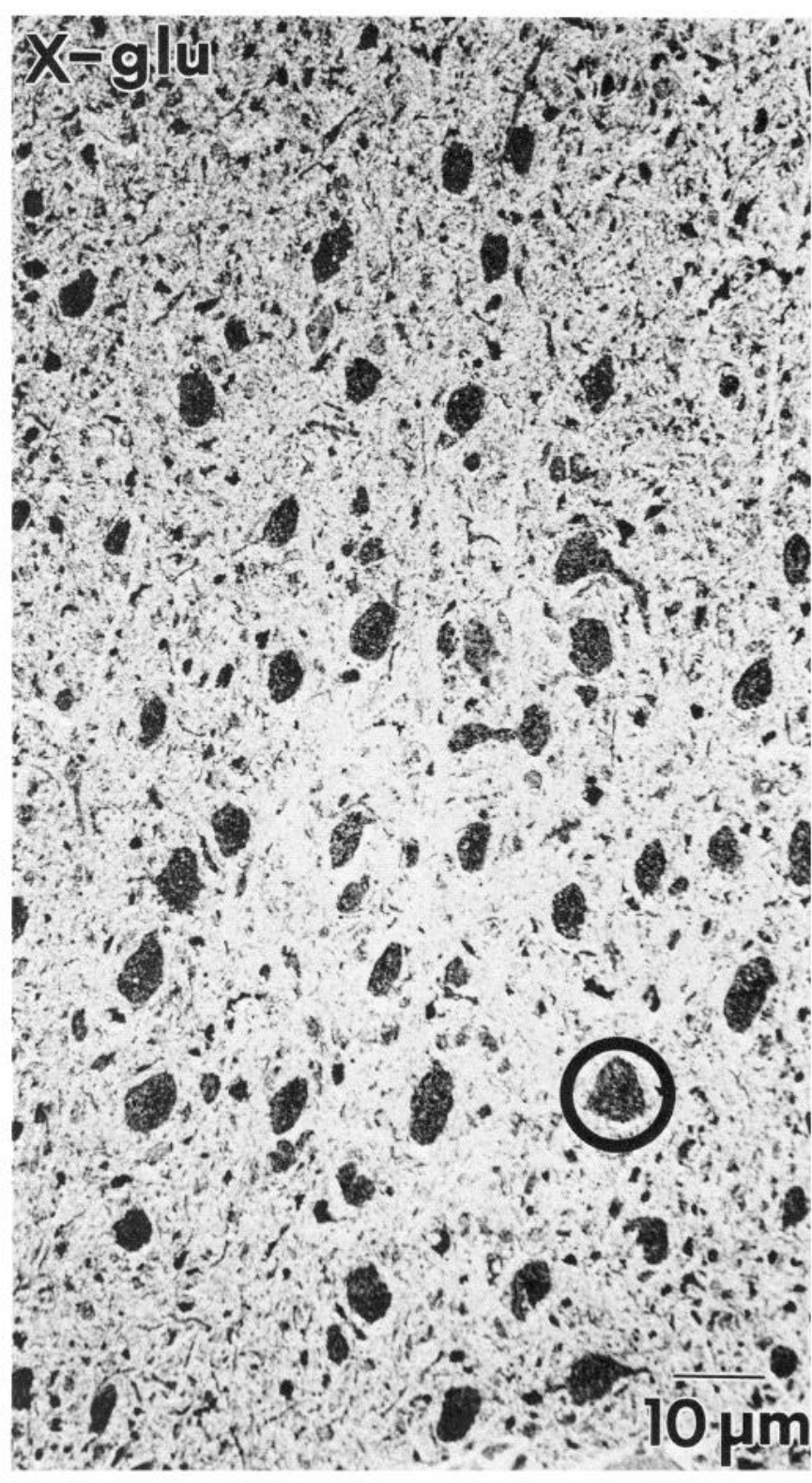

Figure 8. Glutamate immunoreactivity $(X-g l u)$ in horizontal section through sublamina $\mathrm{b}$ at level of the $\mathrm{Mb}$ bipolar-cell axon terminals. These bulbous endings, one of which is circled, form a roughly regular array at $1500-1800$ terminals $/ \mathrm{mm}^{2}$. There are no unlabeled terminals.

tal cell axon terminal, or (3) a rare section through a glycinergic interplexiform cell.

\section{Horizontal cells: detailed observations}

Certain horizontal cells in the goldfish retina display some glutamate immunoreactivity, but the labeling can vary for subtypes of horizontal cells. Because some fish horizontal cells are well known as GABAergic interneurons, this provided us a good opportunity to ask how much glutamate, the immediate precursor of GABA, is maintained in a GABAergic neuron. Under most circumstances, the glutamate immunoreactivity of the distal GABAergic horizontal cells is low (Fig. 14) but clearly elevated over that of Müller's cells. However, a proximal layer of non-GABAergic horizontal cells is even more glutamate immunoreactive, and this difference is often very marked (Fig. 14).
We do not have control of the factors that influence the glutamate immunoreactivity of horizontal cells, and the levels observed in GABAergic horizontal cells can vary by a factor of 5 among retinas. Within a given retina and within a population, the level seems constant, but under no circumstances do horizontal cell soma or axon terminal levels of glutamate immunoreactivity approach those of bipolar or ganglion cells. The webs of horizontal cell axon terminals in the inner nuclear layer provided an excellent opportunity to sample glutamate immunoreactivity in cell populations by quantitative means and, so doing, led to a very surprising result: Based on combined patterns of glutamate and GABA immunoreactivity, there are at least 3 separate "kinds" of horizontal cell axon terminals. The array of horizontal cell axon terminals in anti-glutamate treated sections exhibited 3 obvious levels of immunoreactivity: Most of the terminals appeared moderately labeled (Fig. 13b, terminals labeled 1), with much lower (labeled 2) and higher (labeled 3) values evident. By alignment with serial sections labeled with anti-GABA IgGs, the 3 kinds of terminals were revealed to be (1) GABA immunoreactive with moderate glutamate immunoreactivity, (2) GABA immunoreactive with low glutamate immunoreactivity, and (3) GABA immunonegative with high glutamate immunoreactivity (Fig. 13b,c). Digital imaging of large fields of terminals established that the 3 visually distinguishable levels of glutamate immunoreactivity actually arose from 3 statistically separable sources and not from a continuum of label densities (see Appendix).

\section{The amacrine cell layer: detailed observations}

The amacrine cells of the goldfish retina are extremely heterogeneous, and the amacrine cell layer itself contains a variety of structures, even though it is dominated by amacrine cell somas. Both bipolar cell somas and horizontal cell axon terminals can be found there, along with Müller's cells and the occasional displaced ganglion cell. Our data indicate that over half of the somas in the amacrine cell layer are GABAergic, and about 35\% of the remaining cells are glycinergic (Marc, 1989; see also Ball and Brandon, 1986). The glutamate immunoreactivity of this layer is tremendously heterogeneous, but by using serial sections labeled with anti-glutamate and anti-GABA IgGs, we can reveal subpopulations of cell types (Fig. 15). The GABA-immunoreactive amacrine cells display a wide range of glutamate immunoreactivities from low levels (e.g., cell 1 in Fig. 11, cell 14 in Fig. 15) to moderate levels (e.g., cell 2 in Fig. 11, cell 13 in Fig. 15). Conversely, there are strongly glutamate-immunoreactive structures in the amacrine cell layer that are unequivocally GABA immunonegative and are clearly identifiable as displaced ganglion cells (Fig. 11) or are similar to small bipolar cell somas (Figs. 11, 15), as predicted by our findings with vertical sections of cone bipolar cells. The complex mixture of cell types and apparent variations in glutamate immunoreactivity in a single image often makes it difficult to resolve quantitative associations among cell form, GABA immunoreactivity, and glutamate immunoreactivity. Quantitative image analysis considerably simplifies this task (see Appendix) and clearly demonstrates that unique groupings of glutamate-immunoreactive cells are associated with distinctive sets of neurons. In particular, GABAergic amacrine cells contain moderate levels glutamate immunoreactivity, always much less than the glutamate immunoreactivity of small, oval GABA-immunonegative profiles. These latter cells, though in the amacrine cell layer proper, actually contain the same levels of glutamate immunoreactivity 

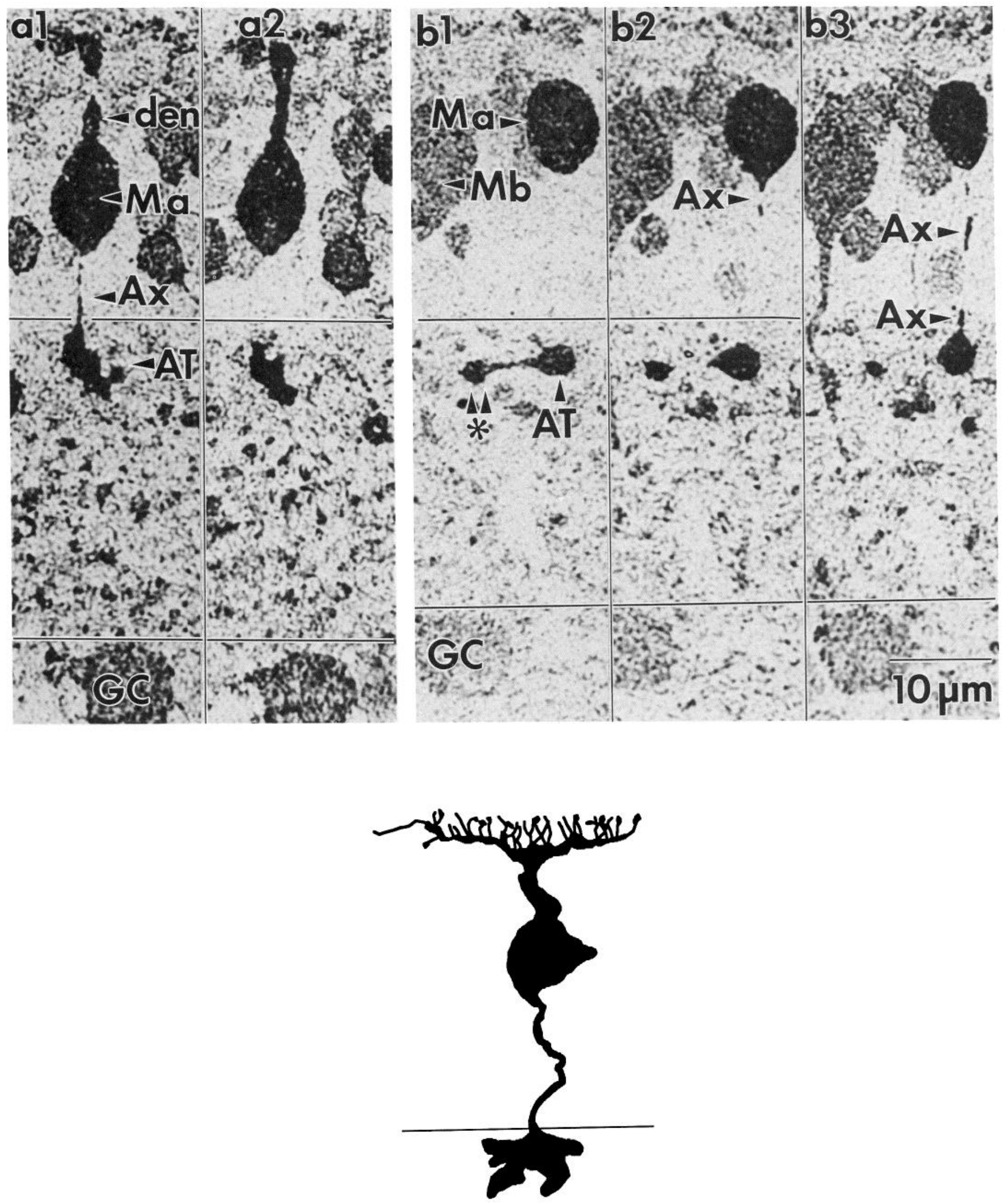

Figure 9. Glutamate immunoreactivity of type $M a$ bipolar cells. The upper panels show 2 sets of serial sections through Ma bipolar cells with their somas located in the middle $(a 1, a 2)$ or the distal part $(b 1-b 3)$ of the inner nuclear layer. The lower panel is a Golgi-impregnated Ma bipolar cell drawn to scale; the horizontal line in the drawing shows the amacrine cell layer/inner plexiform layer border. $A T$, axon terminal; $M b$, type Mb bipolar cell; see Figures 3 and 7 captions for other abbreviations and symbols, respectively. 
Figure 10. Concordant localization of ${ }^{3} \mathrm{H}$-serotonin uptake $\left({ }^{3} \mathrm{H}-5 \mathrm{HT}\right)$ and glutamate immunoreactivity $(X-g l u)$ in goldfish bipolar cells. Bipolar cells exhibiting both markers are indicated with asterisks (circles). The single arrowhead indicates distal bipolar-cell soma for reference; 3 ganglion cells are also marked $(G)$.
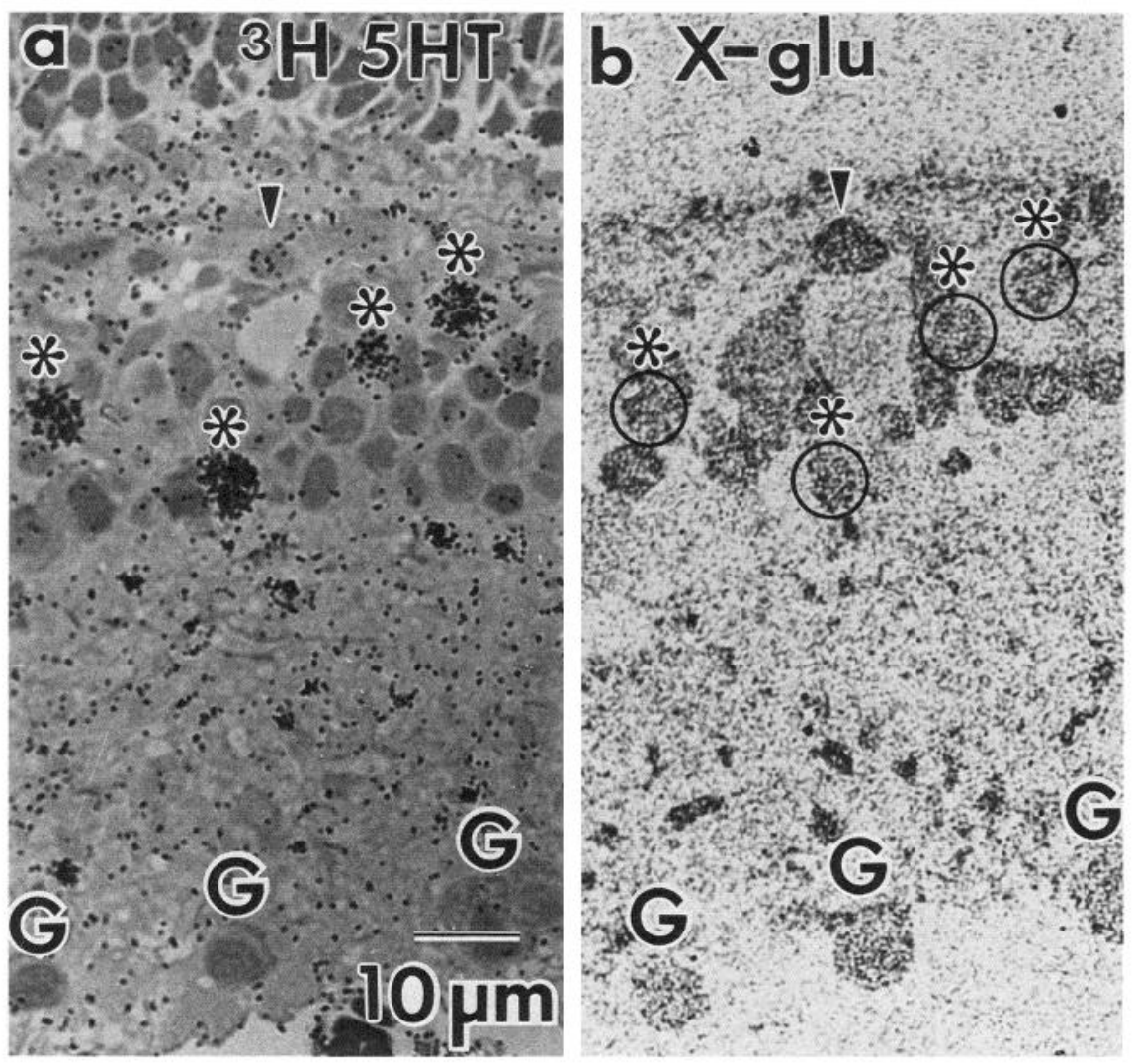

as bipolar cells, and they probably are bipolar cells, perhaps even of a single type. For example, a sample of small, GABAimmunonegative, glutamate-immunoreactive profiles are circled in Figure 15, where it can be seen that they seem to comprise a uniform array. These data indicate that at least $5 \%$ of the somas in the amacrine cell layer are bipolar cells.

\section{The ganglion cell layer: detailed observations}

The ganglion cell layer in the goldfish displays clear glutamate immunoreactivity among most of the somas therein (Fig. 16a). The glutamate-immunoreactive cells have a variety of features characteristic of ganglion cells: medium-to-large soma diameters, multipolar morphology, dendrites arborizing in the inner plexiform layer, and occasional axonlike processes extending off large dendrites. Consistent with the notion that virtually all ganglion cells are glutamate immunoreactive, every bundle of axons in the optic fiber layer contains many strongly glutamateimmunoreactive fibers. Those somas in the ganglion cell layer showing intermediate levels of glutamate immunoreactivity turn out to be displaced GABAergic amacrine cells (Fig. 16b). Some small somas are completely unlabeled by either antiserum and are probably microglia; the foot pieces of Müller's cells form irregular glutamate-immunonegative lakes in the optic fiber layer. One very surprising finding was the extremely high glutamate immunoreactivity of all perivascular and vascular epithelial cells and red blood cells. The significance of this is unknown, but we have observed it in many vertebrate species (R. E. Marc, unpublished observations). The glutamate levels of the displaced GABAergic amacrine cells proved to be, as expected, significantly lower than that of ganglion cells (see Appendix).

\section{Relative levels of glutamate content}

A fundamental goal of immunochemical assay is the measurement of true antigen concentrations. We cannot directly achieve that goal, but we may estimate relative glutamate levels across cells, provided 3 assumptions are made: (1) Under identical assay conditions, the stoichiometry of antibody binding in semithin sections is the same as that observed with model antigens. (2) The intracellular cross-linking environment is similar across cell types, rendering the observed immunoreactivities primarily

Figure 11. Serial pair of sections showing glutamate immunoreactivity $(X$-glu $)$ and GABA immunoreactivity $(X$-GABA in distal inner plexiform layer and small part of amacrine cell layer. Structures $1-9$ are GABAergic amacrine cells arrayed in a strand; their corresponding glutamate immunoreactivities are much lower than those of bipolar cells or ganglion cells and are somewhat variable (see text). A large displaced ganglion cell $(d G C)$ is strongly glutamate immunoreactive but shows no GABA immunoreactivity at all. This further documents the high selectivities of these antisera. A presumed bipolar cell $(B C)$ in the amacrine cell layer is circled. Structures 10-18 are Ma bipolar cell axon terminals in sublayers 1 and 2 of the inner plexiform layer. Note that they are highly glutamate immunoreactive and surrounded by GABA-immunoreactive material. A presumed Müller's cell stalk is indicated with an asterisk in both sections. The double arrowheads indicate the trajectory of a large dendrite from a nearby GABAergic transient amacrine cell. There is a slight shift and rotation between the matched figures, so corresponding areas are marked with a rectangle. 


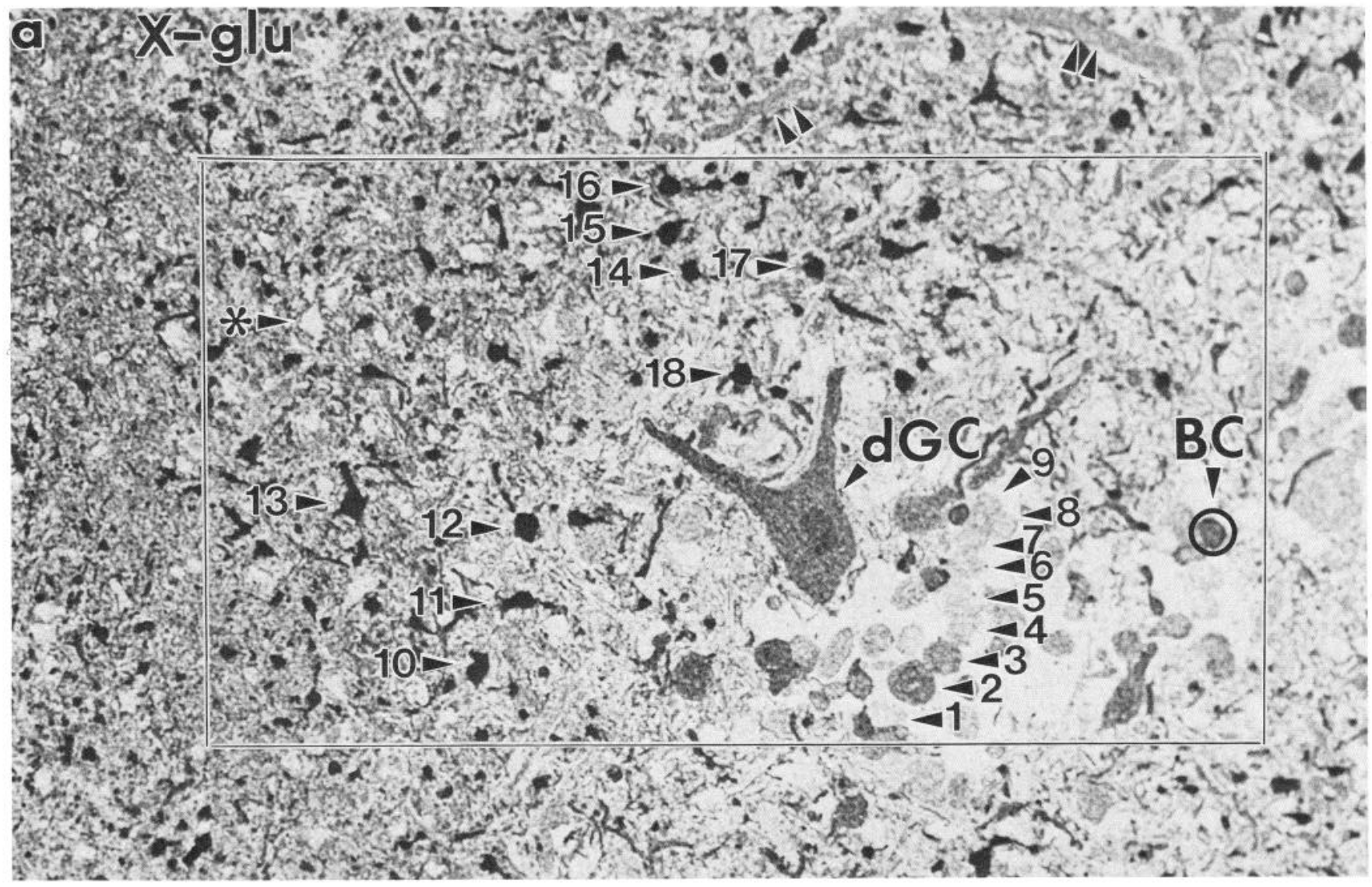

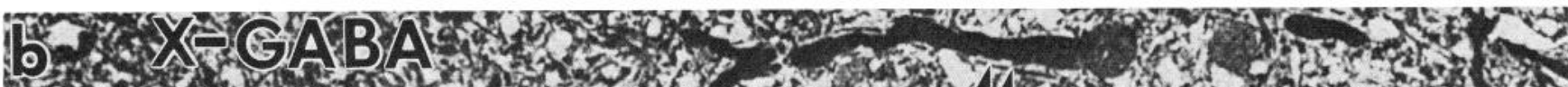

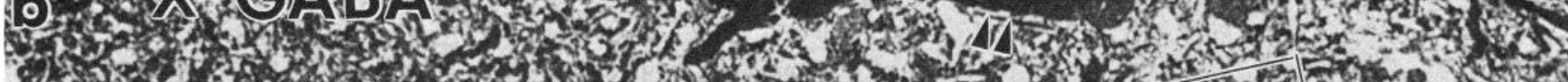

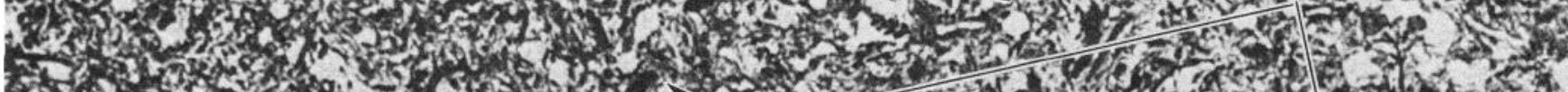

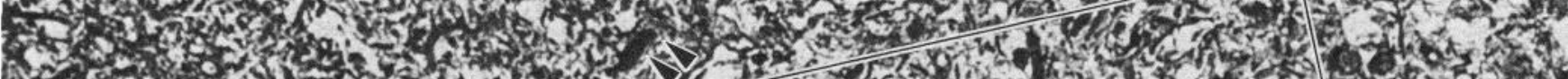

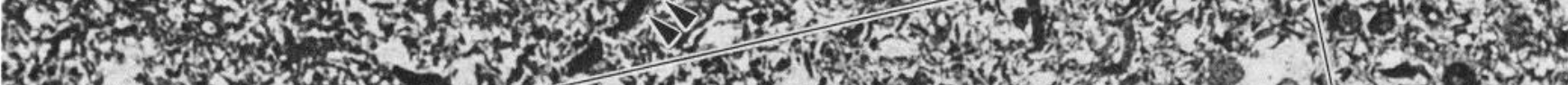

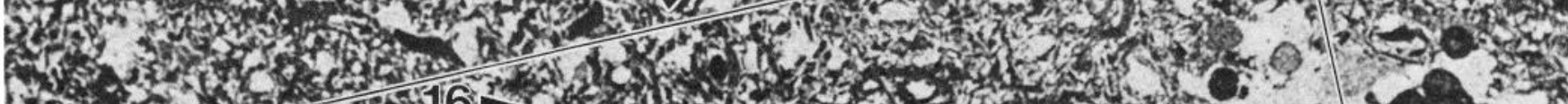

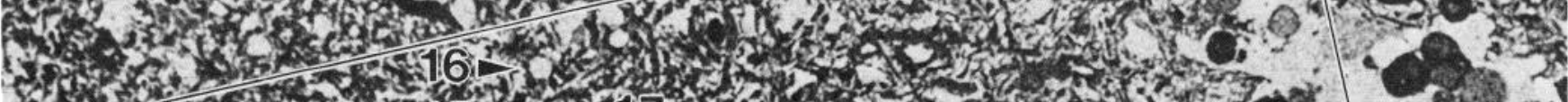

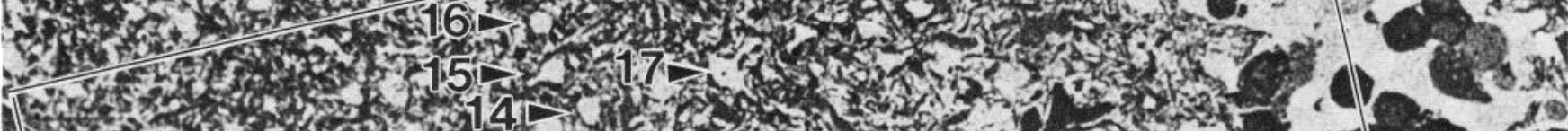

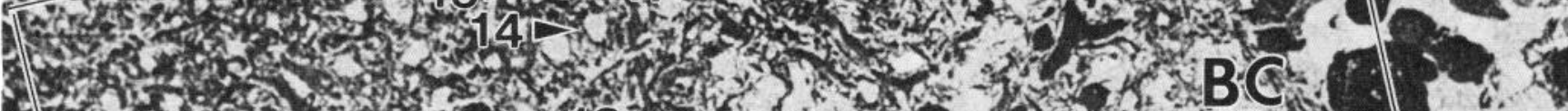

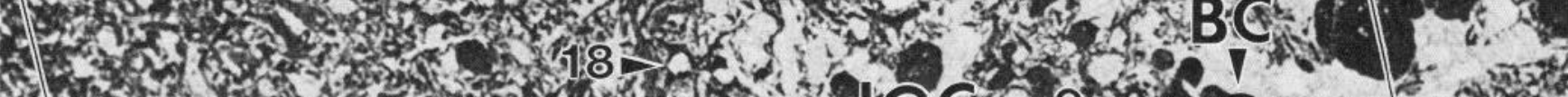

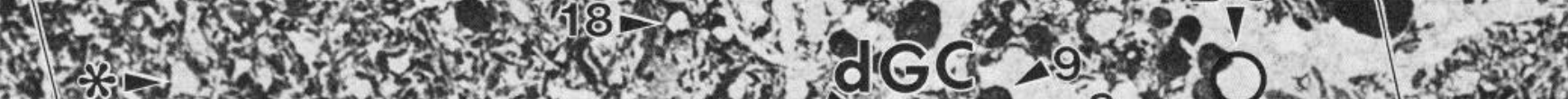

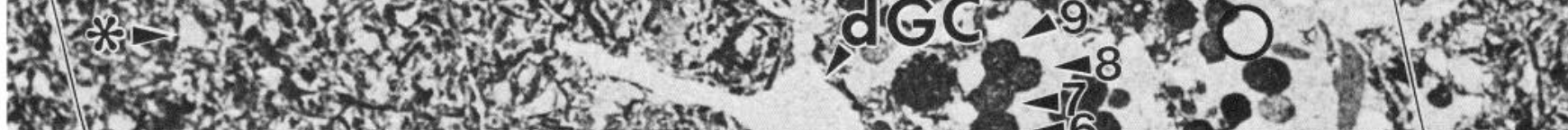

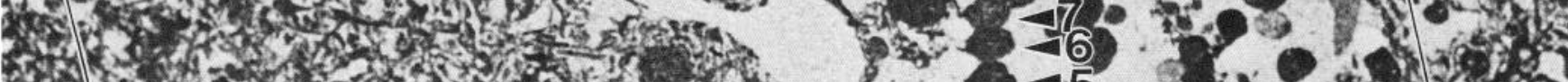
T. 5 (2)

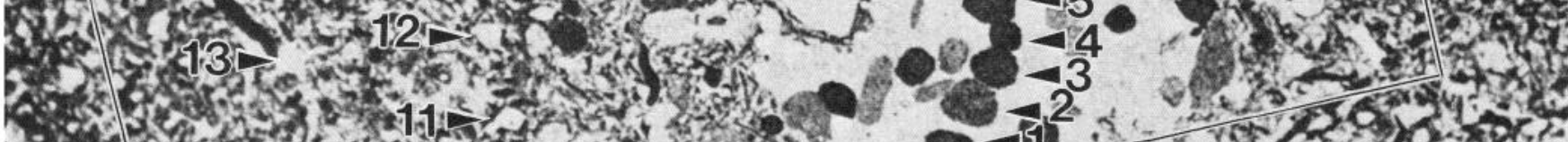

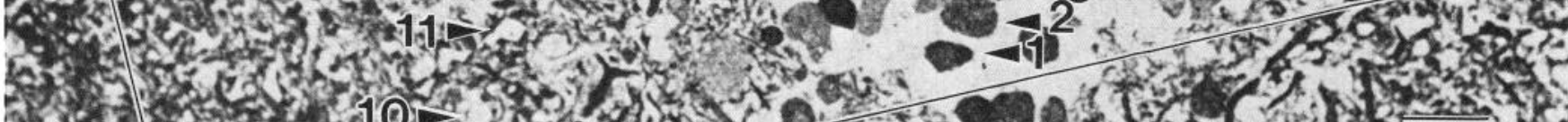

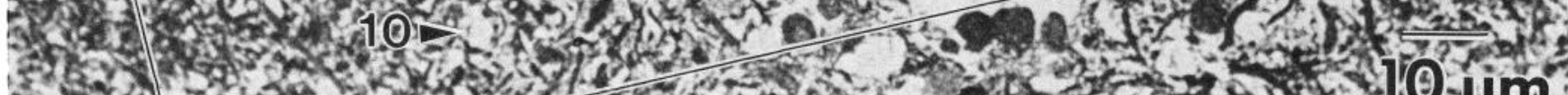

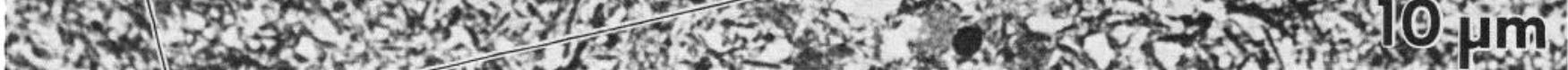




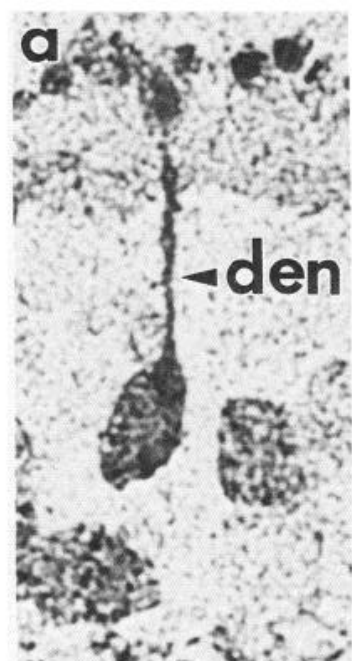

$\because-50=0,5 ?$

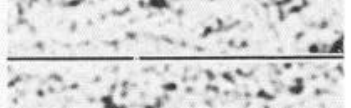

$-3^{2} x^{2}+2$

ro $3 x^{2}, x^{\circ}$

is b
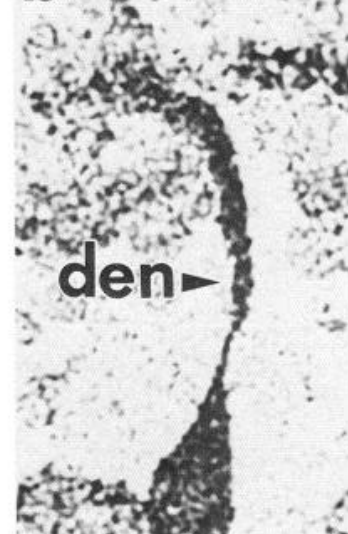

क्स c $2-2 i^{2}$

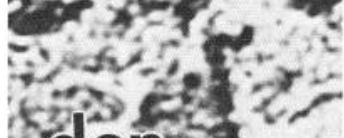
adeng

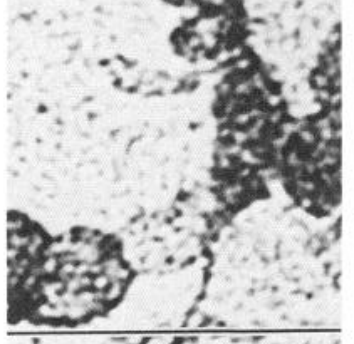

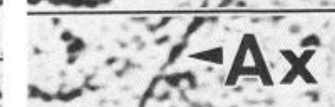

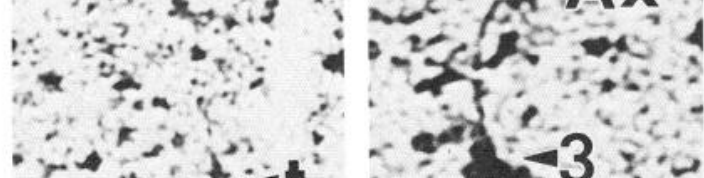

ant

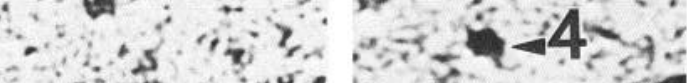

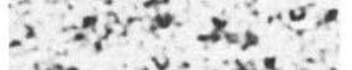

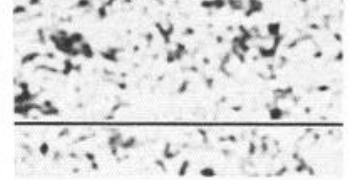

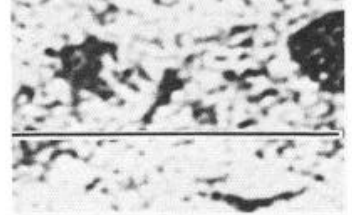

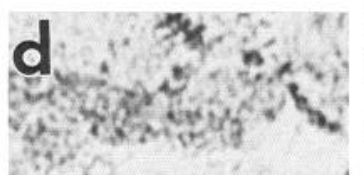

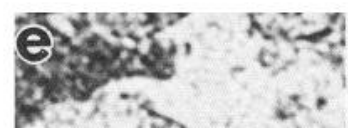

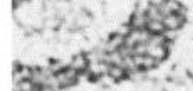

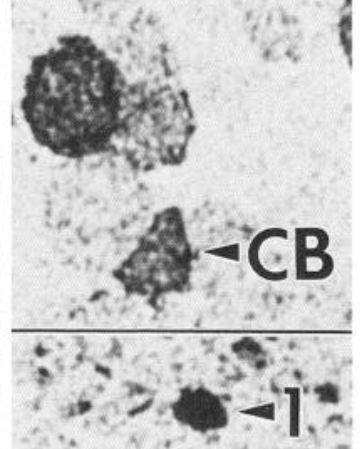

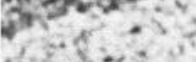

93

asime

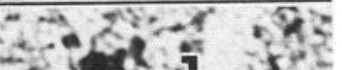

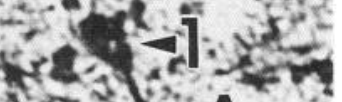

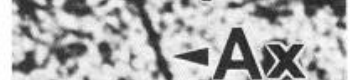
$\rightarrow x^{2}-1 x^{2}$ $\therefore$ - 1 <

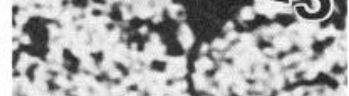
A $2 n^{-6}$ $x^{2}, x^{2}+5$

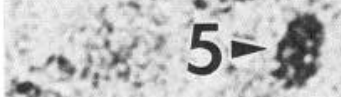
$3 x^{2}=5$ $x^{2}-y^{2}-2$

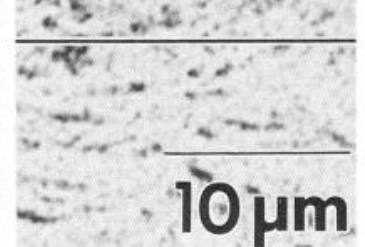
S. -10 um

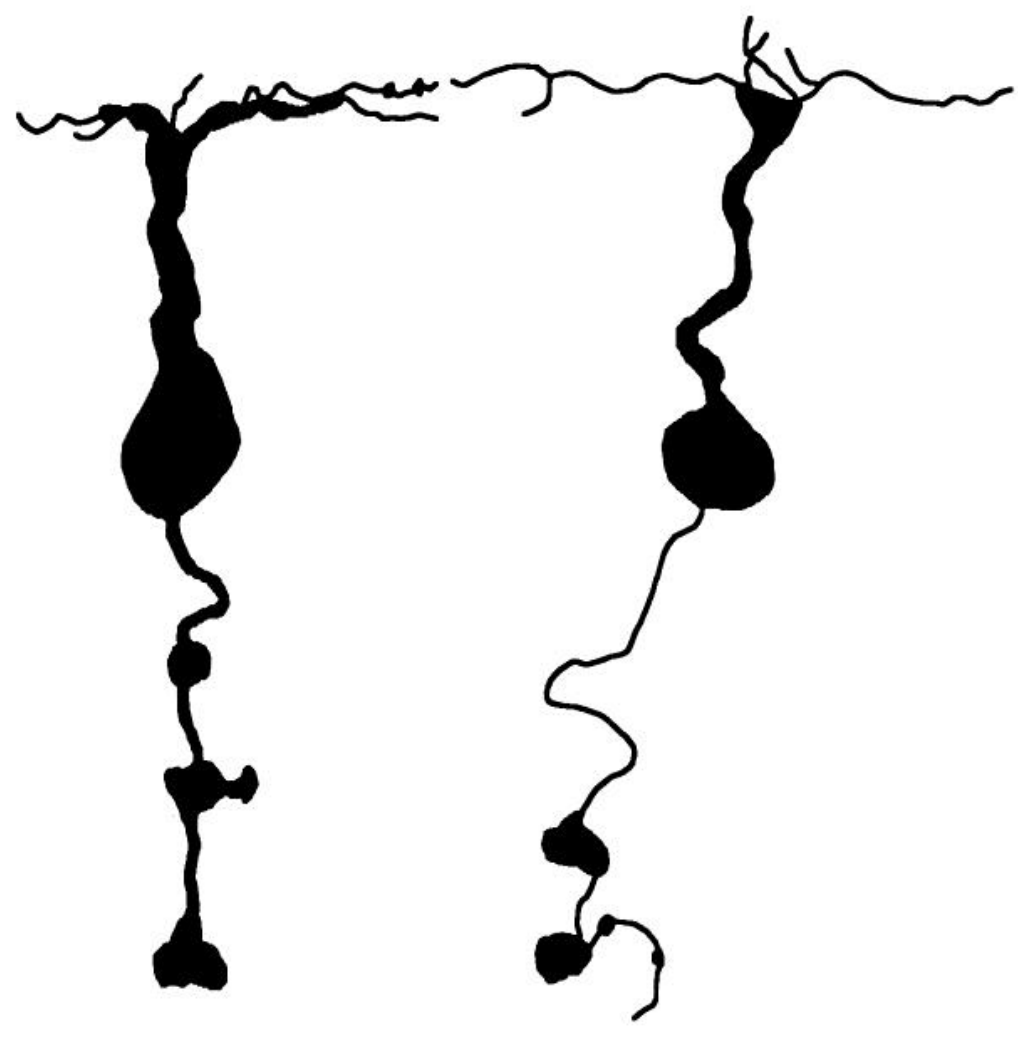


dependent on hapten concentrations. (3) The measured immunoreactivity is due to glutamate. If the signal obtained in weakly immunoreactive cells is from some cross-reactive antigen, the third assumption will underestimate true differences in glutamate levels, though there exists a test of antigenic homogeneity in a sample population (see Appendix for details).

The mean optical densities ( \pm 1 SD) of 10-30 cell samples from each of 14 different structures in a single preparation were obtained from digital frames. The highest densities measured in the goldfish retina were from vascular cells (Fig. 16), close to saturation as measured for dot immunoassays. The mean vascular cell densities were matched to a density of 0.9 , and all other values were scaled relative to that. The inverse of the saturation equation of (see Fig. 18) was used to convert all optical densities to relative concentrations. These data are displayed on a logarithmic scale in Figure 17.

Retinal neurons can be clustered into 4 categories based on their relative glutamate levels: (1) Those cells we expect to be glutamatergic (photoreceptors, bipolar and ganglion cells) have the highest intracellular glutamate levels. (2) In turn, GABAergic horizontal cells and amacrine cells have low but significant levels of glutamate, about 10-fold less than bipolar and ganglion cells. (3) Most non-GABAergic amacrine cells and Müller's cells have extremely low resting glutamate levels, about an order of magnitude less than GABAergic neurons and 2 orders of magnitude less than bipolar and ganglion cells. (4) Finally, a subset of nonGABAergic horizontal cells and their axon terminals, along with a heterogeneous grouping of somas representing about $10 \%$ of the amacrine cell layer, have glutamate levels similar to or 23-fold higher than GABAergic amacrine cells. The volatility of glutamate levels in certain retinas and certain cells is exemplified by a set of measurements made in a retina where ganglion cell signals were good but not particularly outstanding (Fig. 17, open squares), and though bipolar cell labeling was unaltered (not shown) and Müller's cell labeling was unchanged, the ganglion cells displayed a 4-fold loss in glutamate levels relative to their normal signals.

To what real concentrations do these relative values correspond? In hindsight, this may be a simple question to answer. The concentration of glutamate in whole retina is actually the mass-average concentrations of differently sized compartments containing different amounts of glutamate. The concentration in each compartment can therefore be calculated if we know its relative size and the fraction of the retinal glutamate it contains. We do not have any good estimates of glutamate concentration in whole goldfish retina, but because most neural tissue seems to maintain similar average levels of glutamate, we will assume a minimum whole-tissue concentration of $2 \mathrm{~mm}$, as reported for mammalian and avian retinas (Van Harreveld, 1976). This concentration is actually the average of the glutamate levels in many retinal compartments. We can employ digital image analysis to decompose patterns of immunoreactivity and solve for each compartment's glutamate content (see Appendix for details). Applying these methods to images such as those in Figure $3 a$, we find that photoreceptors and bipolar and ganglion cells account for $31 \%$ of the retinal mass and $69 \%$ of the retinal glutamate. The mean concentration of glutamate in that complex compartment is thus $2 \mathrm{~mm} \times(0.69 / 0.31)$ or $4.45 \mathrm{~mm}$. If we examine the restricted compartment composed of $\mathrm{Ma}$ and $\mathrm{Mb}$ bipolar cells, we find that $26 \%$ of the retinal glutamate is localized in $7 \%$ of the mass for a mean bipolar cell concentration of $7.4 \mathrm{~mm}$. This leads us to the conclusion that some bipolar cells could have glutamate levels as high as $10 \mathrm{~mm}$, whereas Müller's cells and glycinergic amacrine cells probably contain 50-100 $\mu \mathrm{M}$ glutamate. GABAergic neurons contain intermediate glutamate levels, $0.3-0.7 \mathrm{~mm}$. The error in this approach resides almost entirely in the whole-tissue value, and if the true goldfish retinal glutamate concentration is actually different, the results can be corrected easily.

\section{Discussion}

\section{Glutamate immunochemistry}

Immunochemical localization of glutamatelike haptens has been achieved in many neural structures, including the hippocampus (Storm-Mathisen et al., 1983), cerebellum (Somogyi et al., 1986), and retina (Ehinger et al., 1988). In each case, there has been a strong correlation between the cells or terminal fields displaying the highest glutamate immunoreactivity and those expected to use some excitatory amino acid as their neurotransmitter. Importantly, postembedding techniques as executed in this study and that of Ehinger et al. (1988) have revealed the generally cxpccted pattcrns of labeling for photoreceptors, bipolar cells, and ganglion cells. For example, we can demonstrate that a variety of well-known bipolar cell types and somas of other bipolar cells whose connectivities we do not yet know all show high glutamate immunoreactivity. We can provide no evidence for a bipolar cell class that lacks high glutamate immunoreactivity. But beyond these and other specific observations on the goldfish retina itself, our findings also carry 3 other strong messages: (1) The stoichiometric nature of postembedding immunocytochemistry allows estimates of intracellular concentrations. (2) Glutamate levels vary among neuronal types in an orderly way, and GABAergic neurons contain about an order of magnitude less glutamate than presumed excitatory neurons, but much more than glia or presumed glycinergic neurons. (3) Aspartate levels are apparently too low and its distribution too diffuse to render it a likely transmitter substance in the goldfish retina.

\section{Glutamate as a retinal neurotransmitter}

Excellent summaries of physiological and pharmacological evidence for glutamate as a retinal neurotransmitter are available (Miller and Slaughter, 1985; Massey, 1990). Suffice it to say that

\footnotetext{
$\leftarrow$

Figure 12. Glutamate immunorcactivity in presumed conc bipolar cells. The upper panels show various bipolar cells with small ovoid somas and characteristic patterns of termination in the inner plexiform layer. $a$, A small soma located in the middle of the inner nuclear layer, with a slender primary dendrite. $b$, A small soma located directly in the amacrine cell layer, possessing a long primary dendrite that broadens slightly as it reaches the outer plexiform layer; a terminal swelling $(t)$ was shown in serial sections to be connected to this bipolar cell. $c$, A possible CG bipolar cell with terminal swellings in layers 3 and 4 of the inner plexiform layer. $d$, A small soma in the amacrine cell layer that could be shown in serial sections to be connected with terminal swellings in sublayers 1,3 , and 5, characteristic of $C_{B}$ bipolar cells. $e$, A single section through a bipolar cell axon with tristratified terminal swellings, characteristic of $\mathrm{C}_{\mathbf{B}}$ bipolar cells. Lower panel, Golgi-impregnated $\mathrm{C}_{\mathbf{B}}(l e f t)$ and $\mathrm{CG}_{\mathrm{G}}(r i g h t)$ bipolar cells. $A x$, axon; $C B$, cone bipolar soma; den, major dendritic branch.
} 


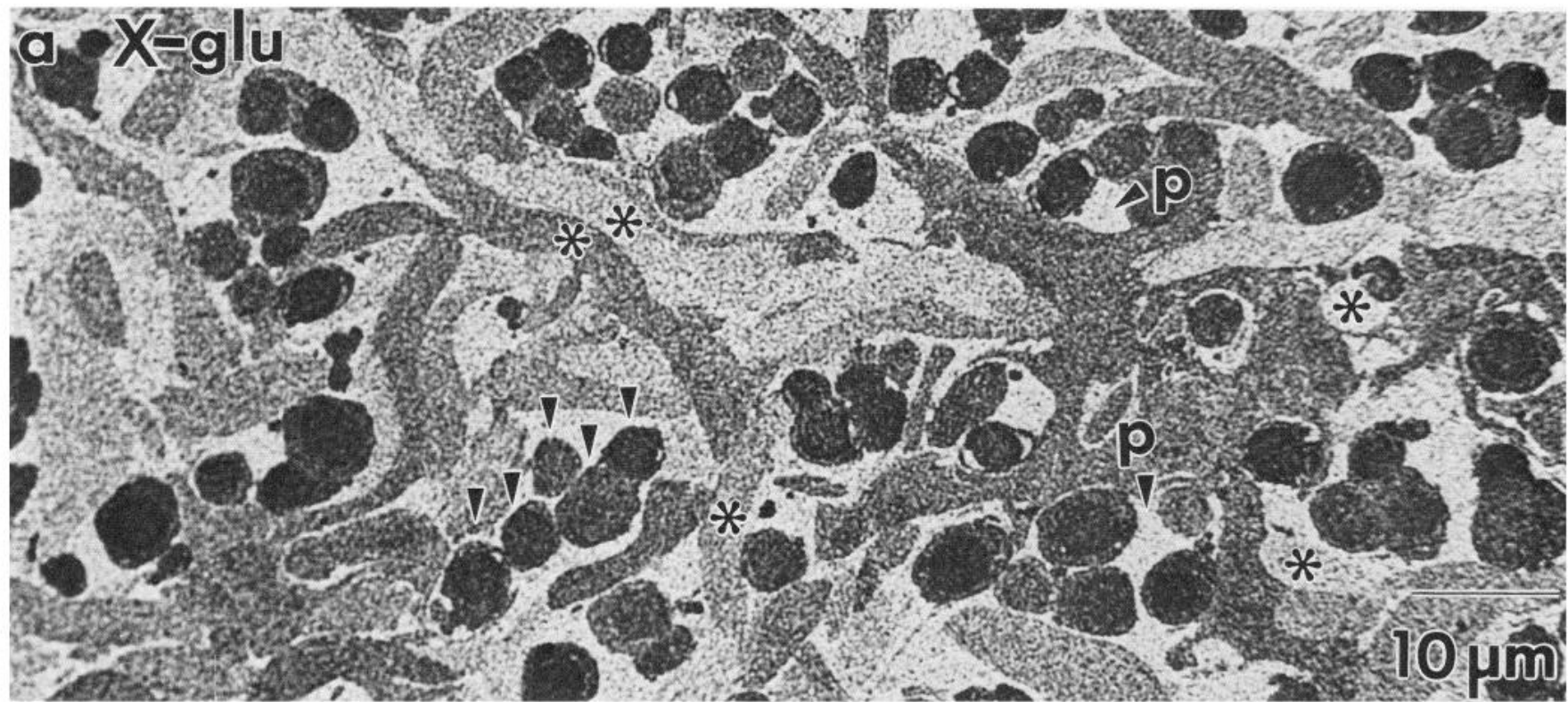

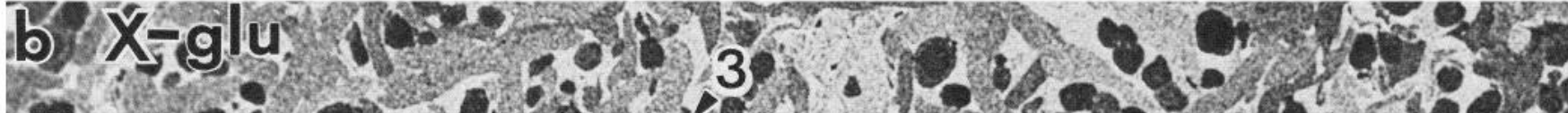

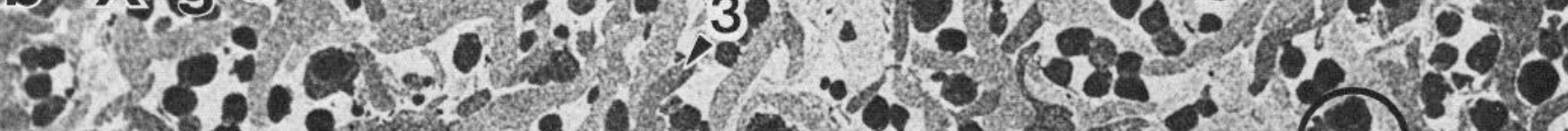

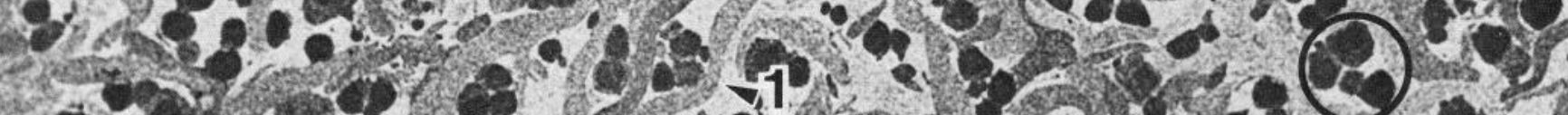

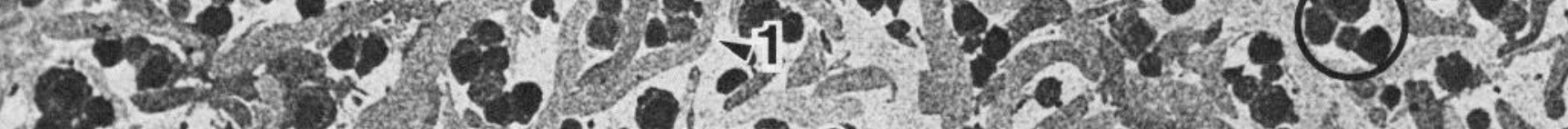

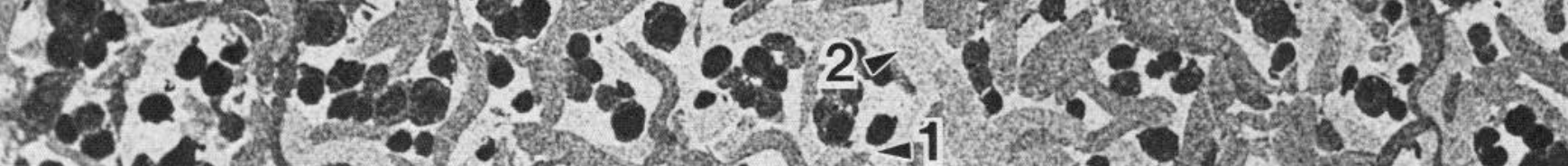

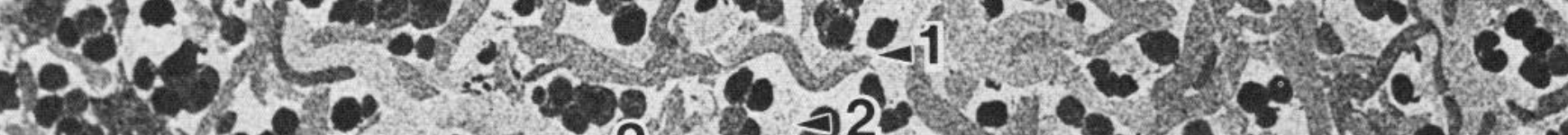

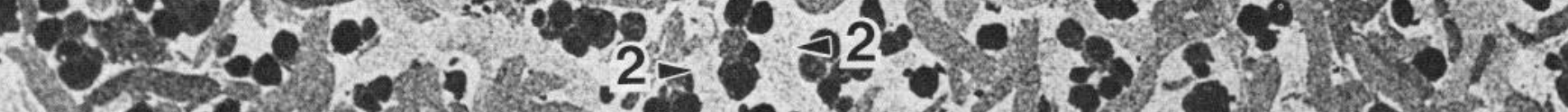

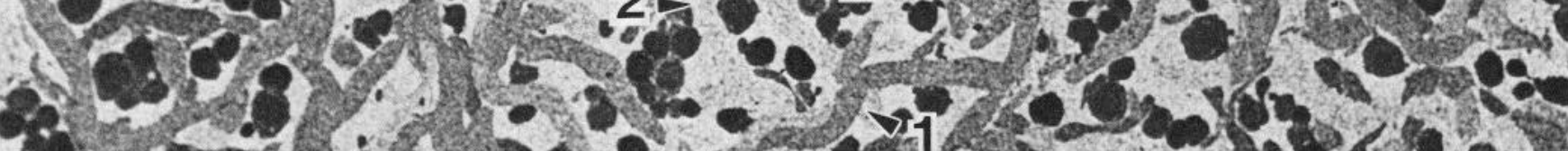

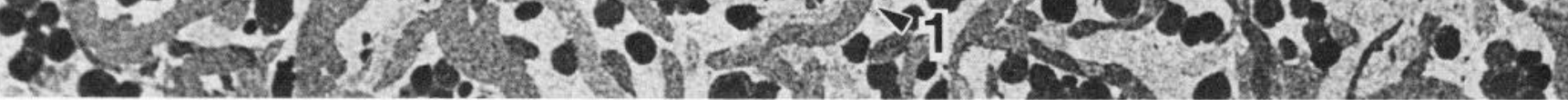

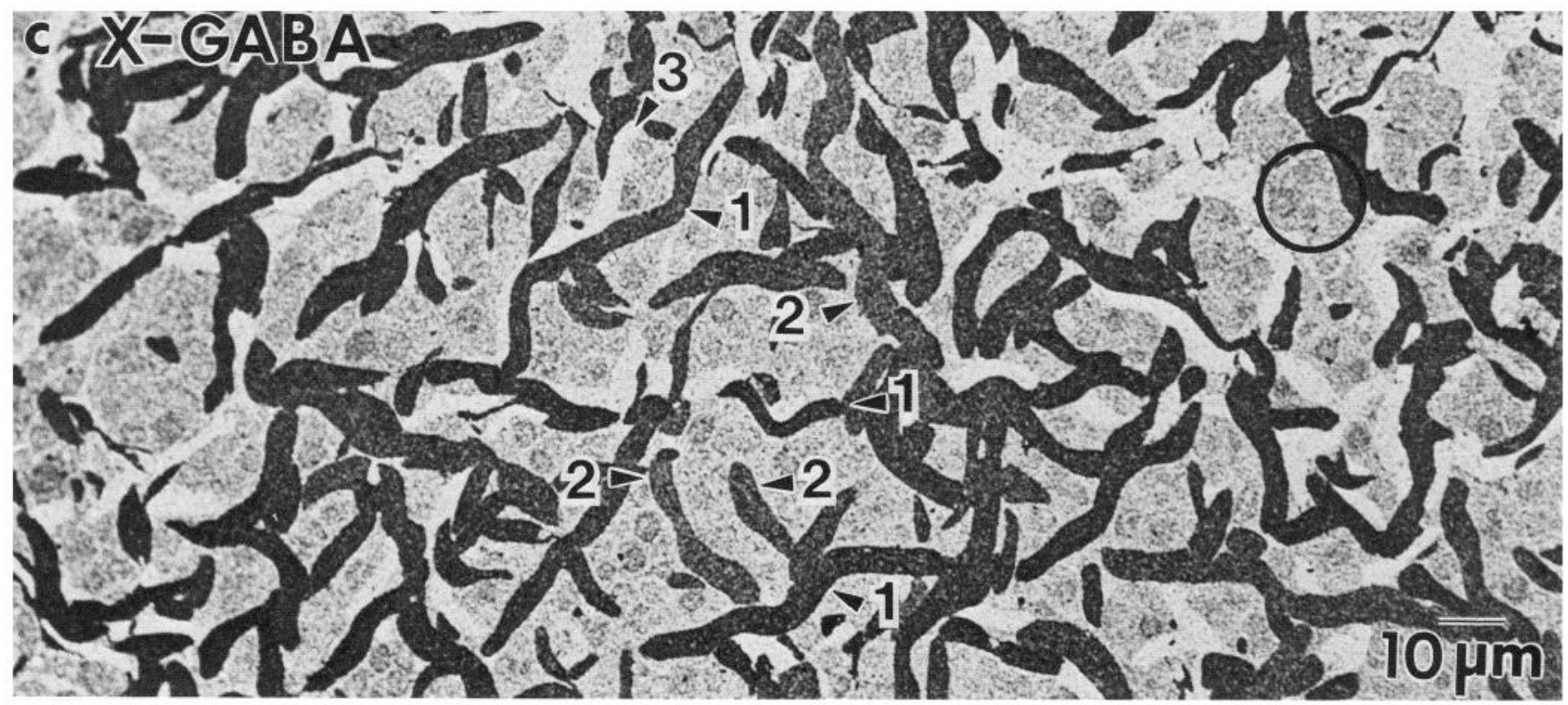




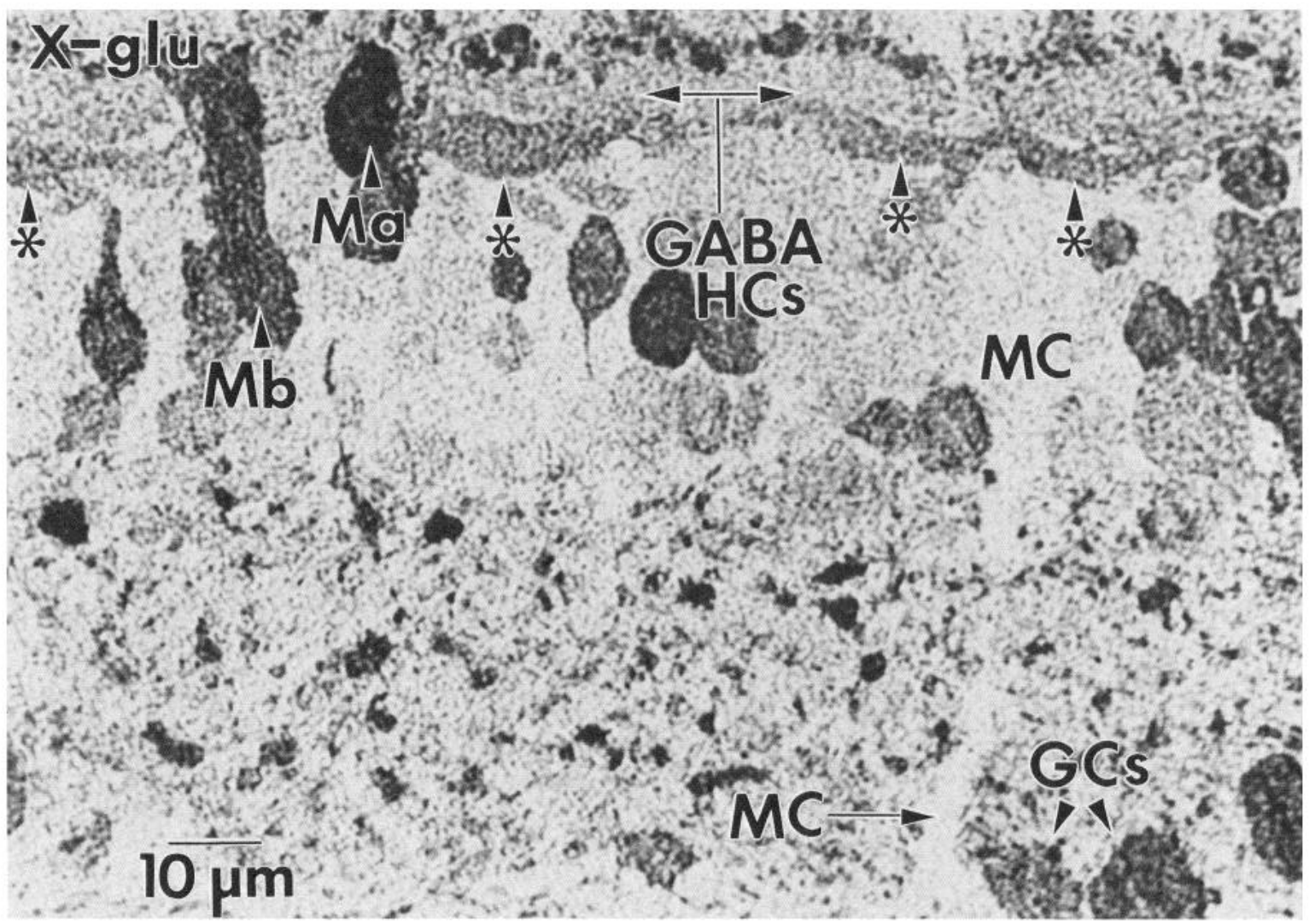

Figure 14. Glutamate immunoreactivity $(X$-glu) in horizontal cells (500-nm vertical section, SIG detection). The distal horizontal cells in the goldfish are GABAergic, and they possess modest intracellular glutamate levels. However, non-GABAergic proximal horizontal cells (asterisks) show even higher levels of glutamate immunoreactivity. We have not determined the identities of these horizontal cells. $H C$, horizontal cell; see Figure 3 caption for other abbreviations.

glutamate must remain the front runner because it is present in abundance in most of the right places, and because it mimicks the activation of the light-driven receptor mechanisms. There have been other candidates, however, such as aspartate, $N$-acetylaspartylglutamate (NAAG), and homocysteic acid.

In the goldfish retina, aspartate has a more diffuse distribution and apparently lower concentration than glutamate. Moreover, L-aspartate is electrically ineffective on isolated horizontal cells (Lasater and Dowling, 1982; Ishida et al., 1984) and is a very poor agonist at non-NMDA receptors (Mayer and Westbrook, 1985). Although Ayoub and Lam (1984) reported that L-aspartate could evoke release of ${ }^{3} \mathrm{H}-\mathrm{GABA}$ from isolated horizontal cells (but at only $1 / 3$ the maximum release evoked by L-glutamate), Yazulla (1983) demonstrated that L-glutamate-evoked release of ${ }^{3} \mathrm{H}-\mathrm{GABA}$ from horizontal cells was potentiated in the presence of $\mathrm{D}$-aspartate, which inhibited the action of
L-aspartate in the same preparation. Likewise, dark-evoked release was unimpeded by D-aspartate (Yazulla, 1985). From these perspectives, it is hard to suggest that aspartate should be considered as equivalent to glutamate as a likely neurotransmitter for photoreceptors, bipolar cells, or ganglion cells. These findings do not exclude preferential elevations of intracellular aspartate levels in unique subsets of retinal neurons (Eldred and Yaqub, 1989).

NAAG has been proposed as a possible retinal neurotransmitter, based on some immunocytochemical evidence (e.g., Kowalski et al., 1987) along with recent release data (Williamson and Neale, 1988b). NAAG is present in high concentrations in much neural tissue, prompting consideration of its potential role in neurotransmission (Koller et al., 1984). It should not be forgotten that $N$-acetylated acidic amino acids are critical regulatory components in glutamate metabolism and the regulation

Figure 13. Serial horizontal sections through inner nuclear layer displaying glutamate ( $a$ and $b, X$-glu) and GABA immunoreactivity $(c$, $X-G A B A) . a$, A magnified view of the inner nuclear layer labeled for glutamate immunoreactivity. Note that bipolar cell somas cluster together (arrowheads) in spaces between horizontal cell axon terminals (asterisks). The remaining mass is accounted for by polygonal areas $(p)$ that represent the cytoplasm of Müller's cells as they encase portions of the inner nuclear layer. $b$, A lower-magnification view of glutamate immunoreactivity in the inner nuclear layer. A bipolar cell cluster is circled. The numbers indicate examples of horizontal cell axon terminals displaying 1 of 3 levels of glutamate immunoreactivity $(1$, medium; 2 , low; 3 , high) and corresponding to axon terminals in $c . c$, GABA immunoreactivity in the inner nuclear layer. The axon terminals indicated in $b$ are also numbered here. Type 1 axon terminals are strongly GABA immunoreactive and have medium levels of glutamate immunoreactivity. Type 2 axon terminals are strongly GABA immunoreactive and have low levels of glutamate immunoreactivity. Type 3 axon terminals are GABA immunonegative and have the highest levels of glutamate immunoreactivity found in horizontal cells. 


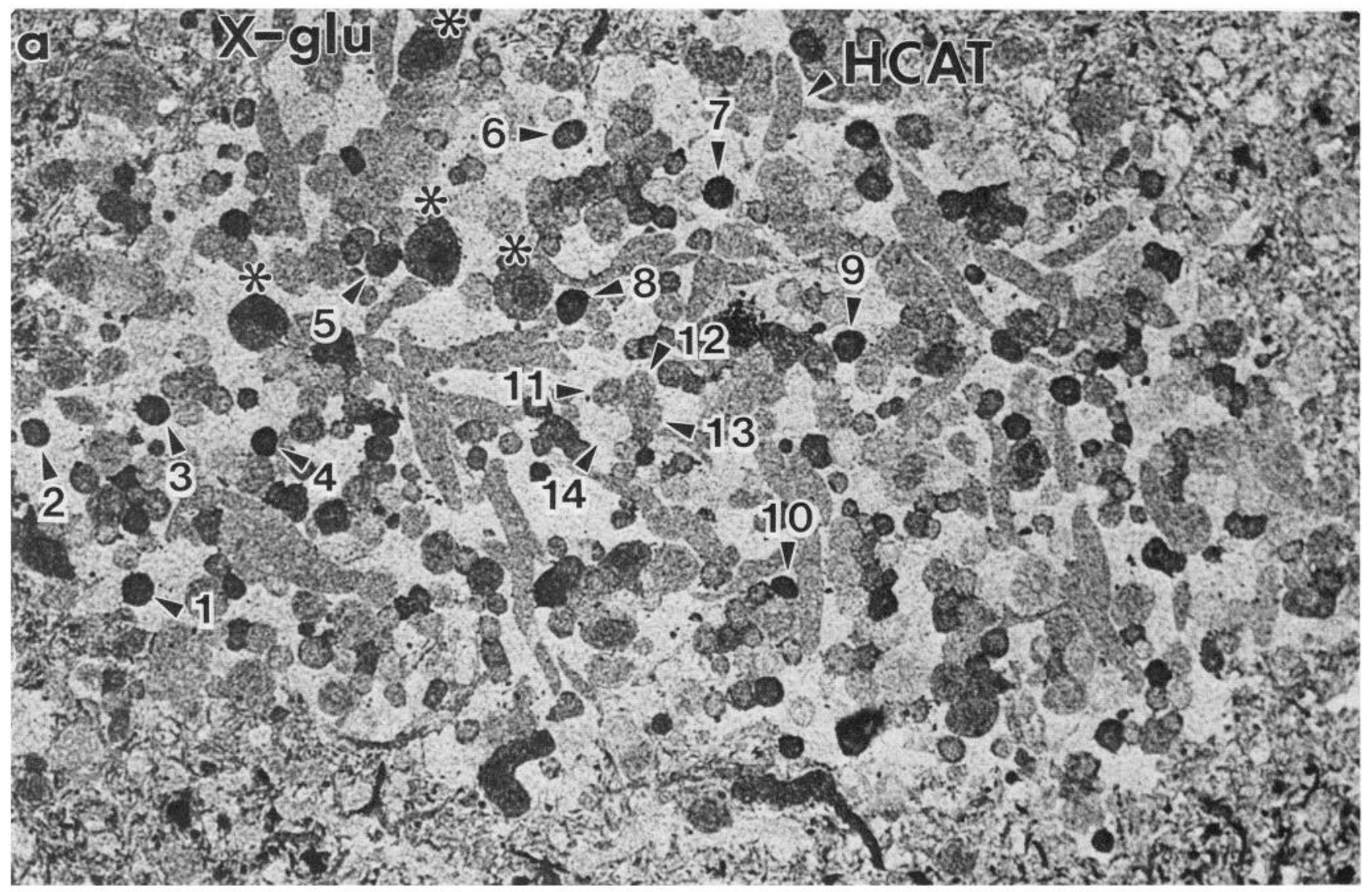

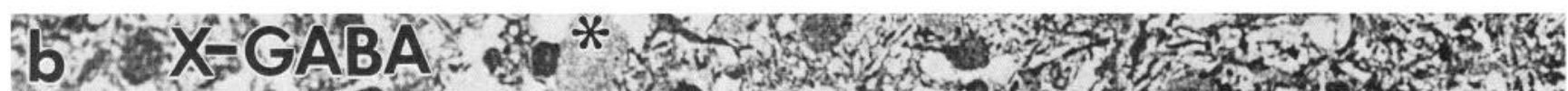
1. 0 . . 1 o n n 2. -1 O

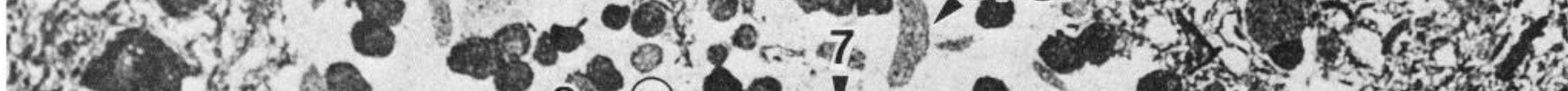
2. - 6.

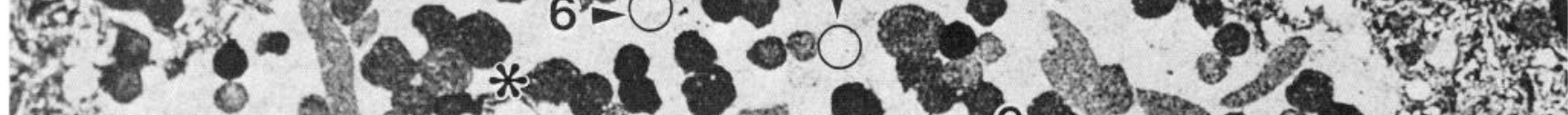

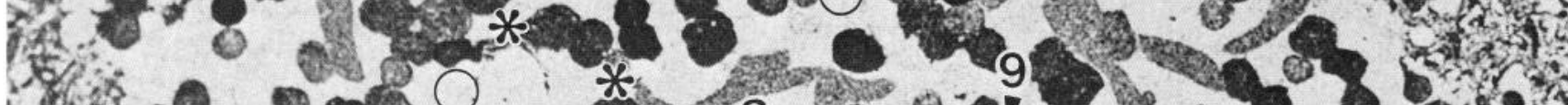
- * $500.8 \%$

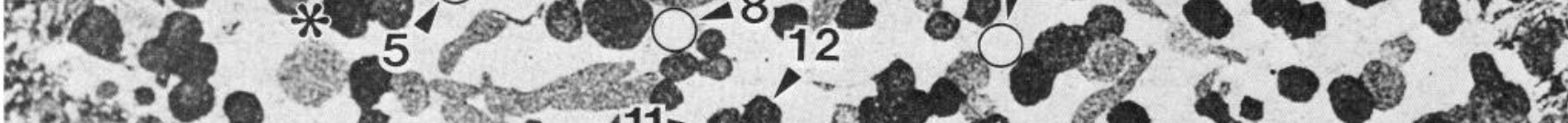

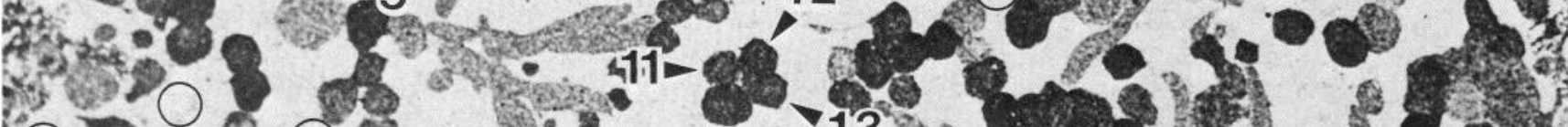

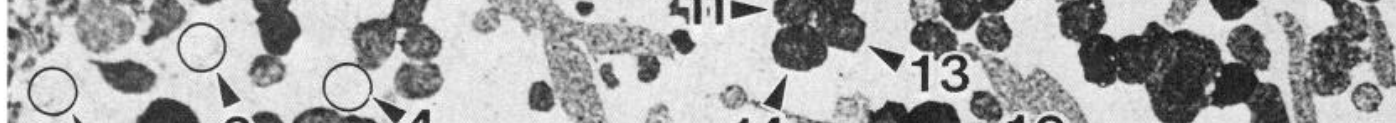

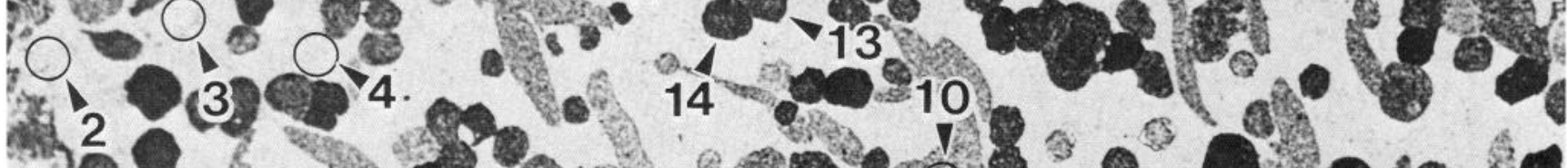

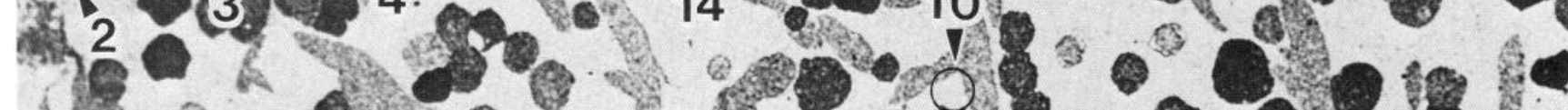

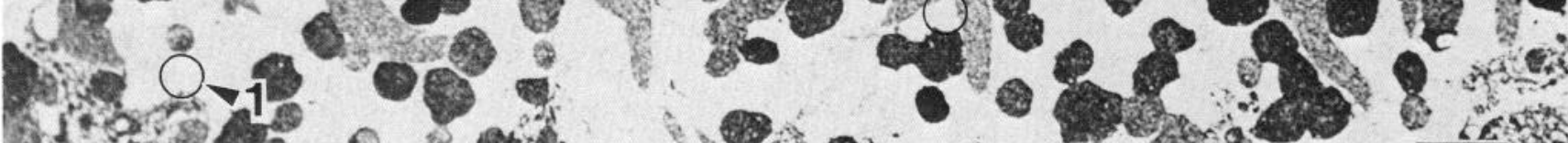

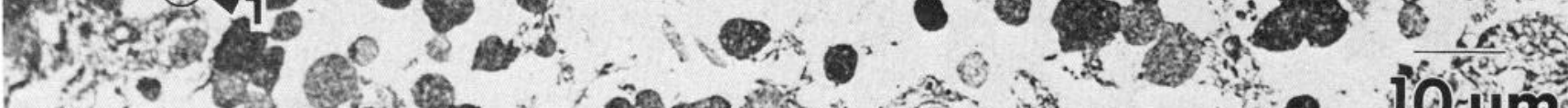
12. 
of intracellular ammonia levels. While ganglion cells (Anderson et al., 1987) and, paradoxically, amacrine cells (Williamson and Neale, 1988a) show modest NAAG immunoreactivity, the labeling pattern is not as definitive as that obtained with antiglutamate IgGs. NAAG is apparently present in photoreceptor, bipolar cell, and amacrine cell synaptic vesicles (Williamson and Neale, 1988a), which would explain its potassium-evoked release (Williamson and Neale, 1988b). But, at best, NAAG is a weak NMDA agonist (Westbrook et al., 1986) and very possibly not neuroactive at all (see Whittemore and Koerner, 1989). The presence of the marker in some amacrine cells (probably GABAergic cells) suggests that it is involved with glutamate metabolism, but not neurotransmission.

Neal has recently proposed L-homocysteic acid (HCA) as a plausible bipolar cell neurotransmitter based on its ability to evoke ${ }^{3} \mathrm{H}-\mathrm{ACh}$ release from the rabbit retina, apparently by activating kainate receptors (Neal and Cunningham, 1989). We do not know the distribution of HCA in the goldfish retina, but neither we nor Ehinger et al. (1988) can adduce compelling evidence that glutamate-immunonegative bipolar cells exist. In our hands, all rabbit bipolar cells are also glutamate immunoreactive (R. E. Marc and S. C. Massey, unpublished observations). HCA is present at about $1 / 1000$ the level of glutamate in the retina (Neal and Cunningham, 1989), and if all of it were distributed in bipolar cells, it would only reach about $50 \mu \mathrm{M}$. If, as suggested by Neal and Cunningham, HCA was constrained to a subpopulation of bipolar cells, we calculate that the population would have to be less than $1 \%$ of all bipolar cells for the concentration of HCA to reach $5 \mathrm{~mm}$, or the same order of magnitude of glutamate. Under these circumstances, HCA can not yet be considered a serious neurotransmitter candidate.

\section{Cellular patterns of glutamate immunorcactivity}

Goldfish photoreceptors are, at best, ill-behaved regarding their glutamate immunoreactivity. As noted by Ehinger et al. (1988) for turtle cones, photoreceptor glutamate immunoreactivity is characteristically concentrated near their synaptic terminals. Our findings also indicate that the photoreceptors are extremely volatile, and that it is easy to evoke (through mechanical stimulation, anoxia, $\mathrm{pH}$ effects, etc.) a rapid loss of intracellular glutamate. We are puzzled by the lack of strong labeling in goldfish rods, given that we know they have potent glutamate uptake (Marc and Lam, 1981) and apparently activate on-center bipolar cells by a glutamate-sensitive receptor mechanism (Nawy and Copenhagen, 1987). We suspect their lack of labeling is related to their small size and possible fragility, because frog rods exhibit outstanding endogenous glutamate immunoreactivity (Marc and Basinger, unpublished observations). We are therefore cautious about interpreting the absence of label in photoreceptors. It is not surprising that incubation of retinas in saline leads to good preservation (or recovery) of photoreceptor glutamate immunoreactivity, as the goldfish is a highly aerobic animal, and retinal dissection invariably involves some anoxic periods. In hippocampal slices, Storm-Mathisen et al. (1986) noted that incubation in physiological medium appeared to "favor the visualization of the transmitter pools of the excitatory amino acids."

The weak labeling of blue-sensitive cones could also be attributed to some metabolic hypersensitivity. However, bluesensitive cones also exhibit less effective uptake of ${ }^{3} \mathrm{H}$-aspartate or glutamate than other cones (Marc and Lam, 1981), and transmission from blue-sensitive cones to horizontal cells has been shown to be more resistant to various glutamate analogs than transmission from red- and green-sensitive cones (Murakami et al., 1972; Mangel et al., 1985). Blue-sensitive cones remain enigmatic regarding their neurotransmitter.

All the bipolar cells we can identify are glutamate immunoreactive, and aspartate is not significantly concentrated in bipolar cells. There are many instances where other markers such as glycine (e.g., Pourcho and Goebel, 1987) or serotonin (e.g., Weiler and Schütte, 1985; Marc et al., 1988) have been localized to bipolar cells, but as shown here, all serotonin-accumulating bipolar cells in the goldfish are strongly glutamate immunoreactive. We concur with Ehinger et al. (1988) in their conclusion that all bipolar cells could use glutamate as a neurotransmitter.

The observation that most, if not all, goldfish retinal ganglion cells show strong somatic glutamate immunoreactivity raises the possibility that they all use glutamate as a central neurotransmitter, consistent with the pharmacological findings in the goldfish optic tectum (Langdon and Freeman, 1986, 1987). There is abundant evidence that ganglion cells in many species contain a variety of peptides or even some conventional neurotransmitters other than acidic amino acids (see Erlich et al., 1987). There is nothing that precludes colocalization of high levels of glutamate and another neuroactive substance in goldfish ganglion cells. However, the GABA-immunoreactive profiles in the ganglion cell layer of the goldfish are displaced amacrine cells and not ganglion cells (Ball and St. Denis, 1986). Furthermore, we never observed any GABA-immunoreactive profiles in optic nerve fiber bundles in goldfish.

We think it particularly noteworthy that, though GABAergic horizontal cells and amacrine cells apparently contain measurable levels of glutamate, the amount of glutamate is an order of magnitude less than that in bipolar cells and ganglion cells. The conclusion might be that a smaller standing pool of glutamate is necessary to ensure steady GABA levels than is necessary to subserve glutamatergic transmission. This is not too surprising in retrospect, because the $K_{m}$ reported for mammalian-brain glutamic acid decarboxylase is about $0.7 \mathrm{~mm}(\mathrm{Wu}$, 1976). It makes sense that the level of glutamate in GABAergic cells is around $0.3-0.7 \mathrm{~mm}$ (from Fig. 17), below or close to the apparent $K_{m}$. The amount of glutamate across the entire population of GABAergic amacrine cells varies widely. We do not know whether each subtype of GABAergic amacrine cell maintains a specific level and that there are variations among subtypes, or whether every individual cell cycles through different

\section{$\longleftarrow$}

Figure 15. Glutamate $(a, X$-glu) and GABA $(b, X$-GABA) immunoreactivity in serial horizontal 500 -nm sections though amacrine cell layer. Although the glutamate immunoreactivity appears complex, it is possible to decipher much of it by examining both images. In $a$, structures numbered 1-10 are the most glutamate-immunoreactive elements. They are small and evenly spaced and can be seen in $b$ to be GABA immunonegative (circles); they are probably bipolar cell somas in the amacrine cell layer. Conversely, a mixed range of glutamate immunoreactivities is seen in a cluster of 4 GABA-immunoreactive cells (11-14). Three other large glutamate-immunoreactive somas that exhibit high, medium, and low levels of GABA immunoreactivity are indicated by asterisks. HCAT, horizontal cell axon terminal. 
a) $X$ gluser - I MbATs * - . . 2

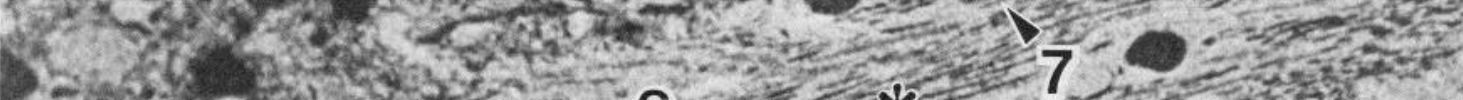

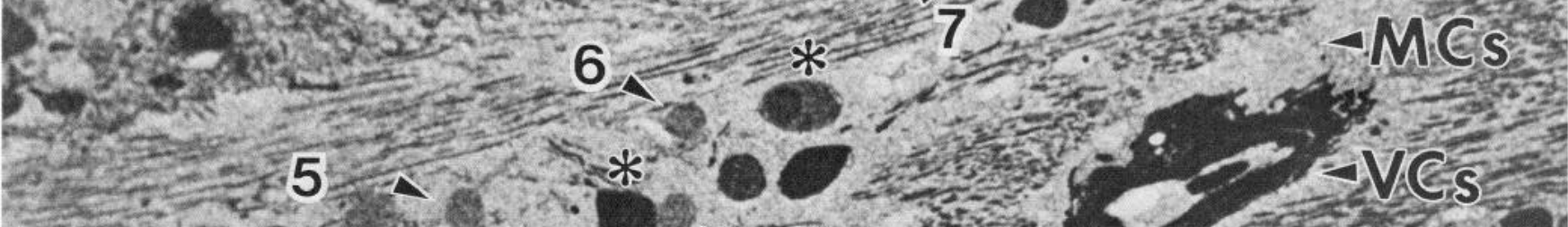

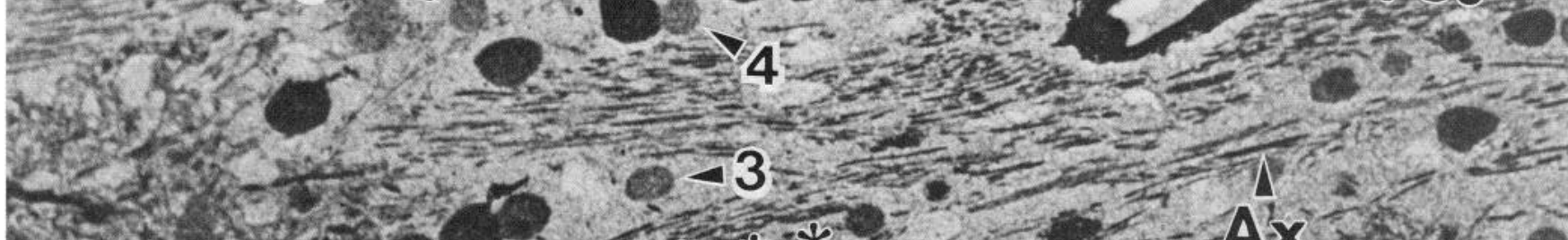
30 200'

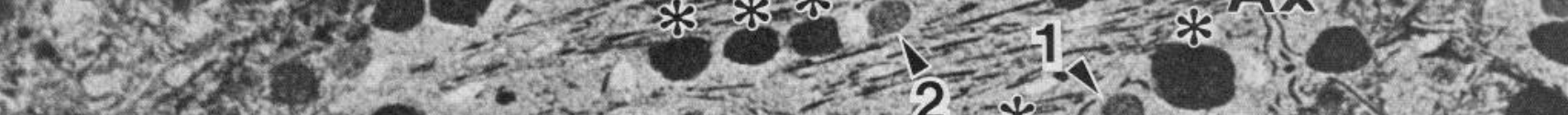
- $20.0 \% 2 \times 19$. 21

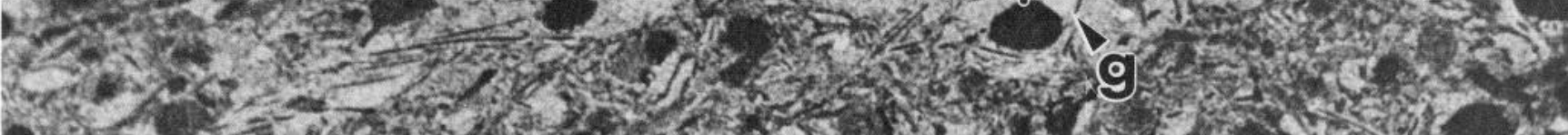
- 50 .

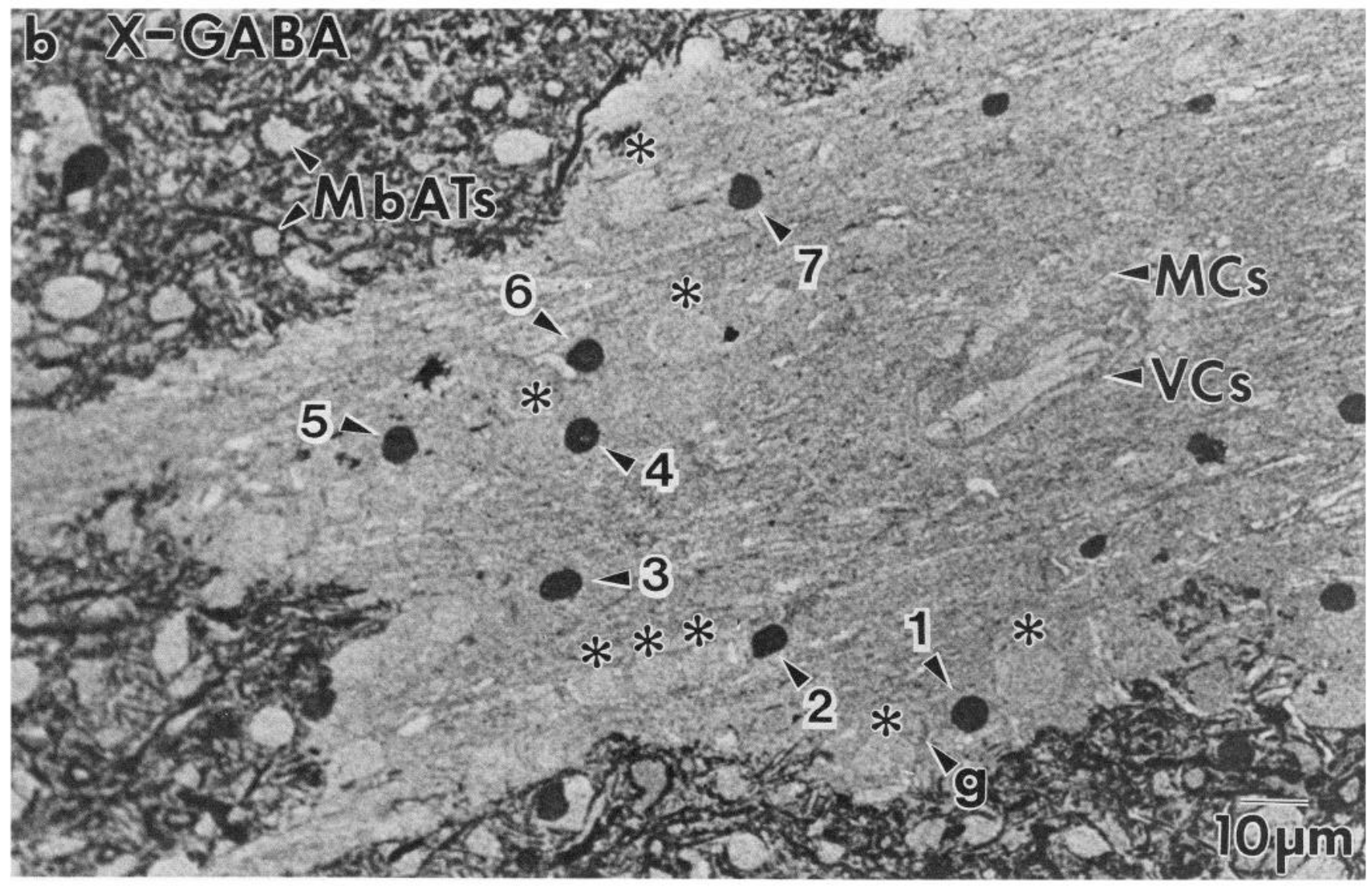




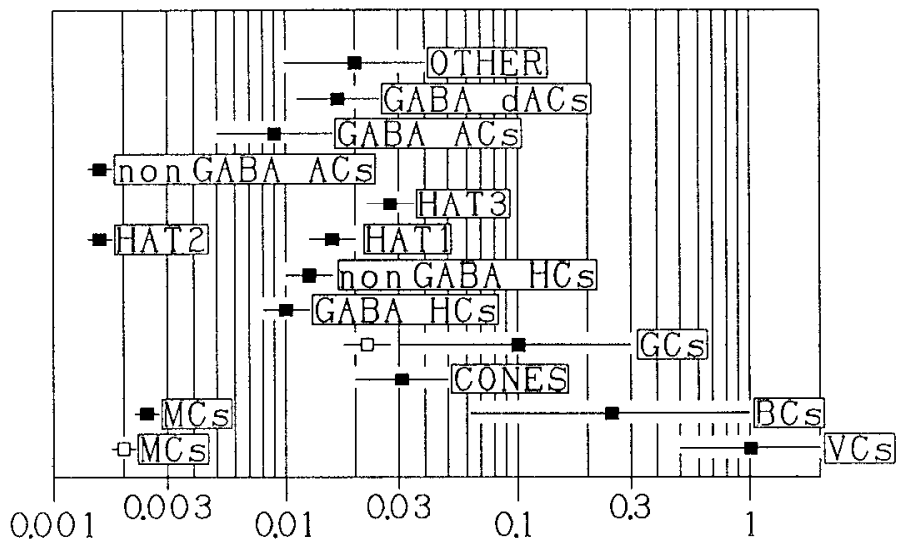

RELATIVE GLUTAMATE CONCENTRATION

Figure 17. Relative glutamate concentrations in 14 retinal cell types inferred from densities of glutamate immunoreactivity. Ten to $30 \mathrm{ex}-$ amples of each cell type were obtained, their mean and 1 SD pixel values were determined, and densities were calculated and converted to relative concentrations based on the saturation function used for Figure 18. The photoreceptor data were taken from red-sensitive and green-sensitive cones. The solid symbols represent the mean values for 1 retina, with 1 SD error bars. The open symbols are ganglion cells and Müller's cells sampled from a retina that showed significant loss of ganglion-cell labeling. Note that the concentration ranges span about $2.5 \mathrm{log}$ units. Because this is the maximum range detectable with our present approach, the relative concentrations in Müller's cells could actually be lower than depicted here. $A C$, amacrine cell; $B C$, bipolar cell; $d A C$, displaced amacrine cell; $G C$, ganglion cell; $H A T$, horizontal cell axon terminal; $H C$, horizontal cell; $M C$, Müller's cell; $V C$, vascular cell.

levels, regardless of subtype. However, the 2 statistically separable pools of glutamate in GABAergic horizontal cell axon terminals (see Appendix) suggests that some orderly process underlies the patterns we see. One interpretation of the bimodal distribution of glutamate levels in GABA-immunoreactive horizontal cells is that there are really 2 kinds of GABAergic horizontal cells, that is, that both types $\mathrm{H} 1$ and $\mathrm{H} 2$ are GABAergic. We can make no clear arguments on this point as of yet, but it is just as possible that all the GABA-immunoreactive profiles are from type $\mathrm{H} 1$ horizontal cells and that glutamate levels in these cells are tightly regulated but multistable, allowing only a finite number of steady-state glutamate concentrations. The somewhat higher glutamate level in non-GABAergic horizontal cells is interesting, because it is the first neurochemical marker we have seen in those cells. Nevertheless, the amount of glutamate is still several-fold less than ganglion cells or bipolar cells, and we think it more likely that all glutamate in horizontal cells is supporting synthesis of another neuroactive agent rather than serving as a neurotransmitter itself.

Finally, Müller's cells continue to fascinate us with their unique properties. We know that Müller's cells in general have potent uptake capacities for acidic amino acids, yet their endogenous levels of glutamate are in the $50-\mu \mathrm{M}$ range. This is consistent with results in CNS astrocytes (Storm-Mathisen el al., 1986)

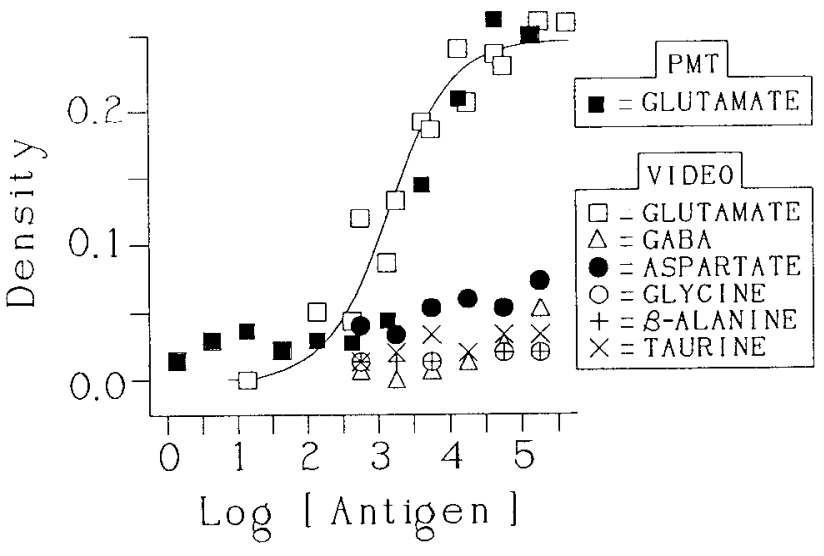

Figure 18. Density of IgG binding to different model antigens as function of solution concentration (spot mass) with SIG detection, measured by spot photometry $(P M T)$ or digital imaging (Video). The density of each spot on a dot immunoassay spanning $5.5 \mathrm{log}$ units of glutamateglutaraldehyde-BSA concentrations was measured from the central $2 / 3$ of the spot with either a Zeiss microphotometer ( $P M T)$ or a CCD camera image displayed as a digital frame (Video), both in the reflectance mode. Density was estimated to be $-\log _{10}(S / B)$, where $S$ and $B$ were the photomultiplier currents or pixel intensities for each spot $(S)$ and its immediate background $(B)$. Data were fitted to a Michaelis-Mentonlike function. Relative densities of anti-glutamate IgG binding to 5 other model antigens over a 2.5-log-unit range of concentrations were measured by CCD camera (Video).

and with the view that glia rapidly convert glutamate to glutamine with glutamine synthetase. It was fortuitous that we chose the frog retina as a model system to test force loading of glutamate and aspartate into Müller's cells, because the action of glutamine synthetase is apparently less rapid in amphibians than goldfishes. So far, we have been unable to obtain a good force load of glutamate in goldfish Müller's cells, though we can easily make them aspartate immunoreactive with incubation in $1 \mathrm{~mm}$ aspartate. This suggests prodigious capacities to metabolize glutamate, and investigating the kinetics of glial glutamate conversion may provide another link in the story of where glutamate is found in the retina, how it functions in neurotransmission, and how it is regulated.

\section{Appendix}

SIG detection of antibody binding on deplasticized semithin sections is physically similar to the process of solid-phase immunoassay (Tijssen, 1985). We have used video capture of immunolabeling patterns followed by standard immunoassay procedures and conventional digital image processing to characterize the specificities of antisera and to determine relative levels of antigen content among cells.

\section{System characterization}

As noted in Materials and Methods, CCD cameras are not radiometrically linear. However, by calibrating each camera at a

Figure 16. Glutamate $(a, X-g l u)$ and GABA $(b, X$-GABA) immunoreactivity in near-horizontal 500-nm section of ganglion cell layer. The glutamateimmunoreactive striations are bundles of axons. Virtually all somas (asterisks and numbers) are glutamate immunoreactive, but at different levels. Vascular cells $(V C s)$ are the most immunoreactive structures in the retina. Apparent ganglion cells are marked with asterisks, and their corresponding images in $b$ are completely GABA immunonegative. The cells numbered $I-7$ are displaced GABAergic amacrine cells, and they have significant glutamate immunoreactivity, but visibly less than ganglion cells. Very few structures are both glutamate- and GABA-immunonegative, and they are probably microglia or astrocytes of the optic fiber layer $(g)$. $M b A T$, type Mb bipolar cell axon terminal; $M C$, Müller's cell. 
fixed gain with known fluxes of light, both linearizing and logarithmic transfer functions of the camera outputs were determined. Thus, optical density or $-\log _{10}$ reflectance can be calculated from transformed pixel intensity values. The first step was to demonstrate that the video system yielded results equivalent to conventional photometry. Dot immunoassays such as those in Figure 1 were sampled by both a spot microphotometer system (PMT) and digital imaging (video), and the resultant spot reflectance density $\left(-\log _{10}\right.$ reflectance) was plotted versus log antigen concentration (Fig. 18). The solid and open squares in Figure 18 represent spot densities determined by PMT and video, respectively, for dot immunoassays of anti-glutamate IgG binding to a range of glutamate-glutaraldehyde-BSA concentrations spanning $5.5 \mathrm{log}$ units. The practical discrimination range of density values spans about $2.5 \mathrm{log}$ units, and it is clear that digital video analysis gives performance equivalent to PMT measures. The data were fitted by eye to a scalable MichaelisMenton-like function on a logarithmic abscissa, and the order of the function was determined from the fitted shape. The function used here was $D / D_{\max }=A^{n} /\left(A^{n}+K^{n}\right)$, where $D$ is the measured density, $D_{\max }$ is the maximal density, $A$ is the antigen concentration, and $n$ is the cooperativity exponent (assuming a 1 -step, full activation cooperativity model). In this case, $n=$ 0.97 . It should be emphasized that this function describes the entire detection process, not just IgG binding, because the final SIG detection step includes a chemographic sensitivity term determining the rate of silver deposition per gold granule. That the order of the function $(n)$ is close to 1 is likely fortuitous and does not imply that the solid-phase binding environment is first order. The function merely serves as a transform to determine relative antigen concentrations from density measurements.

\section{Antiserum characterization}

The next step was to establish the abilities of antisera to discriminate among similar antigens. The binding of anti-glutamate $\operatorname{IgG}$ to a 2.5 -log-unit concentration range of model antigens carrying the haptens GABA, aspartate, glycine, $\beta$-alanine, or taurine was compared to the glutamate antigen (Fig. 18). There is no evidence of type 2 cross-reactivity, and type 1 cross-reactivity must be at least $3 \log$ units less than binding to the glutamate antigen. Thus, the antiserum shows high specificity for glutamate by standard immunochemical criteria (Tijssen, 1985). This observation is not trivial, for some antisera from both commercial and laboratory sources can be shown to exhibit type 1 or 2 cross-reactivity or both. However, the anti-glutamate IgGs used for this study have been demonstrated to exhibit at least 1000-fold selectivity for glutamate over aspartate and over 10,000-fold selectivity for the other model antigens we have tested (containing GABA, taurine, glycine, $\beta$-alanine, glutamine, dopamine, serotonin, tryptophan, or norepinephrine). Obviously, cross-reactivities with compounds absent from neural tissue or substances present only at low concentrations would have little impact on the results described herein.

\section{Fixation dependence}

The antisera employed in this study were all generated by immunogens containing glutaraldehyde as a homobifunctional linker. To test the dependence of SIG detection on fixation conditions, retinas fixed in a series of glutaraldehyde/paraformaldehyde solutions (see Materials and Methods) were sectioned at $500 \mathrm{~nm}$, and spot densitometry was used to determine levels of glutamate immunoreactivity in selected cell types. Glu- taraldehyde was, in fact, absolutely essential for the preservation of glutamate immunoreactivity as revealed by SIG detection. Paraformaldehyde content was uncorrelated with the preservation of glutamate immunoreactivity as far as we can discern. It is our impression that the immunoreactivity is not saturated even at $4 \%$ glularaldehyde, but that good immunoreactivity is obtained at $0.5 \%$ glutaraldehyde, and there is a long plateau between $0.5 \%$ and $2.5 \%$ glutaraldehyde where glutamate immunoreactivity is preserved with equivalent efficiency (Fig. 19).

\section{Verifying adequate affinity and determining antigen homogeneity}

It is beyond the scope of this appendix to fully address the issues of measuring apparent affinities in polyclonal antisera, but 2 facets are important: saturation and apparent affinity. Unless the effective concentration of a target antigen in a sample is greater than the affinity constant of the dominant $\mathrm{IgG}$ for the antigen, one may not be able to saturate the sites in the specimen. If this is so, then one cannot compare binding levels among antisera to different antigens. Thus, it is critical to demonstrate that the level of IgG binding in a section is saturable. This verifies adequate affinity.

Serial sections of the retina shown in Figure 3 were cut at 500 $\mathrm{nm}$ and sequentially processed with anti-glutamate or anti-aspartate $\operatorname{IgGs}$ at 5 dilutions for SIG detection $(1: 500,1: 200$, $1: 100,1: 50,1: 25$ dilutions of the standard $1: 10$ working serum). Binding densities were measured from video images of 10-20 samples each of red-, green-, or blue-sensitive cones or $\mathrm{Ma}$ bipolar cells at each dilution for each antibody and plotted against a $\log _{10}$ antibody abscissa (Fig. 20). All the binding curves reached saturation at some dilution, meaning all the available sites in the $500-\mathrm{nm}$ section were bound in such cases, and that the differences in maximum densities among the measured cells were due to true differences in intracellular antigen concentration. Thus, even though the titer of the anti-aspartate IgG was less than that of the anti-glutamate IgG and the apparent affinity of anti-aspartate IgGs for aspartate was not as high as the antiglutamate IgGs for glutamate, the difference between maximum binding to red-and green-cone glutamate-immunoreactive sites and binding to aspartate-immunoreactive sites in the same physical cones argues that true cone glutamate levels could exceed true aspartate levels by a factor of $7-10$ in this specimen. That all cone types show the same level of aspartate immunoreactivity further substantiates our calibration procedures and the claim that the anti-aspartate IgG is glutamate-blind under these conditions.

A second issue in hapten-based immunochemistry is demonstrating antigen homogeneity. This is based on the distinction between shared reactivity and cross-reactivity (Tijssen, 1985). A hapten, like glutamate, will be linked by glutaraldehyde to the $\epsilon$-amino group of a lysine residue on a variety of intracellular proteins, and for all practical purposes, anti-glutamate IgGs do not discriminate among the different proteins decorated with linked glutamate residues. This is shared reactivity. Thus, the apparent affinity of $\mathrm{IgG}$ binding will be similar if different cells contain the same haptens, regardless of differences in protein content among cell types. Upon examination of the binding curves in Figure 20, it is clear that the antigens in bipolar cells and red-sensitive/green-sensitive cones are indistinguishable. The anti-glutamate $\operatorname{IgG}$ binding curve for blue-sensitive cones is shifted about $0.4 \log$ units higher, which implies that the immunoreactivity they contain might not be glutamate. Converse- 


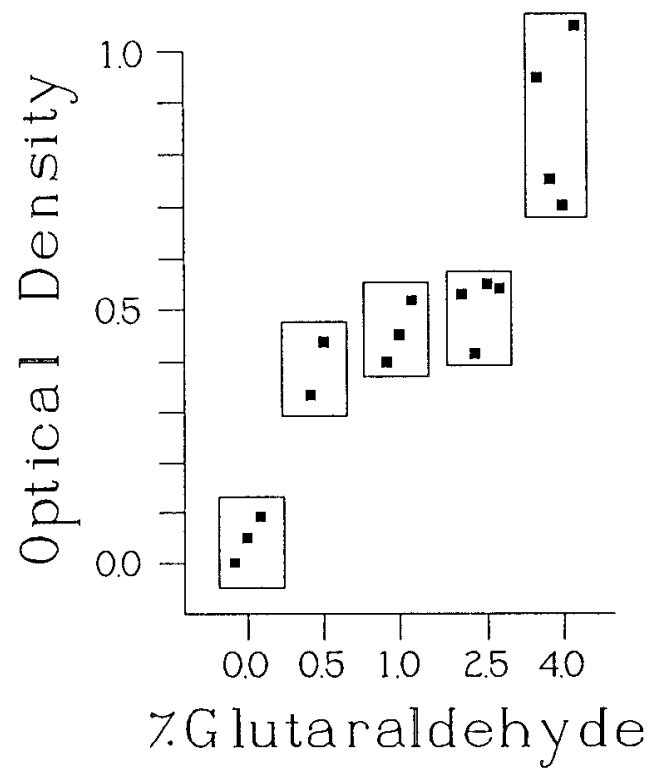

Figure 19. Fixation dependence of glutamate immunoreactivity in goldfish retina. The photometric densities of bipolar cells and ganglion cells from retinas fixed in different glutaraldehyde/paraformaldehyde combinations are plotted as a function of glutaraldehyde concentration on the abscissa. Within each rectangle are the densities measured for 2-4 paraformaldehyde concentrations at each glutaraldehyde concentration. There is a high correlation of immunoreactivity with glutaraldehyde level and almost no correlation with paraformaldehyde level.

ly, we have demonstrated that glutamate-loaded Müller's cells, red-sensitive/green-sensitive cones, bipolar cells, and ganglion cells all have the same apparent affinity for anti-glutamate IgCis. This is a necessary criterion for the demonstration that "unknown" antigens in cells are similar to a known (glutamatedecorated) antigen. This criterion, while not sufficient, is powerful evidence of antigenic identity for the following reason: If the immunoreactivity in bipolar cells, etc., was not due to glutamate but to another, unknown hapten (other than the ones we have already excluded on grounds of specificity), this unknown compound would have to have the same affinity for the IgG as glutamate itself. There exists a small chance of encountering a novel cross-reacting antigen, but it would be very unlikely for it to have the same affinity as the hapten glutamate.

\section{Resolving patterns of horizontal-cell immunoreactivity with digital image processing}

As noted in the section on detailed analysis of horizontal cells, 3 stable patterns of combined glutamate and GABA immunoreactivity were discovered (see Fig. 13). This observation was first made while examining pixel-intensity histograms rather than the photographs themselves. Because a large fraction of the goldfish horizontal cell population is thought to be GABAergic (Marc et al., 1978; for review, see Yazulla, 1986), we planned to document the relative levels of glutamate immunoreactivity in known GABAergic structures as follows: A field of several hundred axon terminals at the midlevel of the inner nuclear layer was captured as a pair of serial digital images (horizontal sections), one labeled with anti-glutamate and the other with anti-GABA IgGs. Our intent was to utilize the GABA immunoreactivity as a filter with which we could statistically examine the levels of glutamate immunoreactivity in presumed

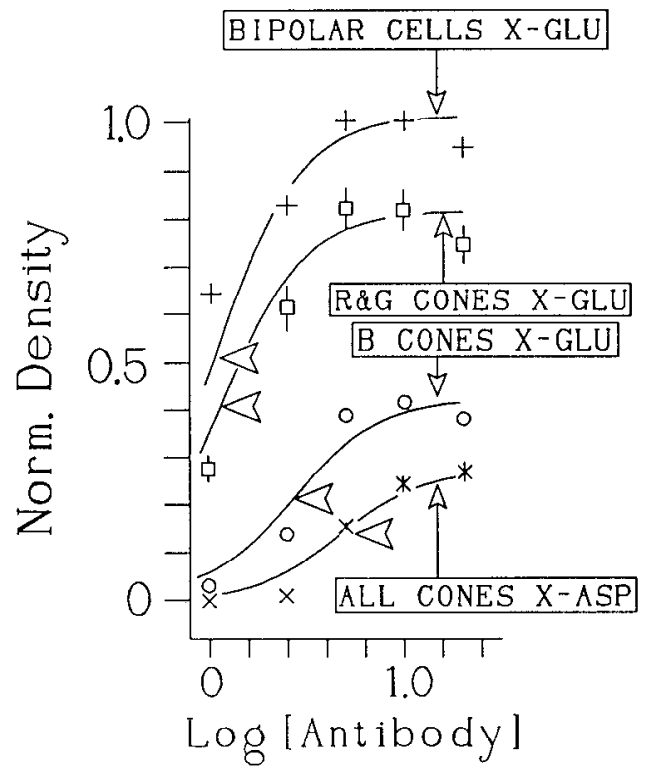

Figure 20. Optical density measurements of glutamate $(X$-glu $)$ and aspartate $(X$-asp) immunoreactivity in bipolar cells and red-sensitive $(R)$, green-sensitive $(G)$, and blue-sensitive $(B)$ cones as function of antibody concentration. Note that all curves reach saturation, indicating sufficient antibody was present to bind all available sites in the sample. Furthermore, the aspartate immunoreactivities of all cones (red-, green-, and blue-sensitive) were similar, so their values were pooled. Curves were fitted as in Figure 18; $n$ values for all curves ranged from 1.9 to 2.0 (differen, from binding as a function of antigen concentration). Vertical bars, 1 SD; where no bars are present, 1 SD was smaller than the symbol. Half-saturation points are indicated by arrowheads.

GABAergic structures. A small sample of such a digitized field is shown in Figure 21. Note that, in Figure $21 a$, there are 3 levels of GABA immunoreactivity, and clusters of bipolar and Müller's cells appear to be moderately GABA immunoreactive. This is due to a cross-reactivity of the anti-GABA IgG with a non-GABA antigen, as proven by a large shift in anti-GABA IgG dose-response curves (not shown; see previous section's discussion of antigenic homogeneity).

Because the glutamate- and GABA-immunoreactive images were obtained from physically separate sections, it was necessary to digitally shift, rotate, and slightly warp one image with respect to the other to obtain accurate superposition. This was achieved with a geometric correction algorithm using bilinear interpolation and interactive "ground control point" (landmark) selection. The image translation, rotation, and local warping was statistically monitored through an interactive least-squares fit of the ground control points. These functions are part of the EASI/PACE image-processing library available from PCI, Inc. (Richmond Hill, Canada). All subsequent image-processing routines (thresholding, logical combinations of images, pixel histograms, etc.) were carried out on the registered images under the Image-Pro II processing environment (Media Cybernetics, Silver Spring, MD). All procedures operate under MS-Dos ${ }^{\circledR}$.

After the images were aligned (Fig. 21 $a, b$ ), the GABA-immunoreactive image was thresholded to a binary image, generating a "mask" where all black areas had a pixel value of 0 , and all white areas (GABA-immunoreactive regions) had a pixel value of 1 (Fig. $21 \mathrm{c}$ ). Single-pixel noise (also known as salt and pepper noise) produced by the binary thresholding of a grayscale image was removed by a $3 \times 3$ median filter (Pratt, 1978). 

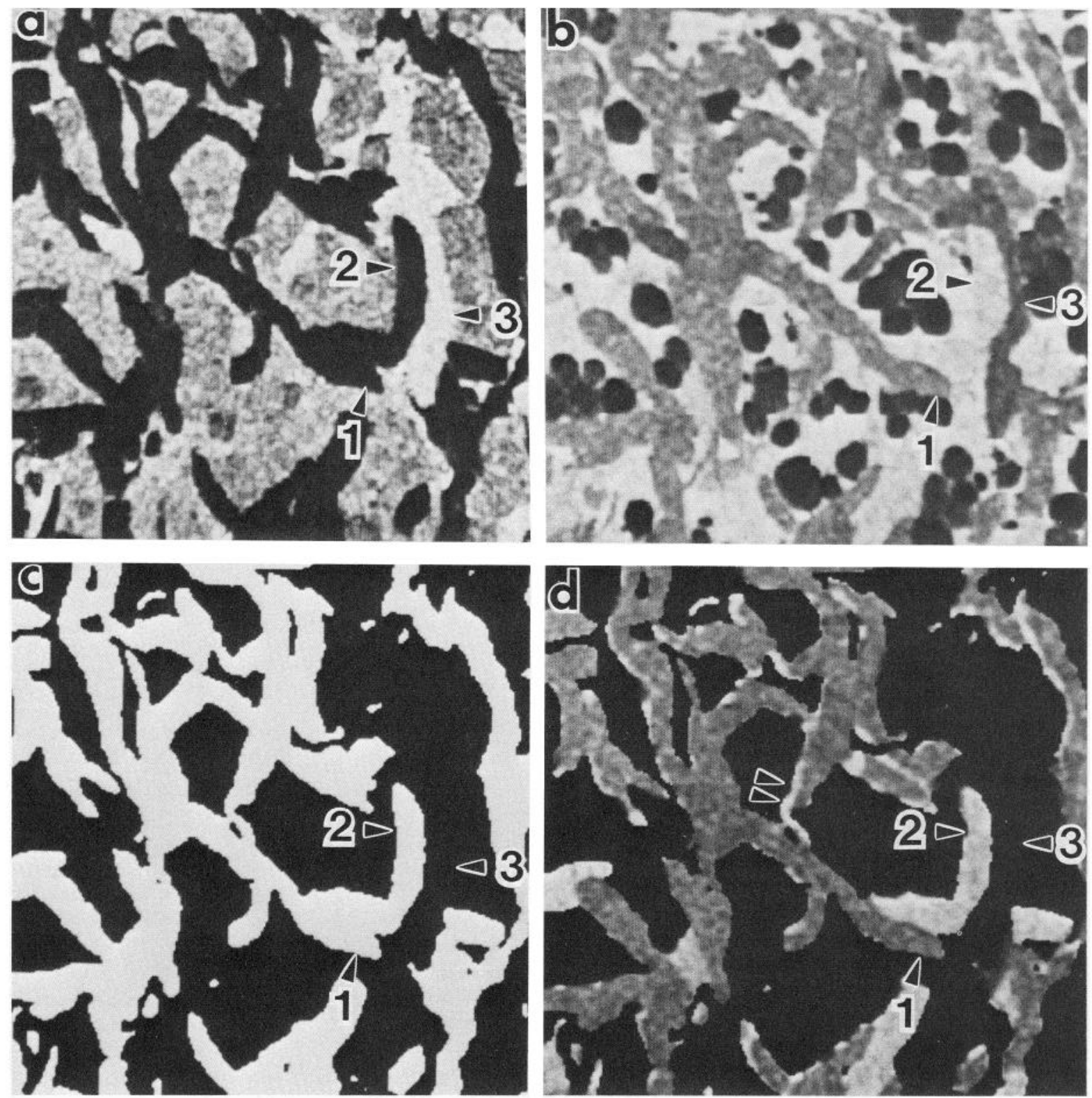

Figure 21. Digital images of glutamate and GABA immunoreactivity in inner nuclear layer taken from serial 500-nm sections. See text for details. $a$, Magnified portion of a large digital image of GABA immunoreactivity in the inner nuclear layer. Three horizontal cell axon terminals are indicated: Terminals 1 and 2 have high GABA immunoreactivity, and terminal 3 is devoid of GABA immunoreactivity. $b$, An aligned portion of the glutamate-immunoreactive serial image. Note that terminal 1 has moderate glutamate immunoreactivity, terminal 2 has low glutamate immunoreactivity, and the non-GABAergic terminal 3 has the highest glutamate immunoreactivity of all the terminals. $c$, A binary mask of GABAergic horizontal cell axon terminals created from $a$. All GABAergic horizontal cell axon terminals have a value of 1 , and the black areas have a value of 0 . A reversed mask can be created that assigns a value of 1 to structures such as terminal 3 and 0 to everything else. $d$, The product of $b$ and $c$. Only those areas corresponding to regions in the mask with a value of 1 are now visible. This clearly reveals the 2 varieties of GABAergic horizontal cell axon terminals. The double arrowheads indicate small edge artifacts due to small, uncompensated size differences in the serial sections.

The product of the glutamate-immunoreactive image and the binary mask yielded a final image displaying the glutamate gray values of the GABA-immunoreactive structures, with all other elements set to 0 (Fig. 21d). There are clearly 2 kinds of horizontal cell axon terminals left: one with moderate glutamate immunoreactivity and one with low immunoreactivity. A histogram of the distribution of pixel values for the full field of several hundred axon terminals also shows that there are clearly 2 kinds of terminals (Fig. 22) and not merely a normal distri- bution or even a skewed distribution around a single mean. By performing a logical NOT operation on the GABA-immunoreactive image and rethresholding it with a window of pixel values, we produced a mask for all GABA-immunonegative axon terminals. The product of that mask and the glutamateimmunoreactive image revealed that the strongly glutamateimmunoreactive non-GABAergic axon terminals also expressed a unique distribution of glutamate immunoreactivity (Fig. 22). One interpretation of our results is that these patterns discrim- 


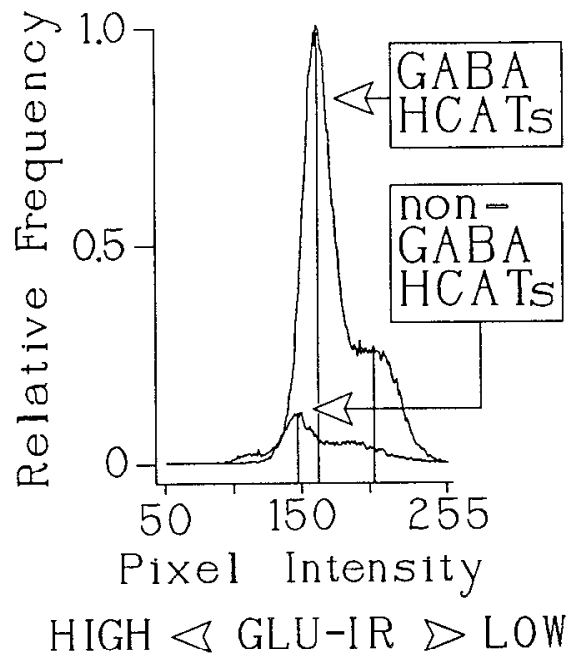

Figure 22. Pixel-intensity histograms from horizontal sections of glutamate $(G L U-I R)$ and GABA immunoreactivity in inner nuclcar layer. Full-sized images (about 5 times the linear size of the frames shown in Fig. 21) were sampled, and histograms were constructed of all the pixel values in GABAergic and non-GABAergic horizontal cell axon terminals $(H C A T S)$ on a true relative scale; vertical lines indicate the pixel values of various points on the histograms. The secondary peak centered at pixel intensity 200 corresponds to about $20 \%$ of the GABAergic horizontal cell axon terminals. The glutamate immunoreactivity of the non-GABAergic horizontal cell axon terminal population is clearly higher than that of GABAergic terminals. The small absolute size of the nonGABAergic horizontal cell axon terminal histogram is partially due to the level of sectioning. The proportion of non-GABAergic horizontal cell axon terminals is much higher in the distal inner nuclear layer than the level shown here. Note that low (dark) pixel values encode high immunoreactivity and high (light) pixel values encode low immunoreactivity in this and all following histograms.

inate functional horizontal cell states; alternatively, subpopulations of GABAergic horizontal cells may exist (see Discussion).

\section{Resolving patterns of amacrine cell layer immunoreactivity with digital image processing}

As just described for horizontal cell axon terminals, we attempted to decompose the complex pattern of glutamate immunoreactivity in the amacrine cell layer using mask analysis and pixel histograms. Large fields of cells lying in the plane of the amacrine cell layer marked with anti-glutamate and antiGABA IgGs were captured as serial image pairs and registered, masks were formed by various thresholding tactics, and histograms of pixel intensity were generated. We examined histograms of (1) the entire unmasked amacrine cell layer, (2) the unmasked inner nuclear layer, (3) the GABA-masked amacrine cell layer, and (4) a NOT-GABA-masked view of the amacrine cell layer (Fig. 23). The entire unmasked distribution of glutamate immunoreactivity in the amacrine cell layer displayed a unique signature consisting of a narrow pcak of high glutamate immunoreactivity and a broad secondary smear of moderate to low values. After GABA masking the image, the broad distribution was revealed to be largely accounted for by GABA-immunoreactive amacrine cells. No GABA-immunoreactive neurons possessed glutamate immunoreactivity as strong as that exhibited in the range defined by the narrow peak. Conversely, a NOT-GABA mask produced a signature consisting of a more clearly isolated narrow peak and a flat mesa composed of mod-

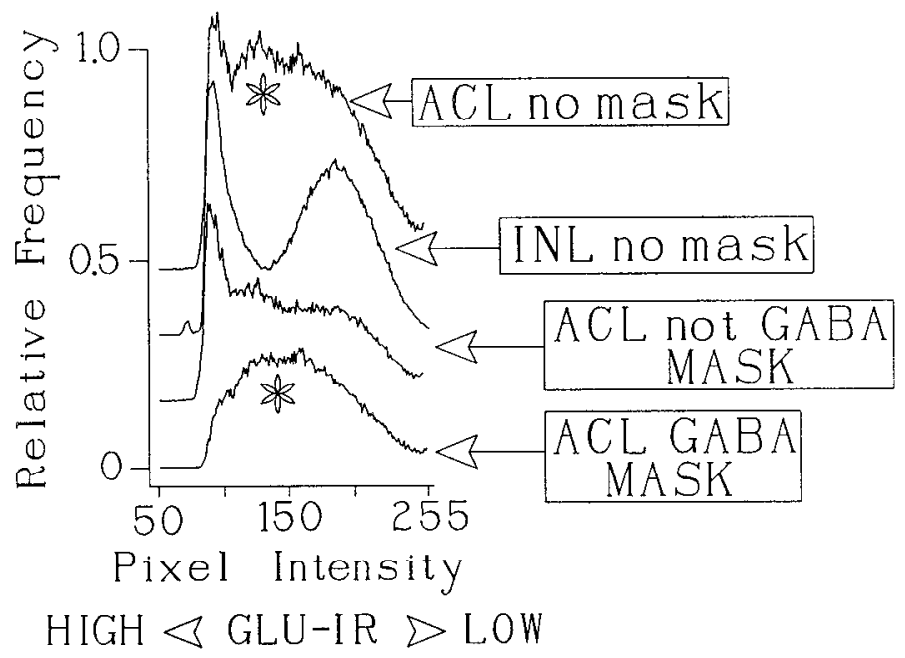

Figure 23. Pixel-intensity histograms from horizontal sections of glutamate and GABA immunoreactivity in amacrine cell layer $(A C L)$. Aligned images of sections taken from the same specimen as those shown in Figure 15 were sampled as pixel histograms with and without various masks. The unmasked amacrine cell layer histogram (top curve) consisted of a narrow peak of high glutamate immunoreactivity (GLU-IR) and a broad, complex band extending the remainder of the pixel range (marked by an asterisk). After masking with a GABA-selective image (GABA-immunoreactive structure pixels value $=1$; all others $=0$ ), the remaining signature consisted solely of the midrange part of the broad band (bottom curve, asterisk). The inverse mask (a logical NOT was performed on the GABA mask) yielded a glutamate histogram composed of a very sharp peak and a long, low, flat table. Comparison with an unmasked glutamate-immunoreactive image of the inner nuclear layer $(I N L)$ revealed the sharp peak to be identical to the signature of bipolar cells. All curves are at their correct scaling relative to each other and are vertically displaced for ease of visualization.

erate signals ranging to very low values, similar to those found for Müller's cells and extracellular space. A comparison of an unmasked sample of the inner nuclear layer showed a clear narrow peak of strong immunoreactivity derivcd from bipolar cells and a completely separate mode due to summed axonterminal, Müller's cell, and extracellular space signals. This analysis emphasizes 2 major points: (1) The narrow peak of pixel intensities from the bipolar cells in the inner nuclear layer is identical to the one found in the amacrine cell layer and argues that there exists a set or sets of bipolar cell somas that may be characteristically positioned in the amacrine cell layer. In retrospect, one can pick out the GABA-immunonegative, highly glutamate-immunoreactive cells of the amacrine cell layer, and they appear to form an even, nonrandom distribution (Fig. 15, numbered circles). These are probably all bipolar cells and may even be all of 1 type. (2) The apparent glutamate content of GABAergic cells is clearly different from that of bipolar cells. The breadth of the pixel-intensity signature for GABAergic amacrine cells argues that many subtypes of amacrine cells contribute to the whole signal.

\section{Resolving patterns of ganglion cell layer immunoreactivity with digital image processing}

Mask analysis of the ganglion cell layer allowed visualization of the distributions of glutamate immunoreactivities associated with ganglion cells and displaced amacrine cells. Unlike the amacrine cell layer, the overall glutamate signature of the ganglion cell layer is simple and composed of a moderate- to high- 


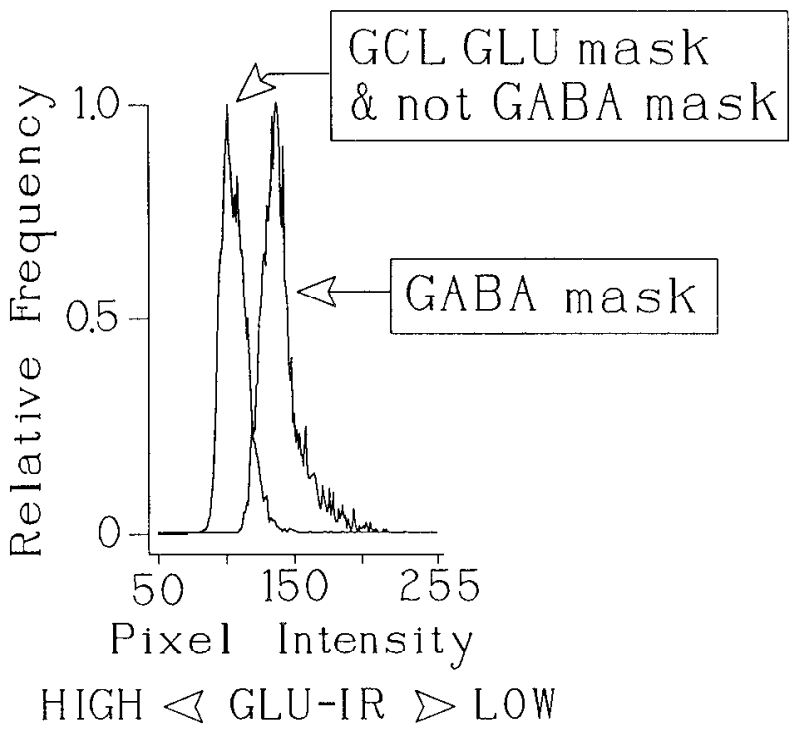

Figure 24. Pixel-intensity histograms from horizontal sections of glutamate $(G L U)$ and GABA immunoreactivity in ganglion cell layer $(G C L)$. Unlike the amacrine cell layer, glutamate levels are more homogenous within a cell group. Two different masks were employed: (1) a binary GABA mask as described previously, and (2) a combined binary GLU + NOT GABA mask. This latter mask selectively reveals ganglion cells and their axons. Vascular cells were manually edited out of the image so as not to contaminate the ganglion cell data. The entire ganglion cell field sampled (about 100 ganglion cells) was uniformly more glutamate immunoreactive $(G L U-I R)$ than displaced GABAergic amacrine cells.

valued peak associated with ganglion cells and a moderate- to low-valued peak deriving from displaced GABAergic amacrine cells (Fig. 24). These results underscore the contention that the glutamate content of GABAergic cells is always less than that of presumed glutamatergic neurons. A secondary observation is that the bandwidth of the displaced GABAergic amacrinecell signals is less than the broad, complex band observed for GABAergic neurons in the amacrine cell layer. Though pcrhaps a subtle point, the implication is powerful: A homogeneous group of GABAergic amacrine cells displays a relatively homogeneous glutamate content. There are 2 possible explanations for the broad band of glutamate immunoreactivity among GABAergic neurons in the amacrine cell layer: Glutamate content in such neurons varies over a wide range (1) among cells regardless of type or (2) among types of amacrine cells, but is homogeneous within a type. Our preliminary observations indicate the latter to be more likely.

\section{Compartmental calculation of intracellular glutamate levels}

One of our goals was to estimate true intracellular concentrations of glutamate. Though it might seem that one could achieve this from calculations of dot assay model antigen concentrations, there are serious barriers to such an approach. First, the dot assay is an adsorptive procedure, and while each spot represents a known mass of antigen, the concentration of the model antigen in solution cannot be directly correlated with an intracellular concentration. Adsorption to Immobilon-P and fluidphase fixation of tissue are 2 quantitatively different means of stabilizing an antigen pool. Second, and more important, we cannot yet verify that any model antigen system has the same density of macromolecular linking residues as in cells.

However, the calculation of intracellular levels is possible if
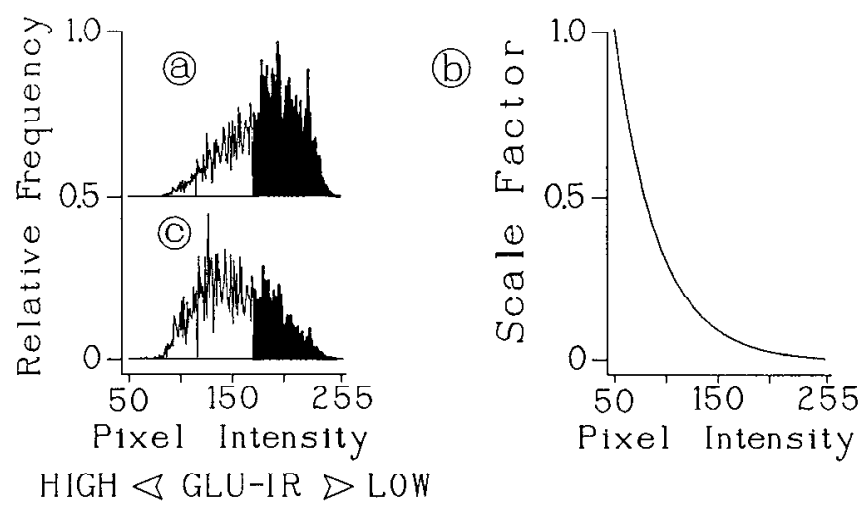

Figure 25. Estimation of actual glutamate concentrations (GLU-IR) in compartment. See Appendix and Discussion for details of calculations and interpretation. $a$, The mass histogram: a total distribution of pixel values in an unmasked vertical section of retina. $b$, The inverse scaling function derived from Figure 18 used to convert each pixel frequency into its glutamate-weighted value. $c$, The content histogram: the distribution of glutamate as a function of pixel value. The shaded areas divide the histogram into fractions residing in photoreceptors, bipolar cells, and ganglion cells (white) or all other retinal mass (black).

we make some reasonable assumptions. First, the kinetics of antibody binding to hapten/glutaraldehyde/lysine in the dot assay must be the same as in deplasticized specimens. We have partially verified this: The chemical preparation of model antigens is, in fact, identical to the tissue fixation process; dehydration, either by solvents or by air, of the model antigens does not change the saturated binding level or apparent affinity of the IgGs (data not shown). Neither plasticizing nor deplasticizing reactions in an anhydrous environment attacks any bonds in these simple antigen constructs and, thus, should have no impact on binding. Thus, cellular IgG binding should scale as model binding. The different physical processes of antigen stabilization (glutaraldehyde fixation followed by adsorption vs. fluid-phase fixation alone) has no demonstrated effect on the subsequent kinetics of IgG binding. A second assumption is that the concentration of intracellular protein across cell types should be similar. At present, we must simply make this assumption without strong evidence. One possible problem is the known loss of amino acids upon exposure to glutaraldehyde (Van Harreveld and Fifkova, 1972). We must explicitly assume that such losses are proportional across cell types. Because both GABA and glutamate immunoreactivities have nearly identical dependences on glutaraldehyde concentration (data not shown), irrespective of cell type, this assumption seems valid.

With these considerations, it is possible to use digital imaging to estimate the dispersion of an antigen such as glutamate into cellular compartments when the whole-tissue concentration of the native hapten is known. The whole-tissue concentration is actually the volumetric average of the glutamate masses in several retinal compartments: $\operatorname{Av}[E]=\left\{\Sigma\left(\left[E_{i}\right] \times V_{i}\right)\right\} / \Sigma V_{i}$, where $\operatorname{Av}[E]$ is the biochemically mcasurcd wholc-rctina value, $\left[E_{i}\right]$ is the glutamate concentration in the $i$ th compartment, and $V_{i}$ is the volume of that compartment. The sums are taken over all compartments. We can use digital imaging to solve for the $\left[E_{i}\right]$ values by identifying the masses of various cellular compartments and their relative glutamate contents. The first step is a reduction from volumetric to planar analysis (Weibel and Bolender, 1973). Because the relina is isotropic in the horizontal plane, we need only calculate the compartmentalization of a 
large sample of scaled pixel values in a vertical image; that is, the concentration of glutamate in a thin vertical slice of retina should be the same as in whole retina if the slice contains a proportional sample of all cell types. The second step is to realize that a scene or image embodies a spatial mapping of masses and intensities, but that a simple description of mass and intensity is all that is required for the calculation; pixel location is irrelevant. We therefore captured pixel histograms for vertical sections of such as shown in Figure 3. Because each pixel represents an equal area, a pixel histogram is simply a plot of the retinal mass associated with each pixel value; we call this the mass histogram (Fig. 25a). Conversely, though each pixel represents an equal amount of mass, pixels of different intensities represent different amounts of glutamate. The mass histogram is therefore weighted with the inverse of the saturation function obtained from the dot immunoassays (Fig. 25b). The new histogram is the relative amount of glutamate associated with each pixel value; we refer to this as the content histogram (Fig. 25c). The original image is then employed to determine the pixel cutoff values associated with each compartment. For example, pixel values of $0-170$ in a digitized version of Figure 3 represent photoreceptors and bipolar and ganglion cells exclusively, while values greater than 170 represent the remainder of the retina. The actual concentration of glutamate in the compartment scales inversely with fractional mass and directly with fractional glutamate content; that is, $\left[E_{i}\right]=\operatorname{Av}[E] \times\left(\mathrm{FG}_{i} / \mathrm{FM}_{i}\right)$, where $\mathrm{FM}_{i}$ is the ratio of pixels in compartment $i$ to total pixels in the mass histogram, and $\mathrm{FG}_{l}$ is the ratio of weighted pixels in compartment $i$ to total weighted pixels in the content histogram. The ability to define a compartment depends on the presence of a signal strong enough to allow selective thresholding.

\section{References}

Anderson KT, Borja MA, Cotman CW, Moffett JR, Namboordiri MAA, Neale JH (1987) $N$-acetylaspartylglutamate identified in rat retinal ganglion cells and their projections to brain. Brain Res 417:172-177.

Ayoub GS, Lam DMK (1984) The release of $\gamma$-aminobutyric acid from horizontal cells of the goldfish (Carassius auratus) retina. J Physiol (Lond) 355:191-214.

Ball AK, Brandon C (1986) Localization of [ $\left.{ }^{3} \mathrm{H}\right]-\mathrm{GABA}$, -muscimol and -glycine in goldfish retinas stained for glutamate decarboxylase. J Neurosci 6:1621-1627.

Ball A, St Denis J (1986) Displaced GABAergic amacrine cells in the ganglion cell layer of the goldfish retina. Invest Ophthalmol Vis Sci [Suppl] 27:332.

Basinger SF, Hall MO (1973) Rhodopsin biosynthesis in vitro. Biochemistry 12:1996-2003.

Beaudet AA, Burkhalter A, Reubi JC, Cuenod M (1981) Selective bidirectional transport of $\left({ }^{3} \mathrm{H}\right)$-D-aspartate in the pigeon retinotectal pathway. Neuroscience 6:2021-2034.

Brew H, Attwell D (1987) Electrogenic glutamate uptake is a major current carrier in the membrane of axolotl retinal glial cells. Nature 327:707-709.

Dowling JE (1968) Synaptic organization of the frog retina: an electron microscopic analysis comparing the retinas of frogs and primates. Proc R Soc Lond [Biol] 170:205-228.

Dowling JE, Werblin F (1969) Organization of the retina of the mudpuppy, Necturus maculosus. I. Synaptic structure. J Neurophysiol 32: 315-388.

Ehinger B, Ottersen OP, Storm-Mathisen J, Dowling JE (1988) Bipolar cells in the turtle retina are strongly immunoreactive for glutamate. Proc Natl Acad Sci USA 85:8321-8325.

Eldred WD, Yaqub A (1989) The diverse localization of aspartatelike immunoreactivity in the turtle retina. Invest Ophthalmol Vis Sci [Suppl] 30:321.

Erlich D, Keyser KT, Karten HJ (1987) Distribution of substance P-like immunoreactive retinal ganglion cells and their pattern of ter- mination in the optic tectum of chick (Gallus gallus). J Comp Neurol 266:220-233.

Famiglietti EV Jr, Kaneko A, Tachibana M (1977) Neuronal architecture of on and off pathways to ganglion cells in carp. Science 198: $1267-1269$.

Ishida AT, Stell WK, Lightfoot DO (1980) Rod and cone inputs to bipolar cells in goldfish retina. J Comp Neurol 191:315-335.

Ishida AT, Kaneko A, Tachibana M (1984) Responses of solitary horizontal cells from Carassius auratus to L-glutamate and related amino acids. J Physiol (Lond) 348:255-270.

Kalloniatis M, Marc RE (1990) Golgi impregnated bipolar cells of the goldfish retina. Invest Ophthalmol Vis Sci [Suppl] 30:1019.

Koller KJ, Zakzec R, Coyle JT (1984) $N$-acetyl-aspartyl-glutamate: regional levels in the rat brain and the effects of brain lesions as determined by a new HPLC method. J Neurochem 43:1136-1142.

Kowalski MM, Cassidy M, Namboodiri MAA, Neale JH (1987) Cellular localization of $\mathrm{N}$-acetylaspartylglutamate in amphibian retina and spinal sensory ganglia. Brain Res 406:397-401.

Landsteiner K (1936) The specificity of serological reactions. Springfield, IL: C. C. Thomas; rev ed, Cambridge, MA: Harvard UP, 1945.

Langdon RB, Freeman JA (1986) Antagonists of glutaminergic transmission block retinotectal transmission in goldfish. Brain Res 398: 169-174.

Langdon RB, Freeman JA (1987) Pharmacology of retinotectal transmission in goldfish: effects of nicotinic ligands, strychnine, and kynurenic acid. J Neurosci 7:760-773.

Lasater EM, Dowling JE (1982) Carp horizontal cells in culture respond selectively to L-glutamate and its agonists. Proc Natl Acad Sci USA 279:936-940.

Mangel SC, Ariel M, Dowling JE (1985) Effects of acidic amino acid antagonists upon the spectral properties of carp horizontal cells: circuitry of the outer retina. J Neurosci 5:2839-2850.

Marc RE (1982) The spatial organization of neurochemically classified interneurons in the goldfish retina. I. Local patterns. Vision Res 22: 589-608.

Marc RE (1989) The anatomy of multiple GABAergic and glycinergic pathways in the inner plexiform layer of the goldfish retina. In: Neurobiology of the inner retina (Weiler $\mathrm{R}$, Osborne NN, eds), pp 5364. Berlin: Springer.

Marc RE, Lam DMK (1981) Uptake of aspartic and glutamic acid by goldfish photoreceptors. Proc Natl Acad Sci USA 78:7185-7189.

Marc RE, Sperling HG (1976a) Color receptor identities of goldfish cones. Science 191:487-489.

Marc RE, Sperling HG (1976b) The chromatic organization of the goldfish cone mosaic. Vision Res 16:1211-1224.

Marc RE, Stell WK, Bok D, Lam DMK (1978) GABA-ergic pathways in the goldfish retina. J Comp Neurol 182:221-246.

Marc RE, Liu W-LS, Scholz K, Muller JF (1988) Serotonergic pathways in the goldfish retina. $J$ Neurosci 8:3427-3450.

Marc RE, Massey SC, Kalloniatis M, Basinger SF (1989) Immunochemical evidence that the fast neurotransmitter of rods, cones, bipolar and ganglion cells is glutamic acid. Invest Vis Sci [Suppl] 29: 320.

Massey SC (1990) Cell types using glutamate as a neurotransmitter in the vertebrate retina. Progress in Retinal Research, Vol 9 (Osborne NN, Chader G, eds), pp 399-425. London: Pergamon.

Massey SC, Miller RF (1988) Glutamate receptors of ganglion cells in the rabbit retina: evidence for glutamate as a bipolar cell transmitter. J Physiol (Lond) 405:635-655.

Matute C, Streit P (1986) Monoclonal antibodies demonstrating GABAlike immunoreactivity. Histochemistry 86:147-157.

Mayer ML, Westbrook GL (1985) The physiology of excitatory amino acids in the central nervous system. Prog Neurobiol 28:197-276.

Miller RF, Dacheux RF (1976a) Synaptic organization and ionic basis of on and off channcls in thc mudpuppy retina: I. Intracellular analysis of chloride-sensitive electrogenic properties of receptors, horizontal cells, bipolar cells and amacrine cells. J Gen Physiol 67:639-659.

Miller RF, Dacheux RF (1976b) Synaptic organization and ionic basis of on and off channels in the mudpuppy retina: II. Chloride-dependent ganglion cell mechanisms. J Gen Physiol 67:661-678.

Miller RF, Dacheux RF (1976c) Synaptic organization and ionic basis of on and off channels in the mudpuppy retina: III. A model of ganglion cell receptive field organization based on chloride free experiments. J Gen Physiol 67:679-690.

Miller RF, Slaughter M (1985) Excitatory amino acid receptors in the 
vertebrate retina. In: Retinal transmitters and modulators: models for the brain, Vol II (Morgan WW, ed), pp 123--160. Boca Raton: CRC.

Moremans M, Daneels G, Van Dijck A, Canganger G, DeMay J (1984) Sensitive visualization of antigen-antibody reactions in dot and blot immune overlay assays with immunogold and immunogold/silver staining. J Immunol Meth 74:353-360.

Murakami M, Ohtsu K, Ohtsuka T (1972) Effects of chemicals on receptors and horizontal cells in the retina. J Physiol (Lond) 227:899913.

Murakami M, Ohtsuka T, Shimazaki H (1975) Effects of aspartate and glutamate on the bipolar cells in the carp retina. Vision Res 15: $456-458$.

Naka K-I (1977) Functional organization of catfish retina. J Neurophysiol 40:26-43.

Nawy S, Copenhagen D (1987) Multiple classes of glutamate receptor on depolarizing bipolar cells in the retina. Nature 325:56-58.

Neal MJ, Cunningham JR (1989) L-Homocysteic acid-a possible bipolar cell transmitter in rabbit retina. Neurosci Lett 102:114-119.

Pourcho R, Goebel DJ (1987) Visualization of endogenous glycine in the cat retina: an immunocytochemical study with Fab fragments. J Neurosci 7:1189-1197.

Pratt WK (1978) Digital image processing. New York: Wiley.

Scholes JH (1975) Colour receptors and their synaptic connexions in the retina of a cyprinid fish. Philos Trans R Soc Lond [Biol] 270:61118.

Slaughter MM, Miller RF (1981) 2-Amino-4-phosphonobutyric acid: a new pharmacological tool for retina research. Science 211:182-185.

Slaughter MM, Miller RF (1983a) An excitatory amino acid antagonist blocks cone input to sign-conserving second order retinal neurons. Science 219:1230-1232.

Slaughter MM, Miller RF (1983b) Bipolar cells in the mudpuppy retina use an excitatory amino acid neurotransmitter. Nature 303:537-538.

Somogyi P, Halasy K, Somogyi J, Storm-Mathisen J, Ottersen OP (1986) Quantification of immunogold labeling reveals enrichment of glutamate in mossy and parallel fiber terminals in cat cerebellum. Neuroscience 19:1045-1050.

Stell WK, Hárosi F (1976) Cone structure and visual pigment content in the retina of the goldfish, Carassius auratus. Vision Res 16:647657.

Stell WK, Lightfoot DO (1975) Color-specific interconnections of cones and horizontal cells in the retina of the goldfish. J Comp Neurol 159: 473-502.

Storm-Mathisen J, Leknes AK, Bore AT, Vaaland VL, Edminson P, Huang FMS, Otterson OP (1983) First visualization of glutamate and GABA in neurons by immunocytochemistry. Nature 301:517520.

Storm-Mathisen J, Ottersen OP, Fu-Long T (1986) Antibodies for the localization of excitatory amino acids. In: Excitatory amino acids (Roberts PJ, Storm-Mathisen PJ, Bradford HF, eds), pp 101-116. London: Macmillan.

Tijssen $P$ (1985) Practice and theory of enzyme immunuassays. In: Laboratory techniques in biochemistry and molecular biology, Vol 15 (Burdon RH, van Knippenburg PH, eds). New York: Elsevier.
Toyoda J-I, Saito T, Kondo H (1978) Effect of polarization of horizontal cells on the on-centre bipolar cell of carp retina. Nature 276 $399-400$.

Trifonov YA, Byzov AL, Chailahian LM (1974) Electrical properties of subsynaptic and non-synaptic membranes of horizontal cells in fish retina. Vision Res 14:229-241.

Van Haesendonck E, Missotten L (1979) Synaptic contacts of the horizontal cells in the retina of the marine teleost, Callionymus lyra L. J Comp Neurol 184:167-192.

Van Harreveld A (1976) Pharmacology of the vertebrate retina. Prog Neurobiol 8:1-43.

Van Harreveld A, Fifkova E (1972) Effects of metabolic inhibitors on the release of glutamate from the retina. J Neurochem 19:1439-1450.

Van Regenmortel MHV, Briand JP, Muller S, Plaué S (1988) Synthetic polypeptides as antigens. In: Laboratory techniques in biochemistry and molecular biology, Vol 19 (Burdon RH, van Knippenburg PH, eds). New York: Elsevier.

Weibel ER, Bolender RP (1973) Stereological techniques for electron microscopic morphometry. In: Principles and techniques of electron microscopy (Hayat MA, ed), pp 239-296. Reinhold, NY: Van Nostrand.

Weiler R, Schütte M (1985) Morphological and pharmacological analysis of putative serotoninergic bipolar and amacrine cells in the retina of the turlle, Pseudemys scripta elegans. Cell Tissue Res 241:373382

Werblin FS, Dowling JE (1969) Organization of the retina of the mudpuppy, Necturus maculosus. II. Intracellular recording. J Neurophysiol 32:339-355.

Westbrook GL, Mayer ML, Namboordiri MAA, Neale JH (1986) High concentrations of $N$-acetylaspartylglutamate (NAAG) selectively activate NMDA receptors on mouse spinal cord neurons in cell culture. J Neurosci 6:3385-3392.

Whittemore ER, Koerner JE (1989) An explanation for the purported excitation of piriform cortical neurons by $N$-acetyl-aspartyl-glutamate (NAAG). Proc Natl Acad Sci USA 86:9602-9605.

Williamson LC, Neale JH (1988a) Ultrastructural localization of $N$-acetylaspartylglutamate in synaptic vesicles of retinal neurons. Brain Res 456:375-381.

Williamson LC, Neale JH (1988b) Calcium-dependent release of $\mathrm{N}$-acetylaspartylglutamate from retinal neurons upon depolarization. Brain Res 475:151-155.

Wu J-Y (1976) Purification, characterization and kinetic studies of GAD and GABA-T from mouse brain. In: GABA in nervous system function (Roberts E, Chase TN, Tower DB, eds), pp 7-56. New York: Raven.

Yazulla S (1983) Stimulation of GABA release from retinal horizontal cells by potassium and acidic amino acid agonists. Brain Res 275 61-74.

Yazulla S (1985) Evoked efflux of $\left[{ }^{3} \mathrm{H}\right] \mathrm{GABA}$ from goldfish retina in the dark. Brain Res 325:171-180.

Yazulla S (1986) GABAergic mechanisms in retina. In: Progress in retinal research, Vol 5, (Osborne $\mathrm{N}$, Chader J, eds), pp 1-52. New York: Pergamon. 